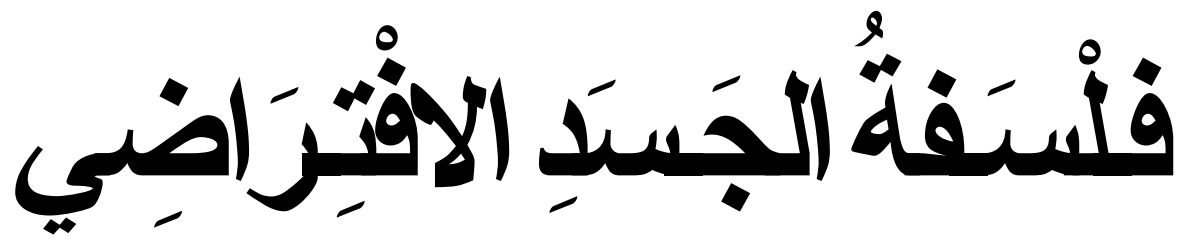

$$
\begin{aligned}
& \text { تحولاثُ العلاقِّ بين الجسدِ والسلطةِ }
\end{aligned}
$$

$$
\begin{aligned}
& \text { د. سامي حما عبد العال } \\
& \text { استاذ مساعد ـ قسم الفلسفة } \\
& \text { كلية الآداب / جامعة الزقازيق الفيق } \\
& \text { شعبة الدراسات النفسية والاجتماعية }
\end{aligned}
$$

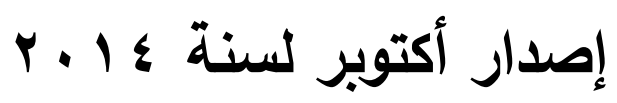




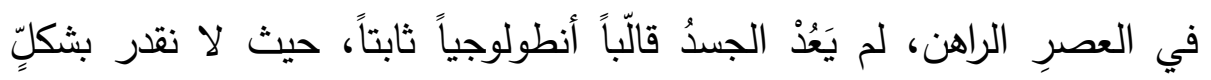

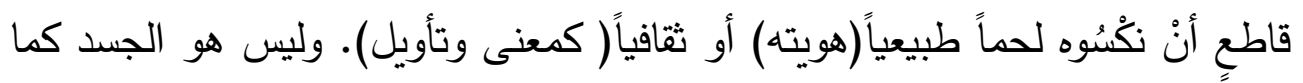

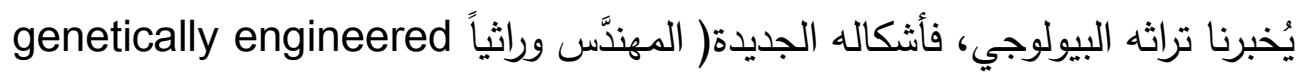

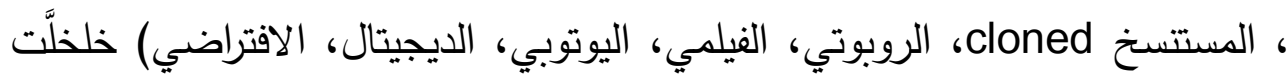

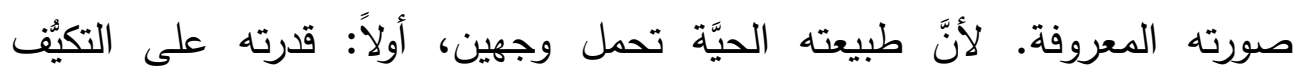

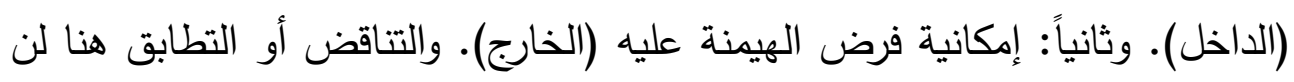
يُحْسم لصالحه بحالِّ، بل لمخالب سلطةٍ تجيد اصطياده اجتماعياً وسياسياً.

أي أنَّهَ بالعودة إلى طبيعة الجسد وغرائزه، كانت تتأسَّس السلطةُ في تاريخ

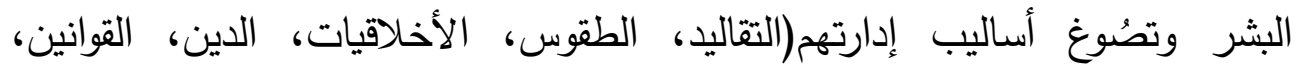

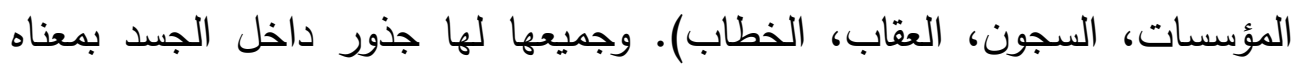

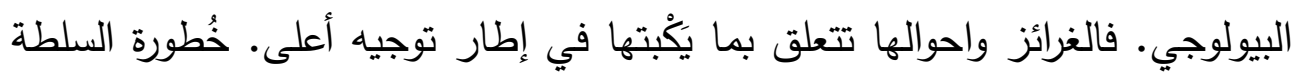

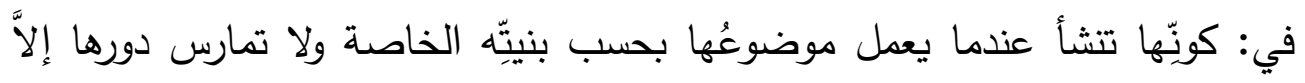
حين تتغاير وفقاً له. وحتى إذا كان الجسدُ(في الثقافة) طاقة حيوية ورمزية، فالسلطة لئلة

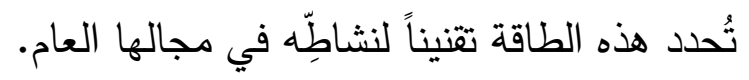

إذن ما حدثَ أنَّ السلطة ظلت ترتبط بماهية الجسد بينما هو تجاوزها مختلفاً بفضل التطور التقني والمعرفي والسيميائي. واصبح الجسدُ- بالطبيعة ذاتها - تقنيةً تُمارس الافتراض والاصطناع والاختلاف والتهجين البشري الرقمي. وهي امكانيات (مثل الذكاء الاصطناعي والمعلوماتية والواقع الافتراضي والسينما والهندسة الوراثية

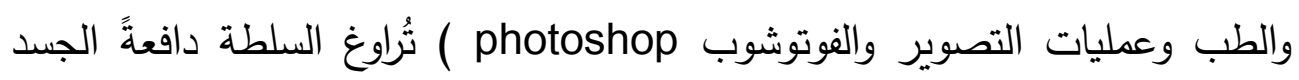
لمزيد من التَّدرر • وبهذا استطاع الجسدُ الراهن اعادة فتح فضاء التفلسف وقضاياه

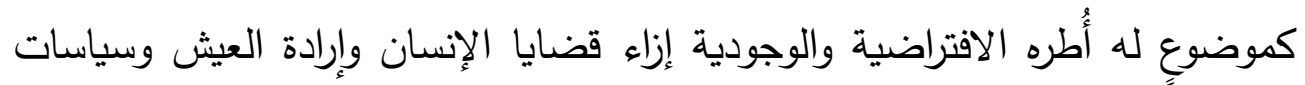
الحقيقة والكثف عن مسائل فلسفية تخص أنماط الحياة والتراث البيولوجي للإنسان. 
وفي هذه الحدود تقدم الدراسةُ رؤيةً لعلاقة الجسد بالسلطة، معتمدة على هذه

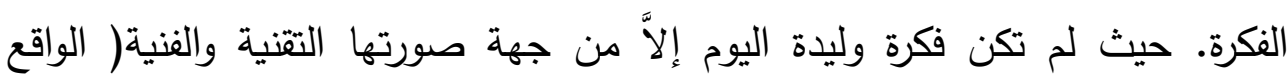

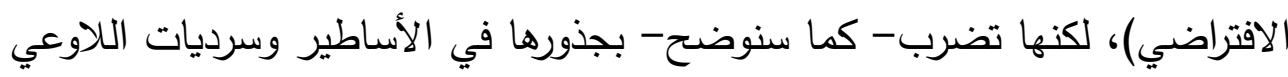

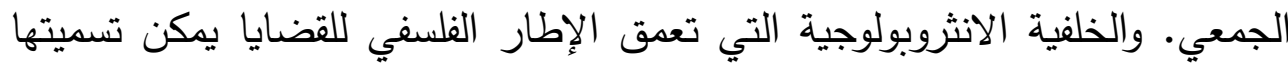

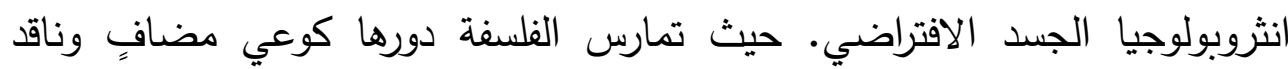
ومتسائل لتحديد إثكال السلطة في تراث الجسد. وسيكون ذللك مساحة مختلفة للتفكير

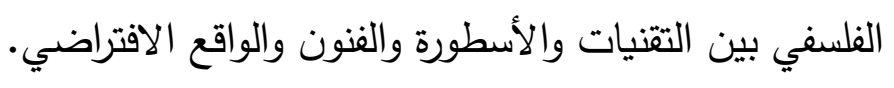

\section{المشكلةُ والتأسيس}

على مستوى الفعل، لم يختِبِ الصراعُ بين الجسد والسلطة رغم اتفاقهما في

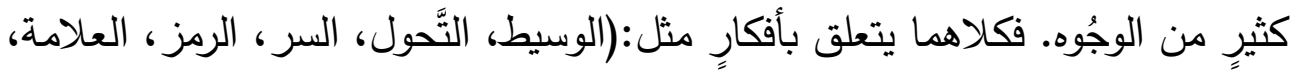

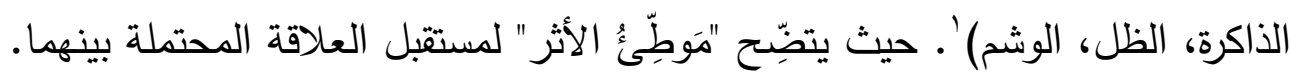

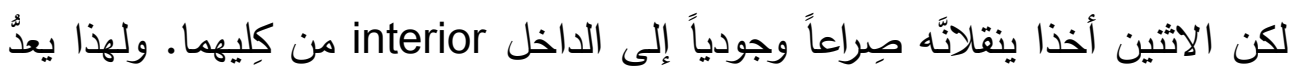

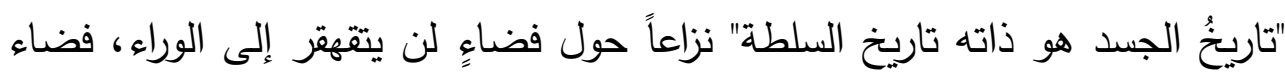

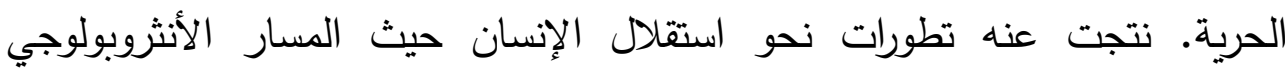

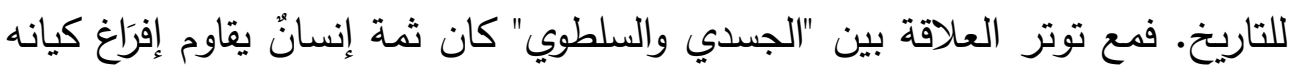

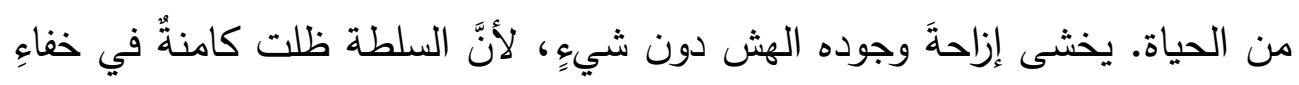

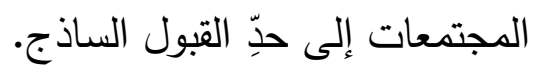

'ـ هذه الأفكار تمثل-كما سنعرض- درجات الصراع بين الجسد والسلطة، لكونها ( أي الوشم والرمز والعلامة والفعل....) إمكانية جسدية وسلطوية

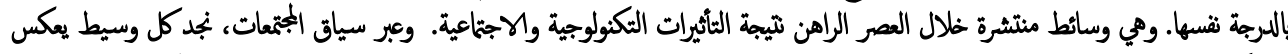

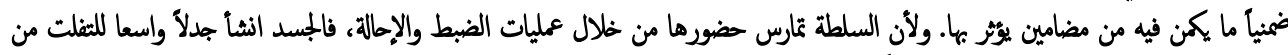

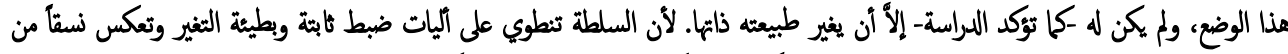

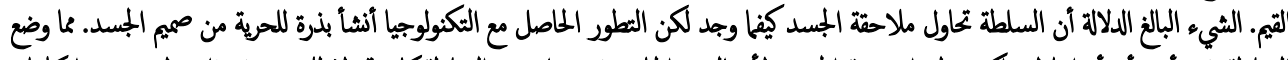

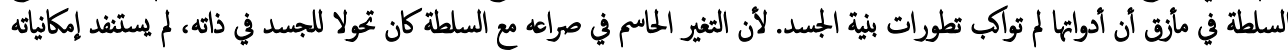

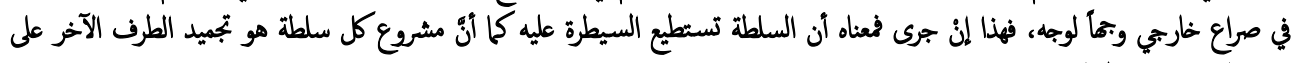
صورتها وبكسب منطثها. 


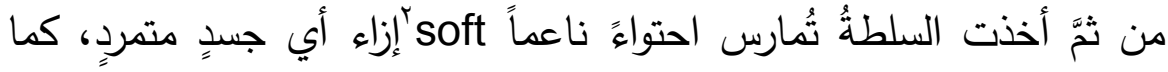
ذهبت إلى استتزاف طاقاته (القعع الرمزي بصوره الثقافية). بينما أحدث الجسدُ داخل

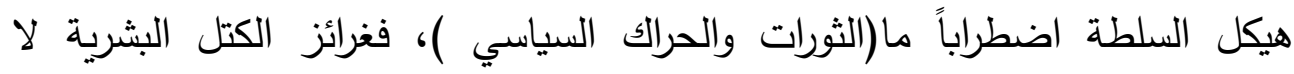

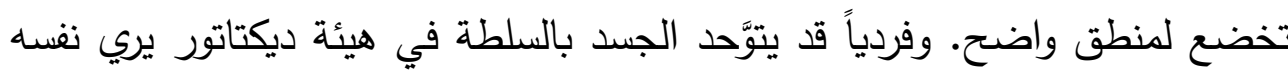

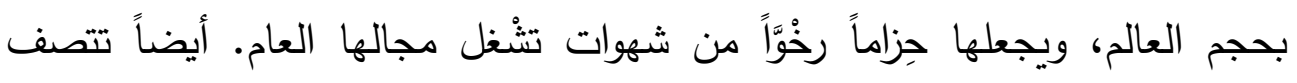
السلطة بأوصاف عضوية: فهي تجوع وتفترس وتفتلك( حيوان الثقافة")، لأنَّها مرتبطة بالغرائز الأولية للإنسان، وبالتوازي قد يتسلَّط الجسد ويضربُ ويُعنيّنَ الآخر . هكذا ثمة اشكالَّ فلسفي مزدوجُ:

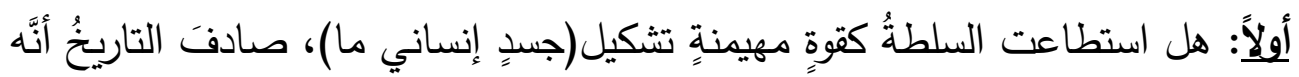

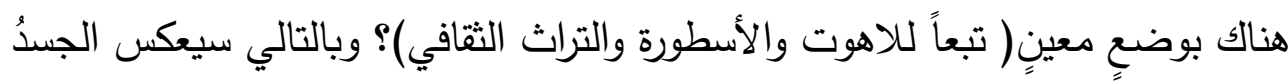

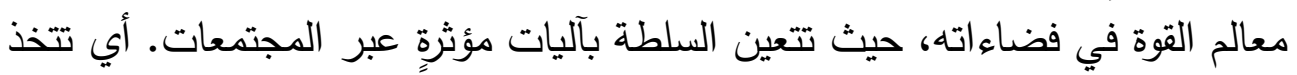
الجسدَ كأداة لحضورها بأشكال تتعلق بطبيعته (البيولوجيا).

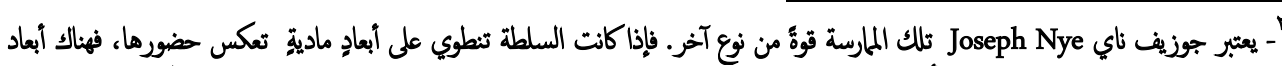

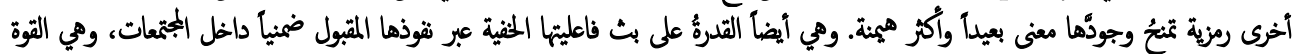

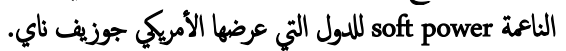

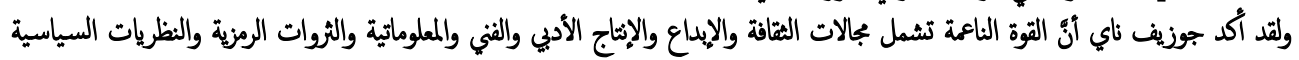

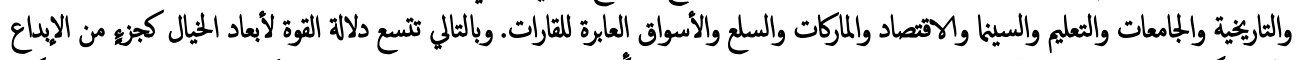

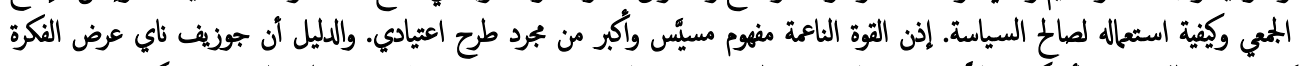

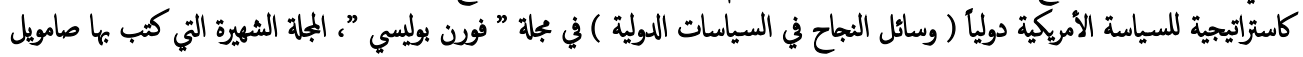

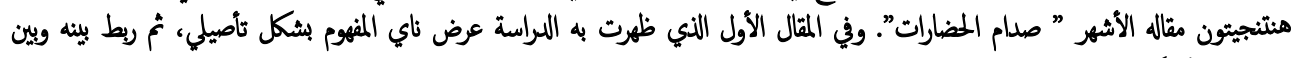
السياسة الأمريكية المارجية في مجلة العلوم السياسية. - Joseph S. Nye, Soft Power, in: Foreign Policy, No. 80, Twentieth Anniversary (Autumn, 1990), Washington post .Newsweek Interactive, LLC, pp. 153-171

- Joseph S. Nye, Soft Power and American Foreign Policy, in: Political Science Quarterly, Vol. 119, No. 2 ( Summer, 2004 ), Pp. 255-270.

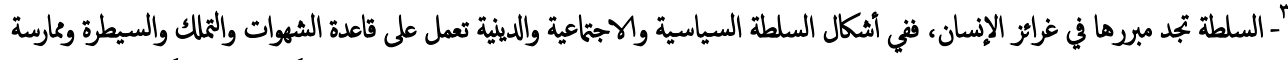

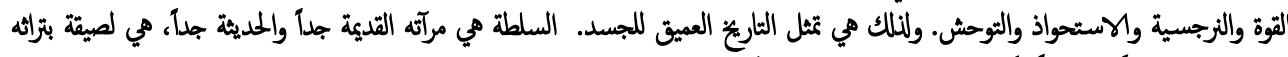

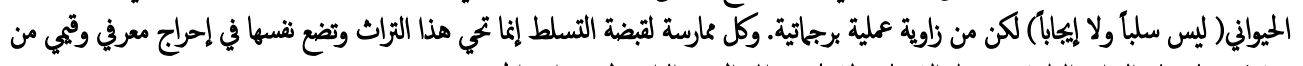

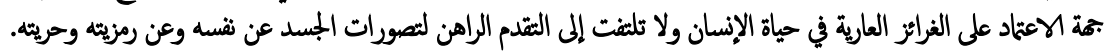


ثَانياً: عكس ذلك، هل تُوجَد للجسد سلطةٌ في ذاته دون قيودِ؛ أي هل استقل الجسد

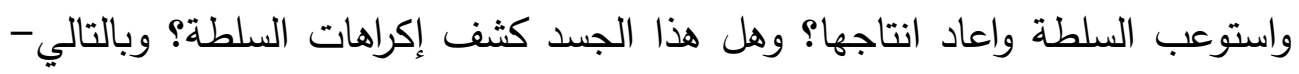

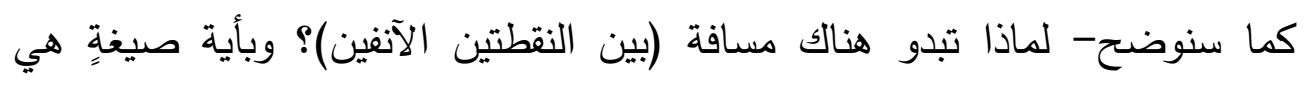
مسافة تُلخص طبيعة الجسد وتحولاته وقدرتنا على توضيح دلالاته؟! virtual body هذا الانتقال بين وجهي الأسئلة يقطعُه الجسد الافتراضي

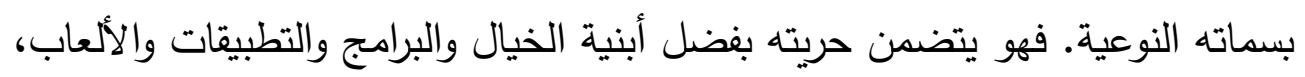

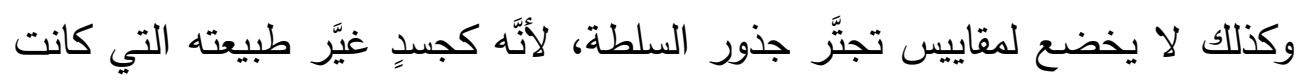

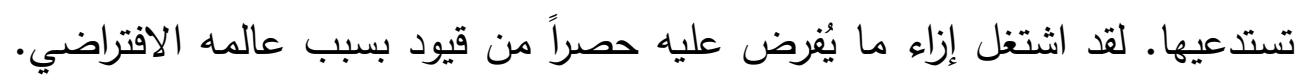

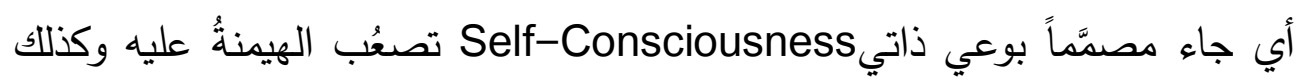
لا يكُف عن اختراق حدوده المفروضة؛ داء داتئ.

إنَّ مفهوم الجسد الافتراضي يطرح قضايا تخص انظمته وخلفياته وكيف

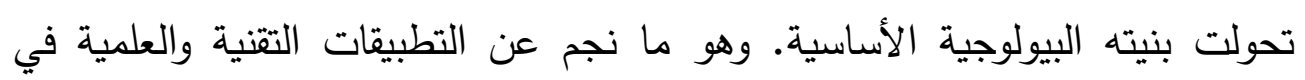

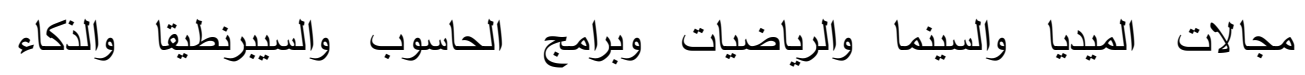

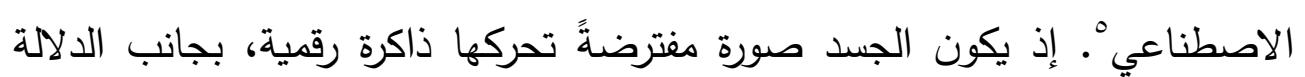
والتخييل لاى المتلقي، حيث يعطينا الواقع الافتراضي أفاق التفاعل.

الجسد الافتراضي جزءٌ من العالم الرقمي مستتداً إلى إدهاش المفارقة بينه

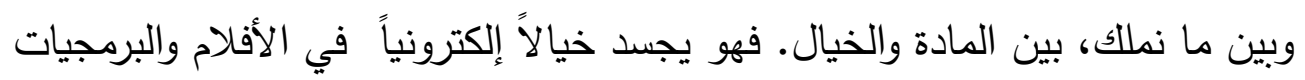

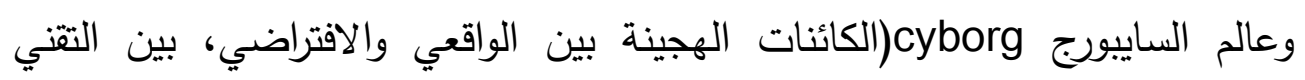
والبيولوجي).

${ }^{4}$-J. J. Hopfield, Neural networks and physical systems with emergent collective computational abilities. Proceedings of the National Academy of Sciences of the United States of America, 79(8):2554-2558, April 1982. P 2556.

${ }^{5}$-Tim Highfield and Tama Leaver, Instagrammatics and digital methods: studying visual social media, from selfies and gifs to memes and emoji. Communication Research and Practice, 2(1):47-62, 2016.pp 51-54. 
وتدخل ضمن دائرة هذا الجسد عدة أشكال أبرزها:

- الشخصيات وهوياتها الافتراضية( صفحات الفيسبوك وانستجرام وتويتر وسناب

$$
\text { شات H....snap chat }
$$

- الكائنات المتخيلة والمتجسدة عبر السينما( الافلام التي تحاكي الكائنات وتبتكر

$$
\text { أخرى عجيبة وغريبة). }
$$

- الشخصيات الممثلَّة افتراضياً( مثل شخصيات فيلم أفتار Avatar وماتريكس .(Matrix

$$
\text { - الاجساد الإلكترونية(الربوتات والكائنات الآلية والتقنيات الثبيهة). }
$$

- الاجساد التي تُزرع داخلها شرائح إلكترونية لترميم بعض الأعضاء وتجديد الوظائف الحيوية.

- الاجساد المُخلَّقة افتراضياً(الأعمال الأسطورية والشخصيات الخارقة والخرافية والحيوانات المنقرضة).

- النصوص والصور واللغات الافتراضية مثل لغة الإيموجي Emoji (أيقونات الوجوه الضاحكة والعابسة والحزينة والمندهشة، كما أنَّ النصوص تقنيات تتجنب

$$
\text { الرقابة والحجب وهي جسد افتراضي ). }
$$

6 - Enney Norton, The Imoji Dictionary, ( Emoji-Presentation-1wijyi.pdf), https://cpb-us-w2.wpmucdn.com/portfolio.newschool.edu/dist/4/3049/files/2015/05/Emoji-Presentation1wijyji.pdf, Pp 1- 23.

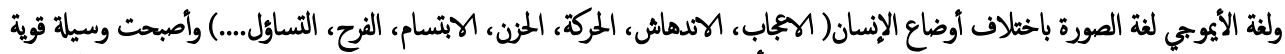

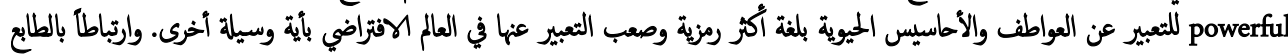

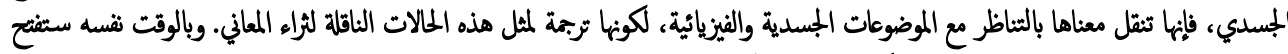

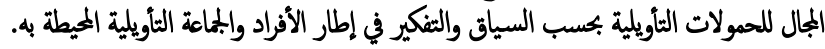

- Luke Stark and Kate Crawford, The Conservatism of Emoji: Work, Affect, and Communication, Social Media + Society July-December 2015: 1-11,

https://sites.tufts.edu/mythritualsymbol2017/files/2017/08/stark-crawford-conservatism-emoji.pdf, p 4. 
- الاجساد القائمة على المحاكاة( رموز الأفراد أو الجماعات أو المجتمعات البديلة

$$
\text { والمناظرة: الإنسان عموماً). }
$$

- الإجساد اليوتوبية التي تتخيل من خلال القصص والأفلام وصور المدن الفاضلة

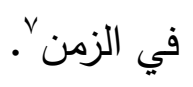

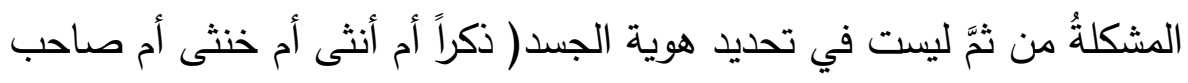

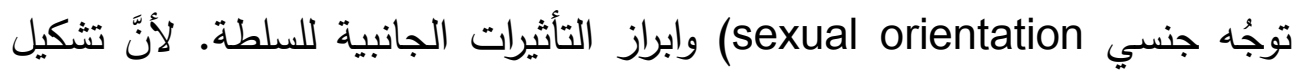

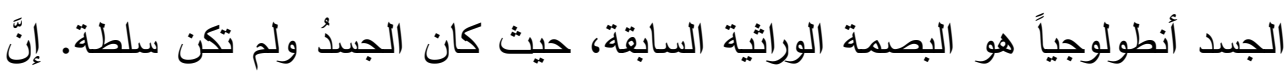
جيناته الثقافية cultural genes أكثر جذرية، حيث الجنه تراث لاهوتي- وجودي كوَّن السلطة ولم يُفلتها عبر الأبنية الاجتماعية المتعاقبة. وبلغ أنْ اخترق حاجز الكيان

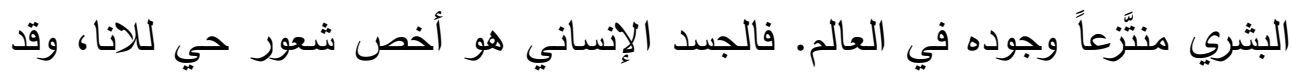
ارتبطت به كافة التعاليم اللاهوتية إزاء العالم والحياة.

ولنلاحظ أنَّ الأسئلة الفلسفية المُثارة ترتبط بماهية الجسد إذ ستأتي تحولاته

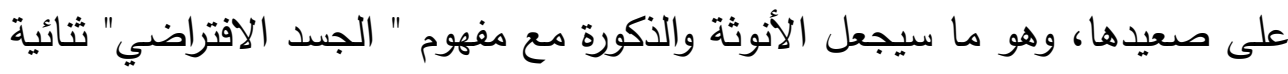

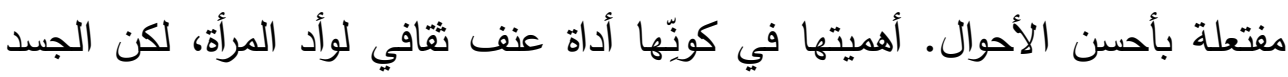

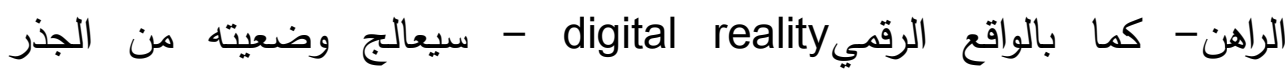

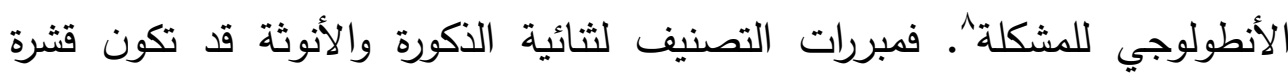

- Subashini Annamalai, Sobihatun Nur Abdul Salam, Undergraduates' Interpretation on WhatsApp Smiley Emoji, Journal Komunikasi Malaysian Journal of Communication Jilid 33(4) 2017: 89 -103. P 91.

- Andrei Catalin Coman, Giacomo Zara, Yaroslav Nechaev, Gianni Barlacchi, and Alessandro Moschitti, Exploiting Deep Neural Networks for Tweet-based Emoji Prediction, University of Trento,Trento,Italy\{andreicatalin.coman,giacomo.zara\}@studenti.unitn.it, moschitti@disi.unitn.it. PP 16 -128.

7- Yann LeCun and Yoshua Bengio. The handbook of brain theory and neural networks. chapter Convolutional Networks for Images, Speech, and Time Series, pages 255-258. MIT Press, Cambridge, MA, USA, 1998.

^ـ الجسد الافتراضي هنا يمثل تأسيسأ للجسد على اصول جديدة، فهو يقوم على تكوين مغاير للطبيعي ومندمج مع دلالته في الوقت عينه. وبأفضل

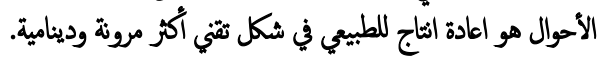


اجتماعيةً للجسد واستعمالاته، لكن انفجار طبيعة الجسد ذاته(افتراضياً-عضوياً) يُحتِّم انفجار أية قشور ويعيد ترتيب أوضاع الجسد ومحمولاته الفلسفية والثقافية".

إنَّ الجسد الافتراضي فجَّر بنية الجسد التقليدي وكسَّر أنماط السلطة، وهنا يمكن استثارة منطق التفكير الفلسفي في هكذا تحول. على سبيل المثال يمكن

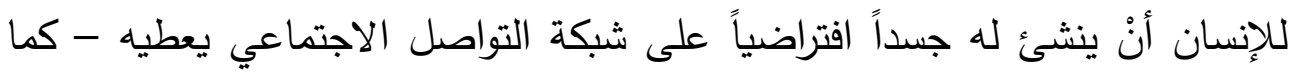

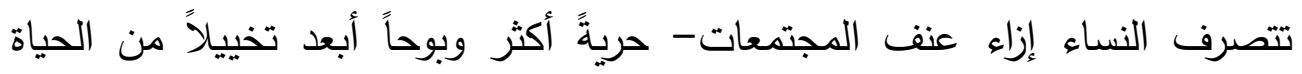
الفعلية. بل يعطيه مجالاً للعيش المختلف، وفوق هذا وذاك يظل الإنسان متعلقاً به، التهاء لأنَّه يدخل حدود ما يريده طوال الوقت، ولا سيما إذا كان مجتمعه يكبل أفعاله

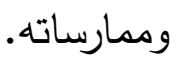

لأنَّ الجسد الافتراضي ينتمي- بلغة زيجموند باومان- إلى عالم " الثقافة

السائلة liquid culture"، حين تغيب احجام الأشياء ويسود قانون التغير والتحول الدائمين في اعماق الحياة. وارتباطاً بالجانب التقني والذكاء الإنساني، فهي ثقافة التئة معبرة

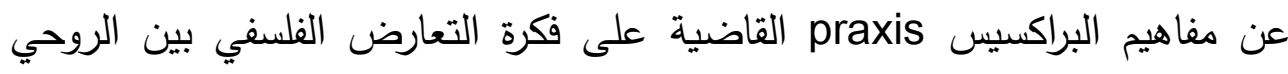
spiritual

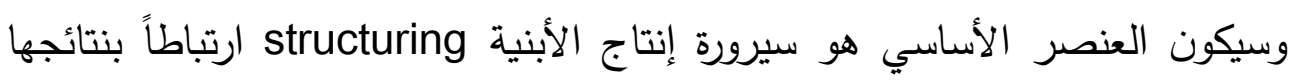
المتموضعة objectified واقعياً '.

وإذا كانت الحداثة الأوروبية قد انتجب الاجساد ذات الكتل والاحجام كنتاج للصناعات الثقيلة والآلات العملاقة، فإنَّ ما بعد الحداثة تتعامل مع النانوتكنولوجي 9-ليس أحل على ذلك من وجود قوانين تعيد تأويل الصور والأوضاع الجسدية في إطار الواقع المتزاضي. والأخير يططينا منظورات للأفعال وتجلياتها. الحياتية أبرز من أي شيء آخر. Eric Goldman, Emojis and the Law, http://digital.law.washington.edu/dspacelaw/bitstream/handle/1773.1/1835/93WLR1227.pdf, PP 1262 - 1266.

${ }^{10}$-Zygmunt Bauman, Culture As Praxis, London, California, New Delhi SAGE Publications (New Edition), 1999. P 43. 
والتقنيات الافتراضية والوسائط المرنة والمواد والشرائح الذكية، إنَّها تكنولوجيا سائلة liquid technology

بؤرةُ الاشكال أنَّ بنية الجسد الراهن وصوره ما بعد الحداثية مرحلة متقدمة بين التقنية والطبيعة نحو المستقبل. وبهذا الإطار لم تعاند التكنولوجيا الطبيعة، إنما

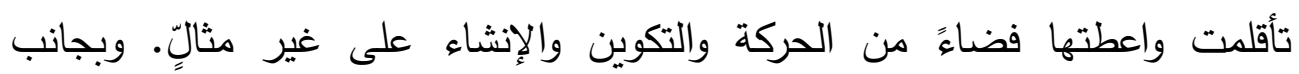

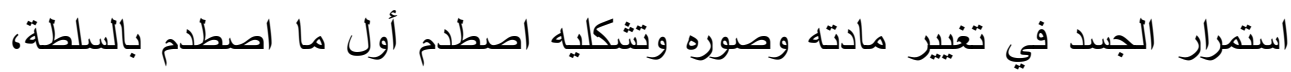

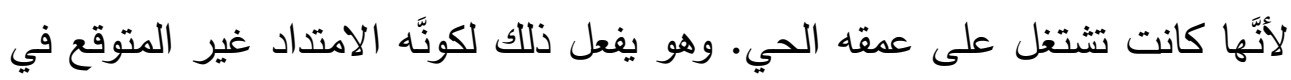

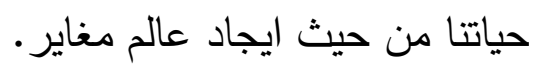

\section{بيولوحيا السلطة}

لقد أبقت السلطة على البُعد البيولوجي للإنسان كقاعدةٍ تستدعيها في أي وقت،

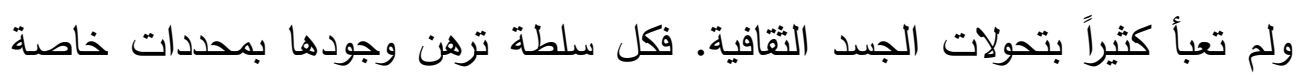

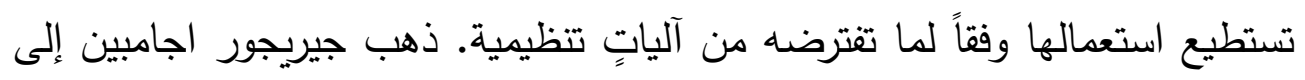

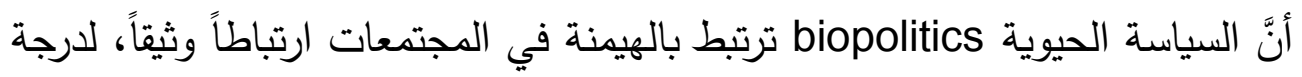
أنَّ" انتاج الجسد السياسي الحيوي biopolitical body هو الفاعلية الأصلية لأيَّة

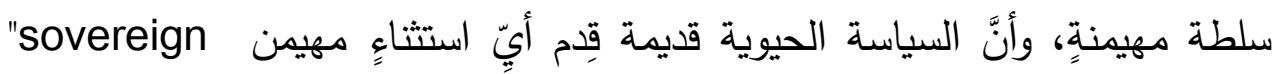
. 'exception

ولذلك فإنَّ مجابهة نشاط الإنسان - برأي الأنظمة السياسية- لا يجب مجاراته

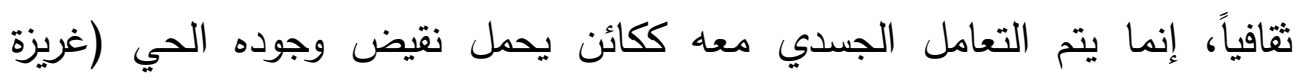

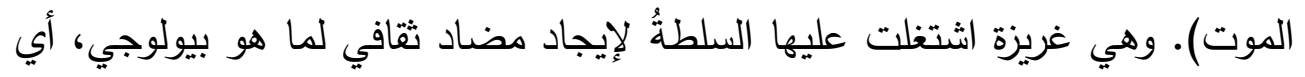

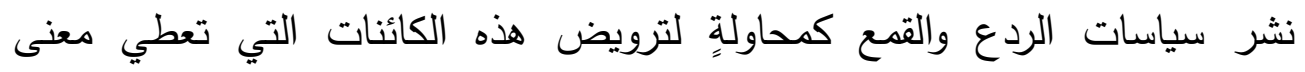

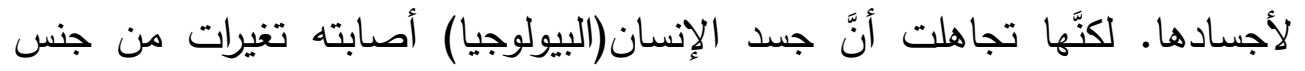

${ }^{11}$ - Giorgio Agamben, Homo Sacer: Sovereign Power and Bare Life, translated by Daniel Heller-Roazen Stanford, CA: Stanford University Press, 1998. p 6. 
الثقافة والمعارف المتقدمة، حتى أنَّ اندماجهما (البيولوجيا والثقافة ) باتَ وضعاً مؤكَّداً في ظل العوالم الإلكترونية والمعارف العلمية. نتيجة ذللك عملت مفاهيم السلطة على ألى العيات

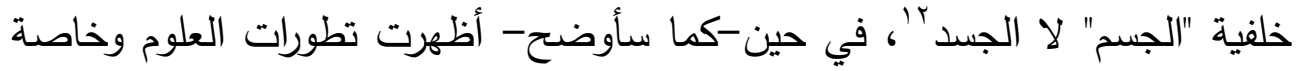
الذكاء الاصطناعي أنَّهَ يستحيل ارجاع الجسدِ إلى خانة الجسم. هكذا تربط السلطة نفسها بطبيعة الكائن الحي، ارتباطها بمكانيزمات حيوية

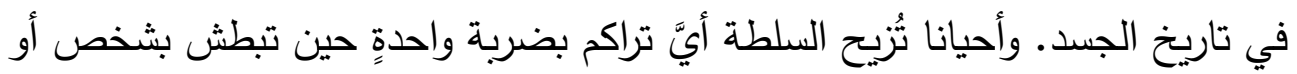

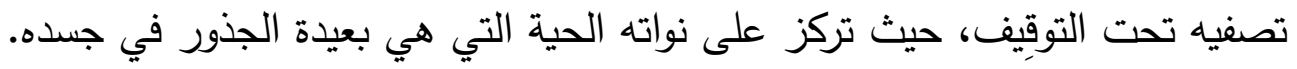
تقف السلطة من ثم لاى طاقات الجسم، ولم تتخط نحو صوره المعرفية والتقنية

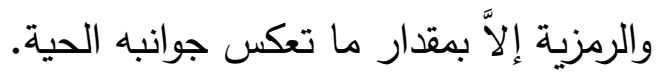

وهذا يعود إلى: أنَّ السلطة تحضر حيث تحضر تفاصيل الحياة ولو كانت في

هيئة جسد راغب ومرغوب، فخلال الحياة تتعلق السلطة بما يُشَّغِل نبضها إزاء الإرادة

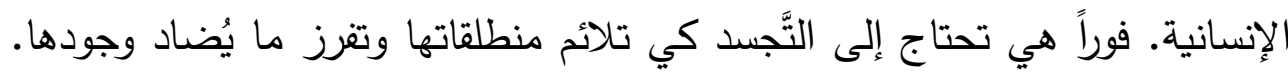

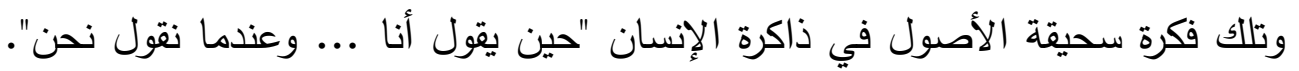

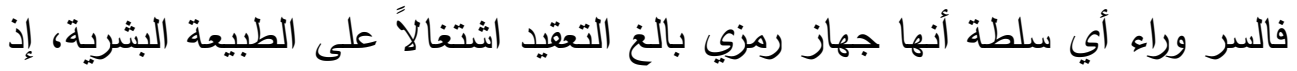
لا تغيب العلاقة العضوية بالكائن الحي داخلنا. والسلطة من تلك الجهة هي المعادل الموضوعي لما تكتثفه داخل الأجساد.

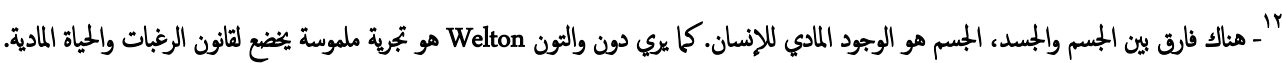

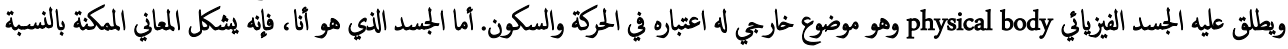

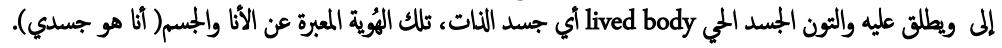
(the identity of the ego and the body: I am my body)

Donn Welton, Body and Machines, in: Postphenomenology: A Critical Companion to Ihde, Edited by Evan Selinger, State University of New York Press 2006. P 198. 
باختصار، تقع ممارسات السلطة- بحسب ميثل فوكو - في إطار

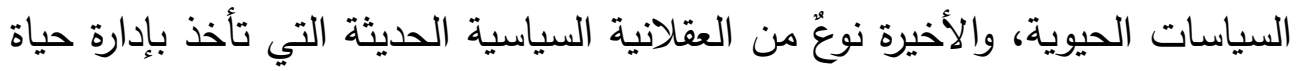
البشر كموضوعٍ لها: لضمان تطور المجتمعات وهندستها بطريقةٍ توافق مفاهيم الدولة

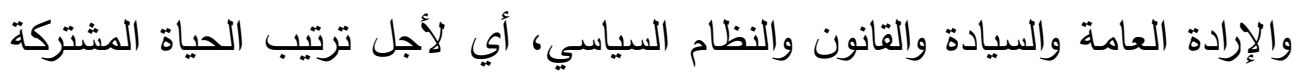
بين الأفراد يجب وضعها وفقاً لتنظيمٍٍ ما.

تسمي السلطة في هذه الحالة بالسلطة الحيوية Biopower حيث يجري تشريع

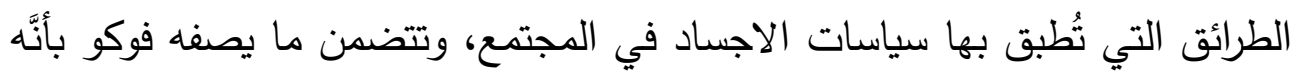

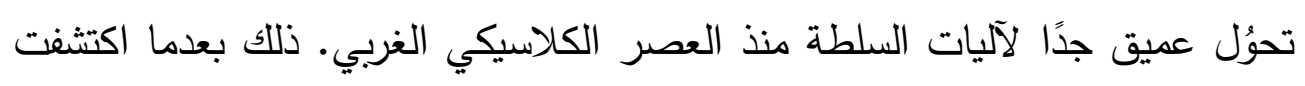

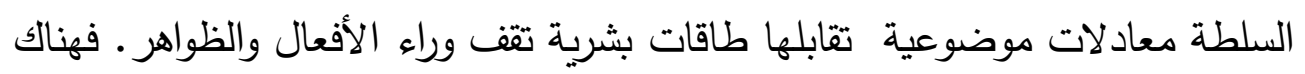

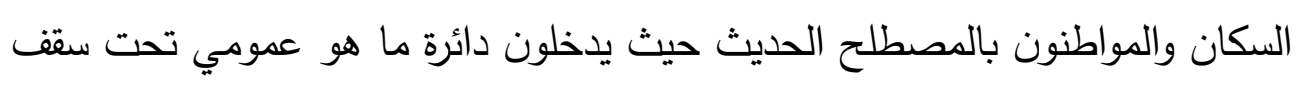

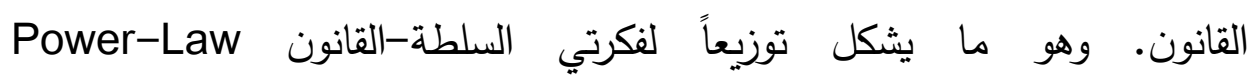
بواسطة علاقات منتشرة في المجتمعات الإنسانية حيث حركة الناس

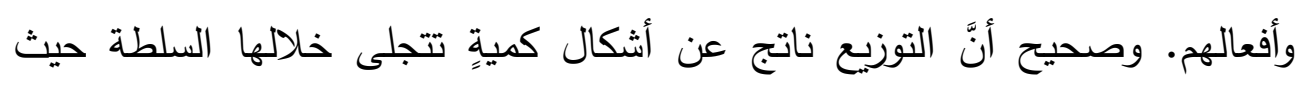

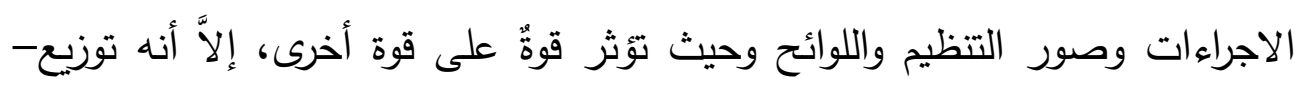

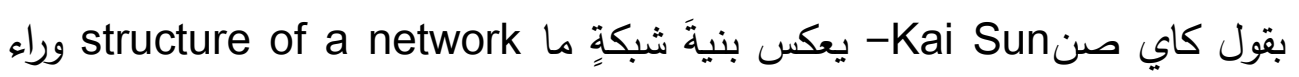

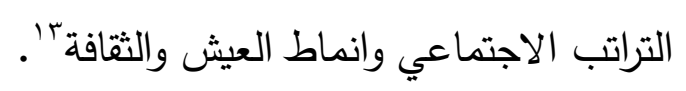

ففي سياق الدولة يتَّ اعتبار الحياة المشتركة جزءاً لا يتجزأ من تتظيمها، ومن

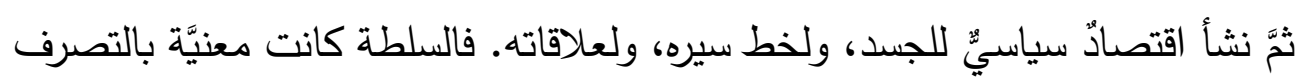
القانوني أو غيره في ظاهرة الحياة المميزة لأصحاب العقد الاجتماعي. وهي ما تجعلهم

${ }^{13}$ - Kai Sun, Explanation of Log-Normal Distributions and Power-Law Distributions in Biology and Social Science, Department of Physics, University of Illinois at Urbana-Champaign, 1110 W. Green St. , Urbana, IL 61801-3080, USA

(Dated:

May

6 ,

2004)

(http://guava.physics.uiuc.edu/ nigel/courses/569/Essays_2004/files/sun.pdf), pP 2- 3. 
مواطنين ورعايا للدولة كخطوة أولى للحقوق والالتزامات. يرى فوكو أنَّ الجسد حدثَ

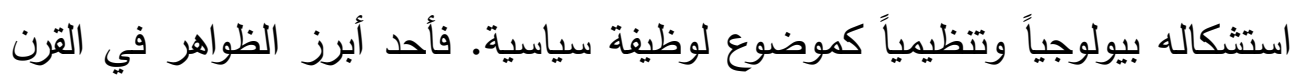
التاسع عشر هي ما تُسى بسيطرة السلطة على الحياة داخل الأفراد وخارجهم بشكلِّ لئل

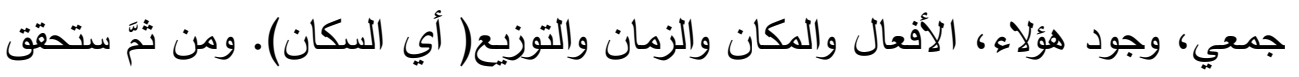

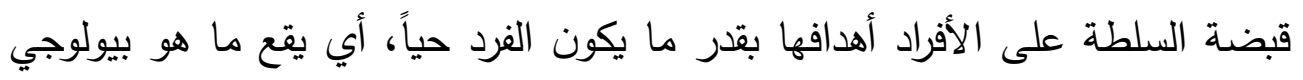
تحت سيطرة الدولة State control '.

ويواصل فوكو الفكرة بإثارته أنَّ النظرية الكلاسيكية للسيادة Sovereignty كانت تحدد حق الحياة والموت ارتباطاً بالملك، وكان هو من له القدرة بحسب النظبه النظية

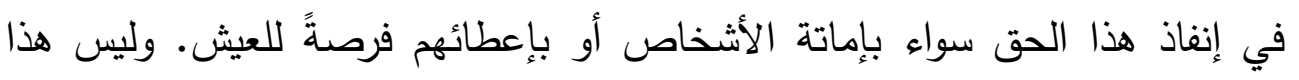
فقط، بل يربطه الملك بجهاز القانون حتى ينتمي مباشرة إلى السلطة القائمة. ويتصور

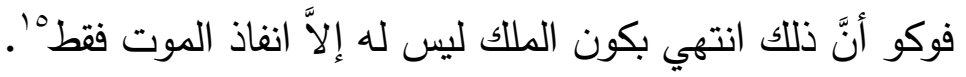

السبب فيما يبدو أنَّ الحياة الإنسانية طاقة طبيعية لا يتركها حاكمّ إلاًّ بالهيمنة

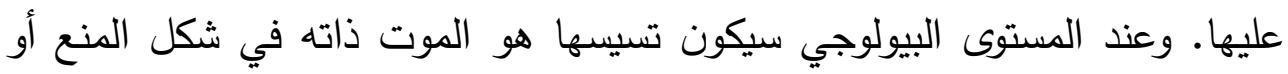

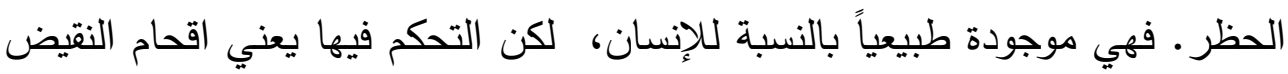

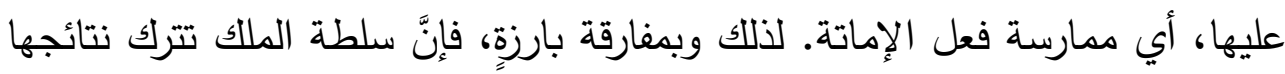

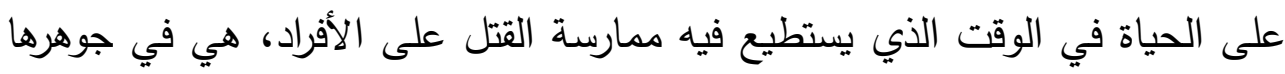

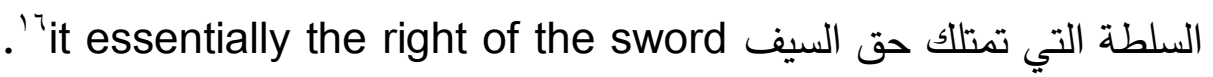

\footnotetext{
${ }^{14}$-Michel Foucault,' Society Must Be Defended', Lectures at the College de France(1975-1976), Edited by Mauro Bertani and Alessandro Fontana, General Editors: Francois Ewald and Alessandro Fontana, English series Editor: Arnold I. Davidson Translated by David Macey, PICADOR, New York 1997, PP 239 -240. 15 - Ibid, p 240.

${ }^{16}$ - Ibid, p 240.
} 
لكن ليس كلُ نتاج السلطة سلبياً، فهي قوة فاعلةً بشكل مقبولٍ على نطاق

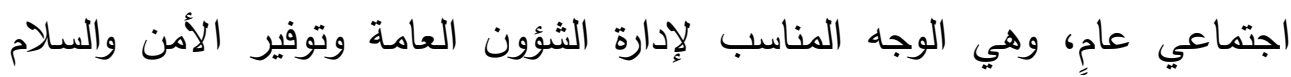
والسيولة كما لها تأثيرها الإيجابي على الحياة، ساعية إلى تحسينها وتطويرها. وربما

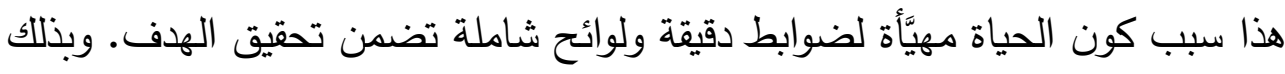

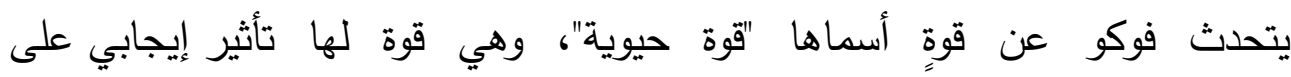

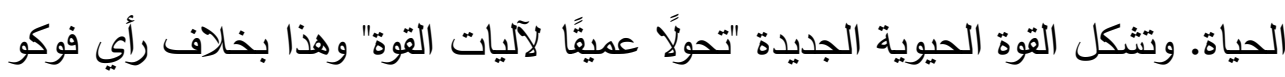

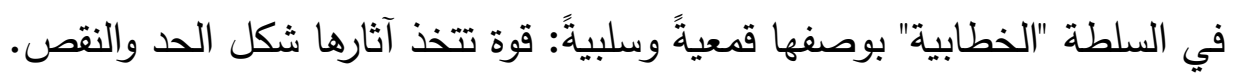
repressive ولذلك يقوم فوكو بإجراء نقد مطول لهذا الأداء القمعي performance

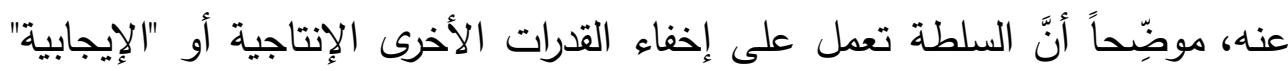

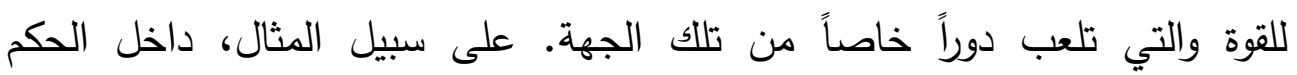

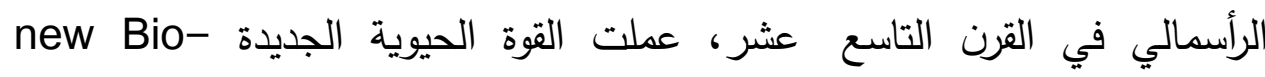

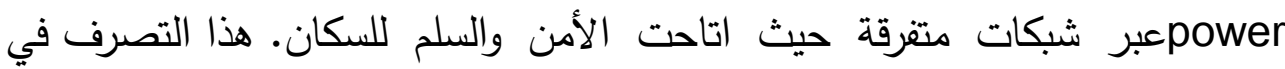
السلطة يعمل من أسفل، من "مستوى الحياة" نفسه بما يُحافظ على كئل كيان المجتمعات "'.

ومع ذللك فالنقطة المهمة تباعاً كون السلطةً بوجهيها تدخل إلى أيّ نطاق

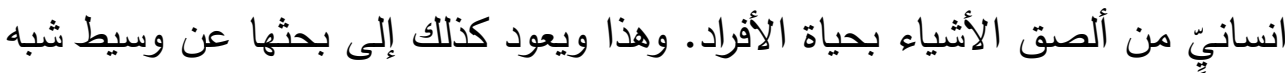
موضوعي لممارسة إجراءاتها وحقيتها بالنسبة للمجتمع والدولة. والفكرة هنا أكثر الأرياء

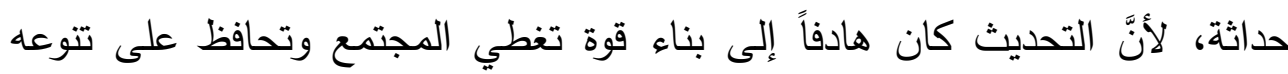

${ }^{17}$ - Hubert L. Dreyfus and Paul Rabinow, Michel Foucault: Beyond Structuralism and Hermeneutics, Second Edition with an Afterword and an interview with Michel Foucault, The University of Chicago Press 1983. Pp129 - 131. 
to واختلافه، أي تزيد الايجابيات to maximize positives .' control negatives

إذن المعنى القديم والمعنى الحديث هما طرفا مفارقة السلطة: كيف تجمع

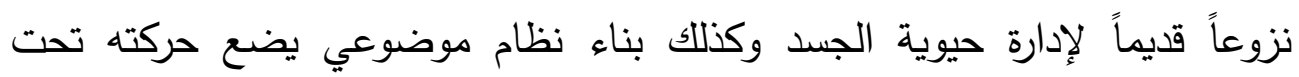

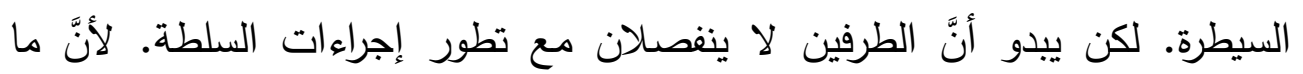

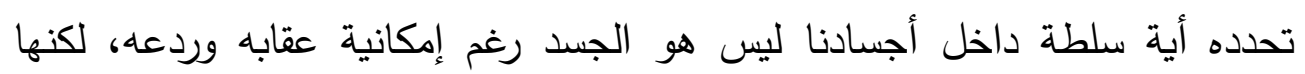

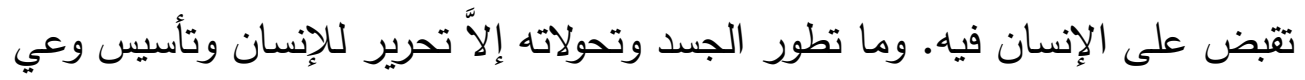
أكثر تحراً مما يقدعه.

يجب الإشارة بإمكانية وجود ذاكرة مختزنة في جسد الإنسان وهي تكاد توحد

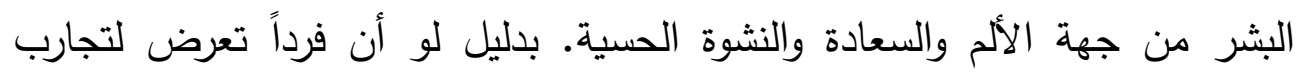
مؤلمة نتيجة ضرر أصاب جسمه، فلن ينسى آثارها البيولوجية مع مرور الوقت، ولئ، وريما

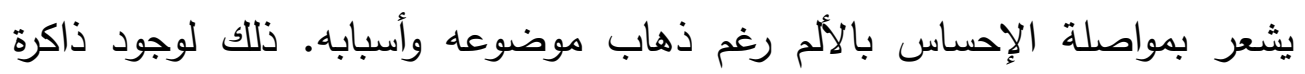

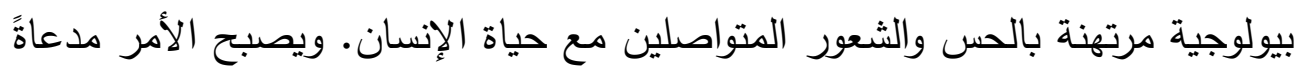

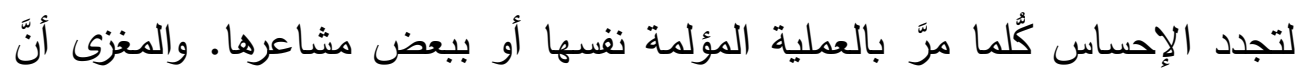

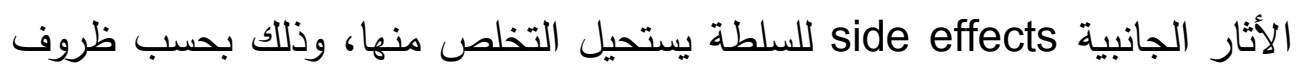
المجتمعات وتكوينها الثقافي.

وبخاصة أنَّ السلطة لا يعنيها تحديد المجال العمومي للأجساد فقط، بل

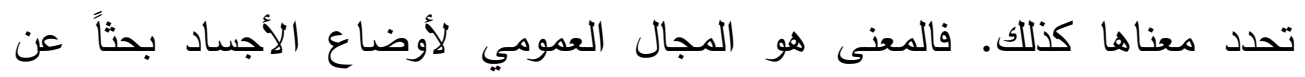

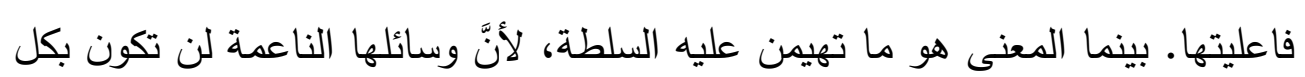

${ }^{18}$ - Kasper Simo Kristensen, Michel Foucault on Bio-power and Biopolitics, University of Helsinki Faculty of Social Sciences Social and Moral Philosophy Master's Thesis, April 2013. P 54. 
الأحوال مؤثرة إلاًّ ما خفي منها. حتى أنْ هناك خطوطاً رمزية تتمسك بها السلطة لوضع الأفراد داخل دائرتها.

ومن ثمَّ فإنَّ الإجراءات السياسية لأنظمة الحكم هي طرق عامة نحو المعنى. وذللك أنَّ مجالاً كهذا يتعذر الاستحواذ عليه. وأنَّ ما يضاعف الإت رصيد السلطة رمزياً

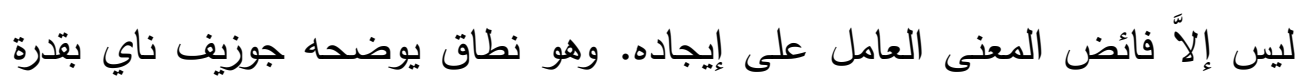
الحب على التأثير غير الملموس في حياتتا وقد يكون له طاقة أعلى من أي شيء الهاء

إنَّها الفكرة التي ستتوافر بدرجة كبيرة في الجسد الافتراضي، فهو يمثل

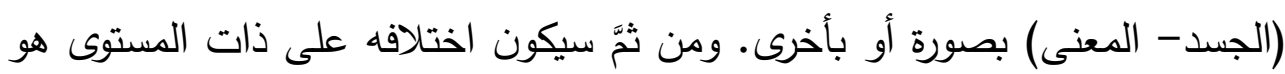

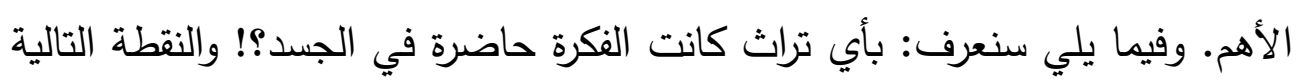

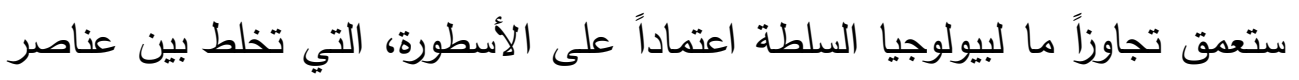

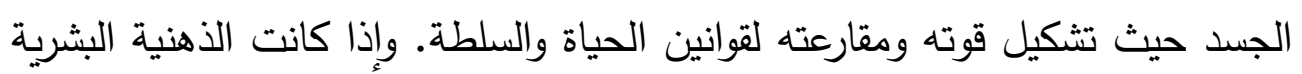

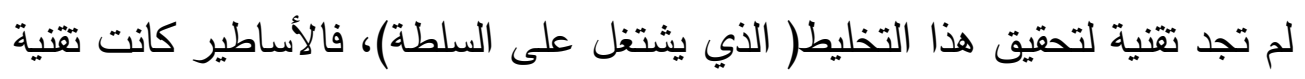
سردية للخيال حيال سؤال الجسد وطبيعته.

\section{تُراث الجسد}

وردت خلفية تحلُل بيولوجيا السلطة في تاريخ الثقافة الإنسانية عبر فكرة التَّحُد

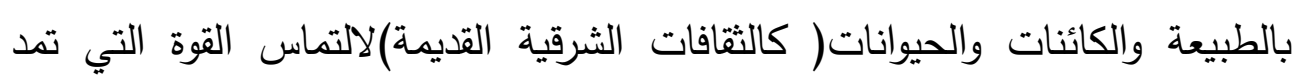

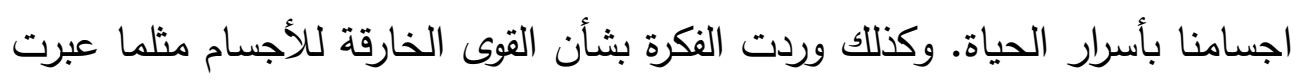
الأساطير عن آلهةٍ لها أنصاف بشرية برؤوس حيوانية وخرافية(الحضارتان الفرعونية واليونانية).

\footnotetext{
19 - Joseph S. Nye, The Future of Power, Public Affairs, New York 2011, P3.
} 
ارتبط التهجين الأسطوري الجسدي( التوليف- الدمج confusion) بالخيال

الذي أبرزته فنون الرسم والنحت والأيقونات والزخارف في المعابد وجدران الدقابر .

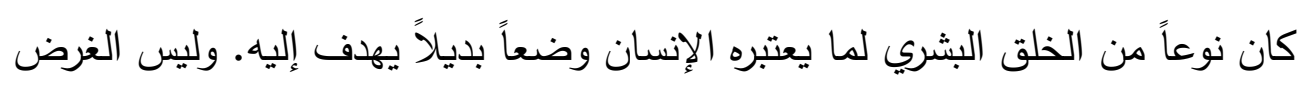

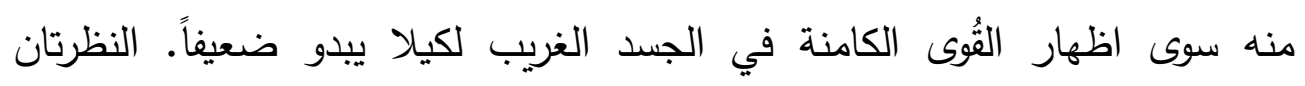

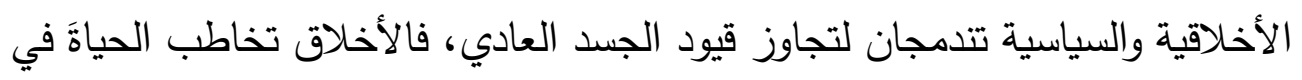

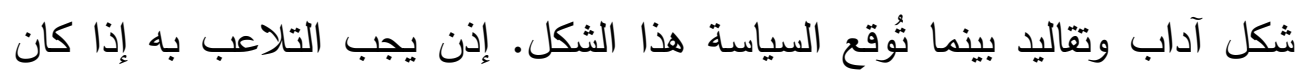

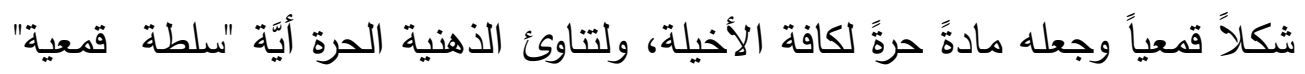

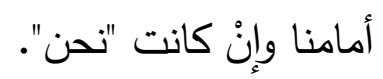
كانت الأساطير الفرعونية واليونانية مجالاً لتداعي اللاوعي بين الواقع

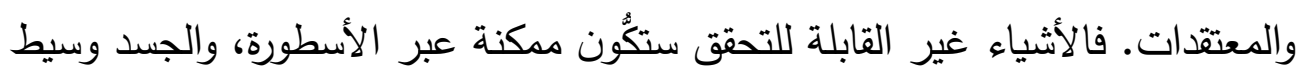

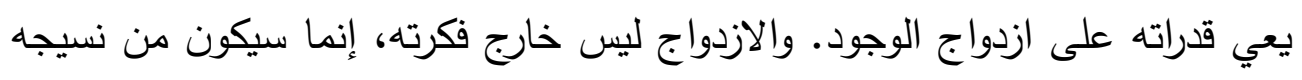
الحي في صورة خيالٍّ. حيث يدمج الجسد الاسطوري غير المرئي داخل طبيعته. الكائن الاسطوري هو افراز للاوعي الجمعي إزاء الأخطار التي يترقبها، وهو

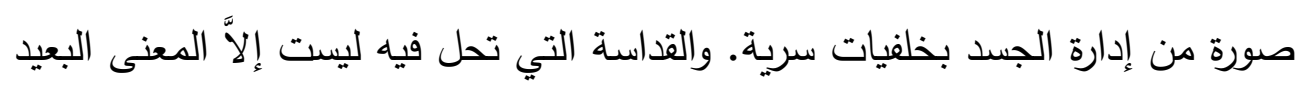

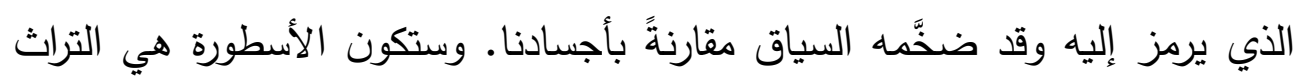

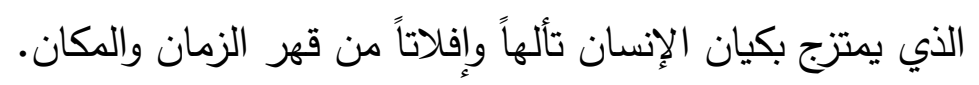

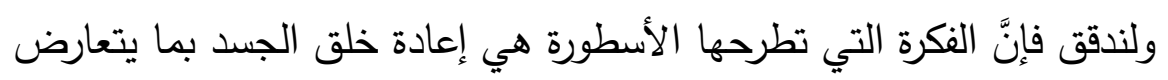

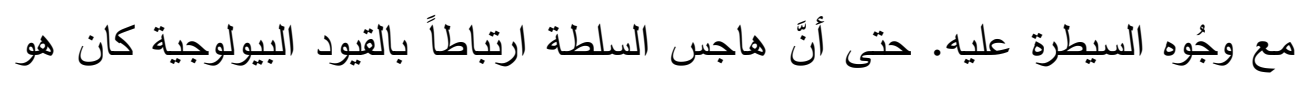

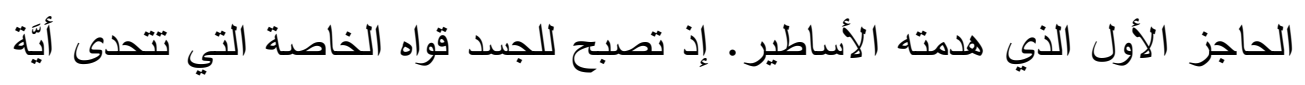

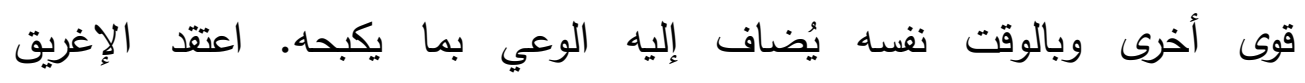

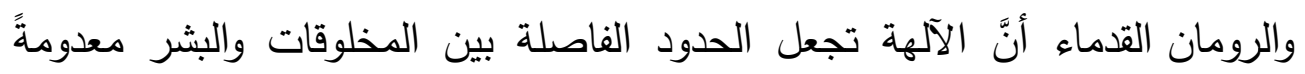
بشكل كبيرٍ 
وكمثالِّ على ذلك كتاب التحولات (مسخ الكائنات) لأوفيديوس Ovidus، وهو مجموعة من الأساطير اليونانية والرومانية عن البشر الذين حولتهم الآلهة إلى الى لإلى

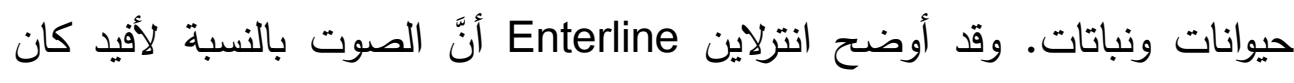

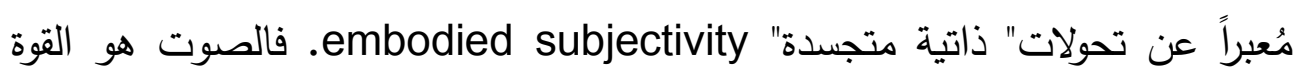

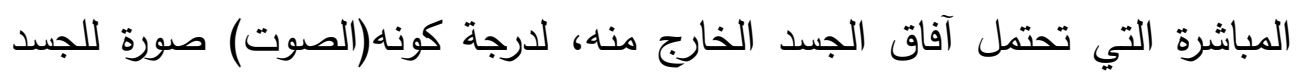

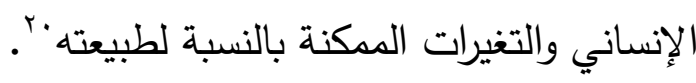

المهم أنَّ ذلك الجسد سيكون استعارةً للقوة المنبثقة عنه، والاسطورة من تلك الكار

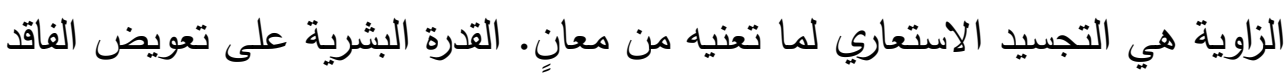

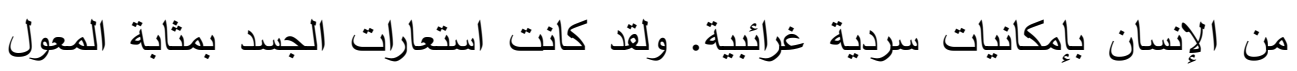

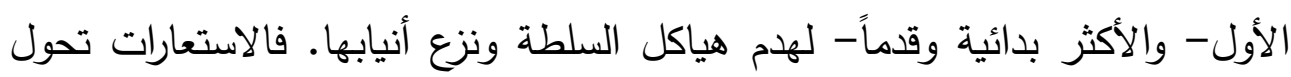

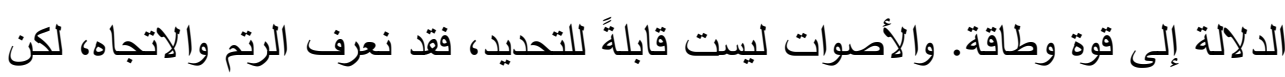

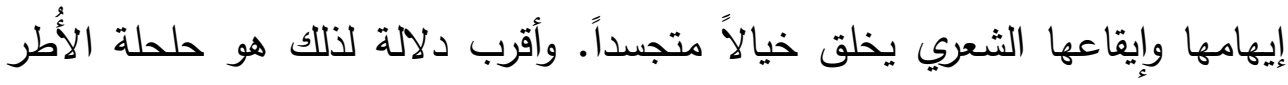

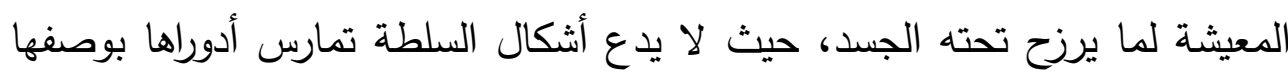
قبضة هيمنة.

هو حال يسميه أندرو فيلدير Feldheer "سياسات الخيال"، أي سياسات الحكي الأسطوري القائم على لعبة تبادل العوالم بواسطة الاستعارات الجسدية. فحينما

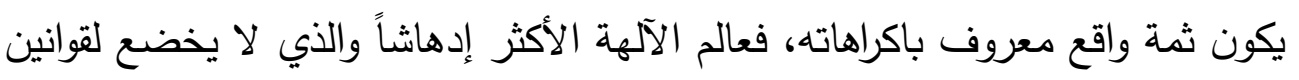

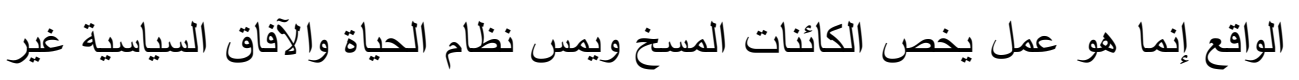

\footnotetext{
${ }^{20}$-Lynn Enterline, The Rhetoric of the Body from Ovid to Shakespeare, Cambridge University Press 2004. PP 39- 40.
} 
المتاحة، لأنَّ العنصر التصويري programmatic الأساسي بصدد ذلك الوضع هو

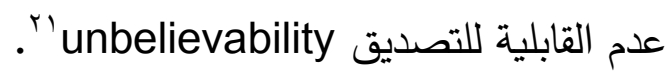

وانعدام القابلية للتصديق بصدد كائن مسخ هو انعدام التصديق للكائنات

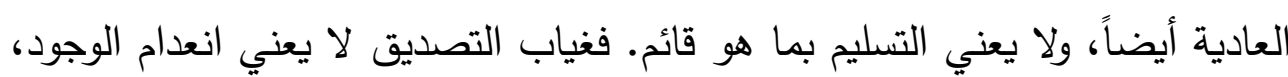
بل دال على أنَّ هناك صوراً تذهل من يتلقاها بقدر ما يذهله جمود الحياة الاعتيادية.

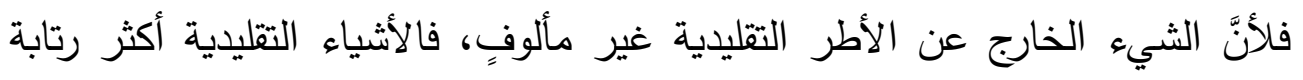

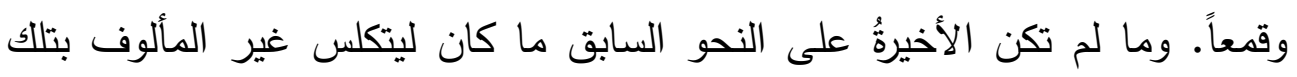

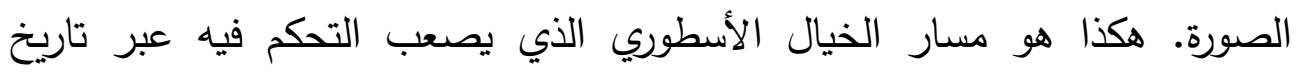
الثقافات الإنسانية، لأنَّه مسار يضع أيَّ واقع في أزمة متعددة الأبعاد. 1- مُساءلة نمط العيش وكيفية التفكير فيما هو راهن وأسباب راهنيته، وكيف يتم

$$
\text { التعامل معه؟؟ }
$$

ץ- إيجاد صور مغايرة للأفعال بوضع علاقات جديدة مع القوى الإلهية

$$
\text { والميتافيزيقية. }
$$

r- اعادة إنتاج سلطة عامة لا تجد مبرراتها فيما هو سائد. حتى وإن كانت الأسطورة سردية ومحتوية على شخصيات فعلية أو تُدخِل غيرها في دائرة

$$
\text { رمزية أشد تأثيراً وقداسةً. }
$$

؟ - لا حدود هناك بين القوى المختلفة للطبيعة وال" ماوراء"، فجميعها قد تحل في

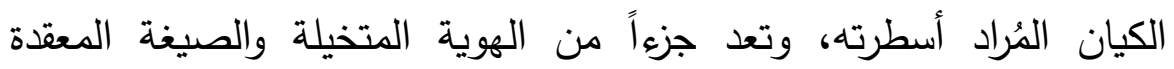

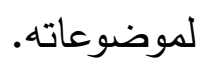

\footnotetext{
${ }^{21}$-Andrew Feldheer, Playing gods: Ovid's Metamorphoses and the politics of fiction, Princeton University Press 2010, p46.
} 
ه- تعددية الفاعلين- لدرجة الصراع التراجيدي- في الأسطورة، من حيث تعددية الآلهة polytheism وهو ما يسميها شيلنج الوجه الثيولوجي للأساطير بَّ.

ولذلك تصبح الأساطير استعارات وجودية بمله الكلمة تحريراً للإنسان من القيود، وجعله مشاركاً في تحديد مصير الأشياء بحسب معتقداته. وبجوار الآلهة يستطيع التعامل معهم عن قرب وإدخالهم في دراما الحياة السياسية وأحداثها. وهو كذلك ما يطلق عليه شيلنج الطابع التاريخي historical للوجود البشري، فالكائنات الأسطورية لها جذور تاريخية وفقاً لطبيعة القوى التي تمثلها، وبالتالي فهي جزء لا يتجزأ من حركة الزمن كما يشير سير الأحداث( الطبيعة - التاريخ) ويدل أصل الآلهة

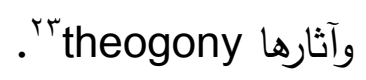

على صعيد الشخصيات التاريخية، سيكون دور البطولة والقدرة على صناعتها أحد وجوه هذا التراث الجسدي. فليس فقط وجود الآلهة في صورة حيوانات، بل ثة أناس هم أفراد لعبوا دوراً خارقاً في الحروب. إنَّ الأبطال مقرونون جسدياً بهذه المعاني

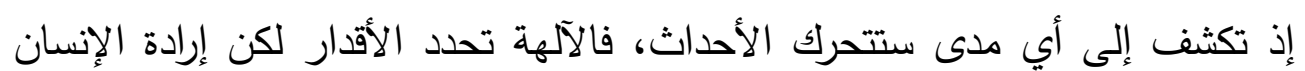
عنصر أساس ضمن هذا النظام.

فزيوس_Zeus- على سبيل المثال - بالأساطير اليونانية هو كبير الآلهة، لكنه

لا يفعل كلَّ شيء مرة واحدةً. يُكتب زيوس باليونانية القديمة هكذا: كعن́ الحديثة: Sías. ويُلَّبَ عند الإغريق بـ" أب الآلهة والبشر" أو كما في اليونانية القديمة وبالنسبة لدلالته الدينية، هو أيضاً أب الآلهة، لأنه يحُم آلهة جبل الأوليمب باعتباره الأب الوريث. وزيوس- بجانب ذلك- هو إله السماء والصواعق في الميثولوجيا

${ }^{22}$-Friedrich Wilhelm. J. Schelling, Historico-Critical Introduction to the Philosophy of Meythology (1856), Translated by Sydney C. Grew, London 1989, P 14.

${ }^{23}$-Ibid, P 15. 
الإغريقية، نظيره الروماني هو جوبتير، ونظيره في الميثولوجيا الهندوسية هو إندرا.

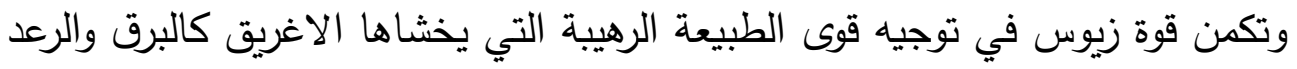

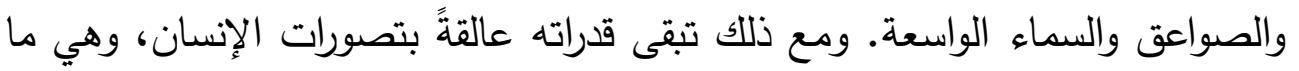

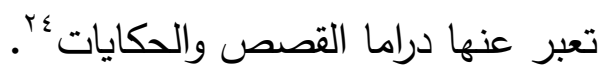

بوضعٍ آخر، تشمل الثقافة الصينية واليُلافيَّة قصصًا لأثخاص يتحولون

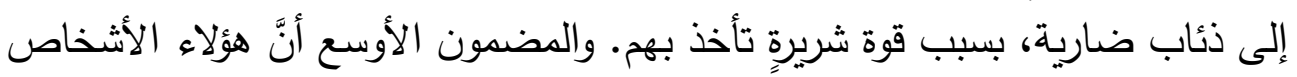

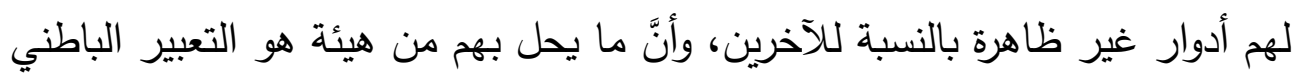

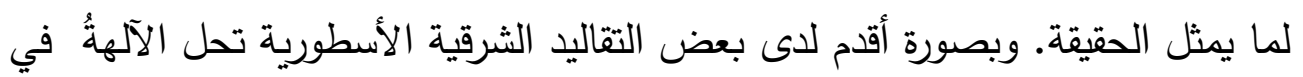

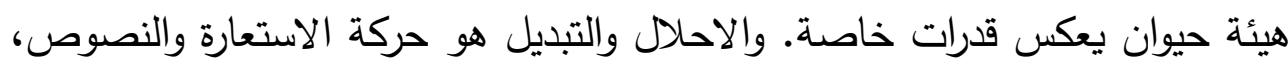

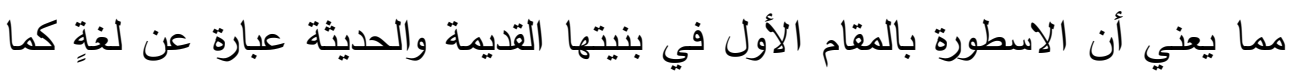

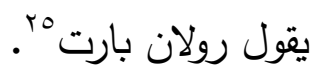

لقد صوَّر المصريون القدماء آلهتهم كحيوانات أو كبشرٍ مع أدمغة الحيوانات،

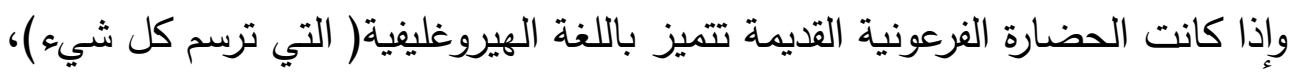
فتلك الصور الجدارية مثلت شبكة من الدلالات في الحياة وما ورائها. كما أنَّ مصادر

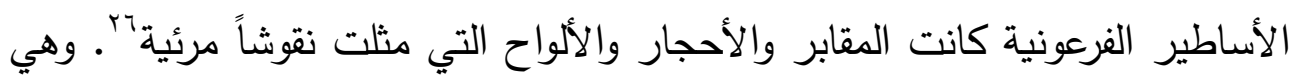
بأدق الأحوال الكتابة التي تستحضر نظام اللغة الأوسع. واللغة بطريقة دريداً (تفضح وتحفظ، تقبض وتبسط) معاً قدرة السلطة على الاحتفاظ بجوهرها الغامض. والكلمات

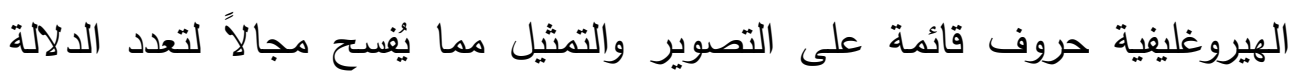

${ }^{24}$ - Helen Morales, Classical Mythology: A Very Short Introduction, Oxford University Press 2007. P 40.

${ }^{25}$-Roland Barthes, Mythologies, Selected and translated from the French by Annette Lavers, The NoonDay Press- New York ,Farrar Straus\& Giroux, 1991. P 10.

${ }^{26}$-Geraldine Pinch, Handbook of Egyptian Mythology(Hand books of World Mythology), ABC-CLIO Santa Barbara, California - Denver, Colorado - Oxford, England, 2002. P 5. 
وبالوقت نفسه انتاج تأويلات(السحر والموت والقداسة والسلطة والشعب والحياة والموت والخلود).

وهذه الاشياء في الثقافة ليست موضوعات، بل معاني تدور حول كل شؤون

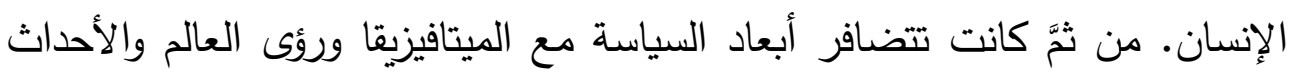

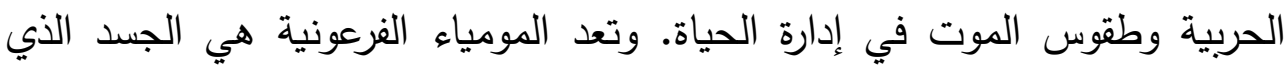

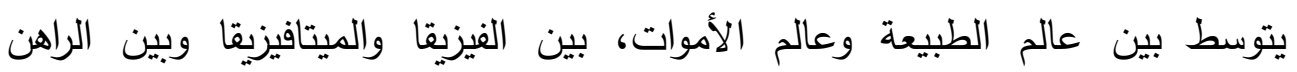

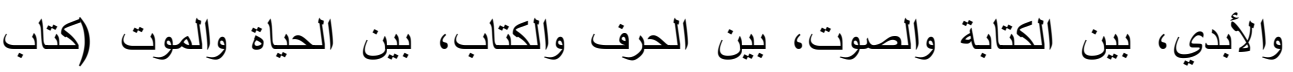

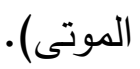

كل ذللك تقف على قمته الآلهة حيث تحكمه وتوجهه نحو المستقبل.

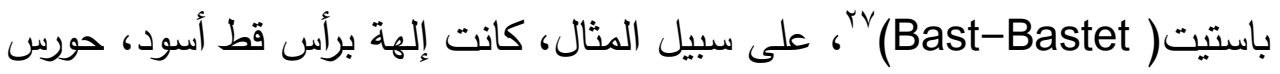
(Horus)

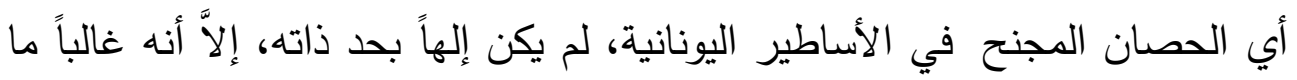

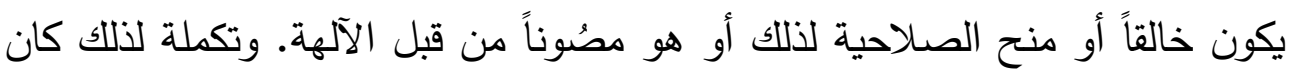

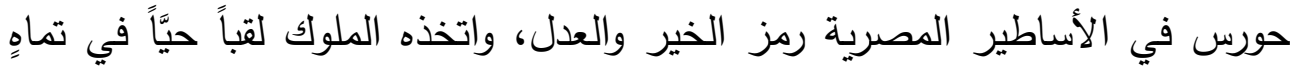

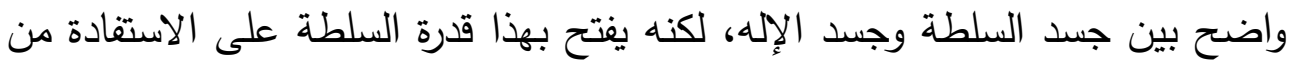

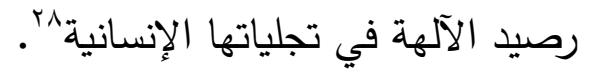

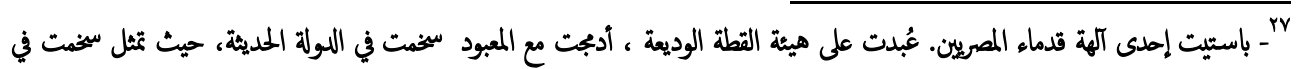

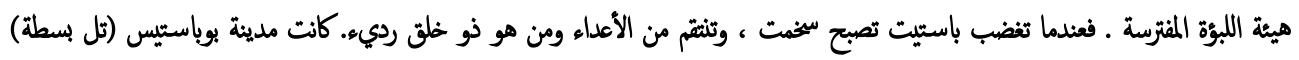

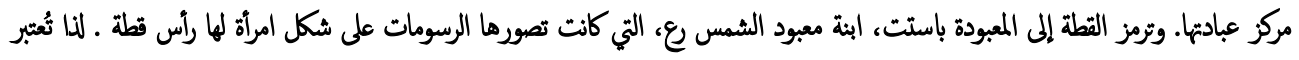

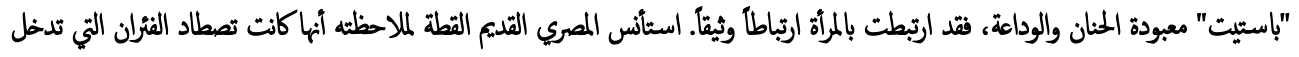

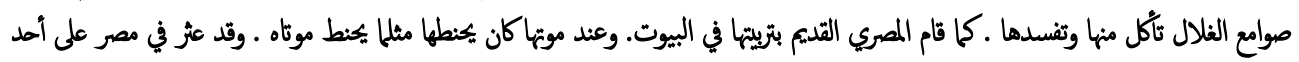

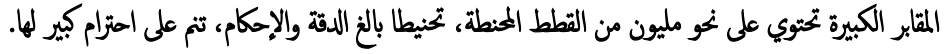

${ }^{28}$ - Steven Creech and Kevin Ruesch, Egyptian Gods: The Lore of The Gods, Bastion Press, 2002. P11. 
وبالتالي لم تغب حتى بهذه الحالة إعادة تشكيل تراث الجسد بما يحقق قدرات

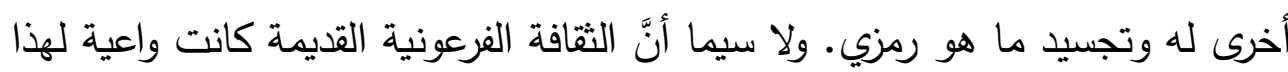

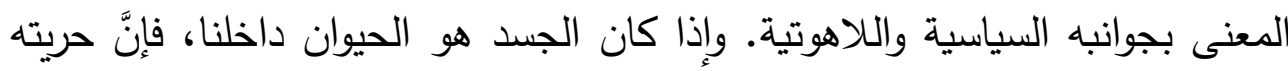

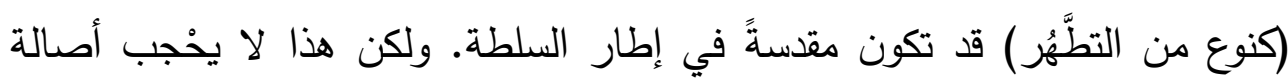

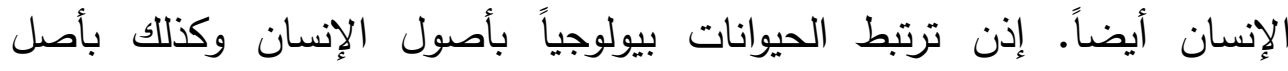

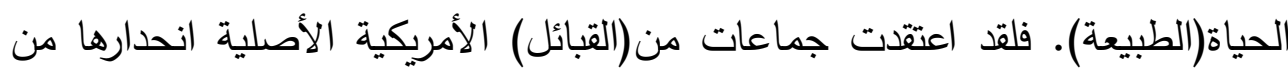
الحيوانات مباشرة، وأرجع شعب "ياو" في جنوب الصين أصولهم إلى (الجد الكلب)

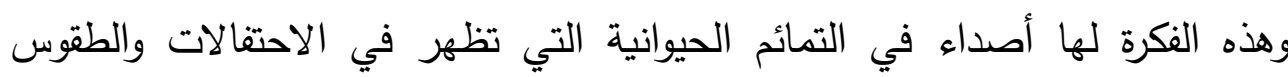

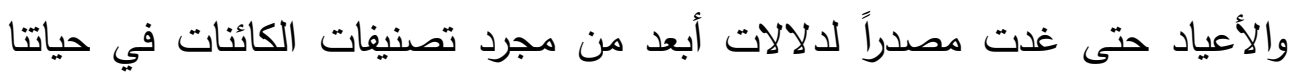

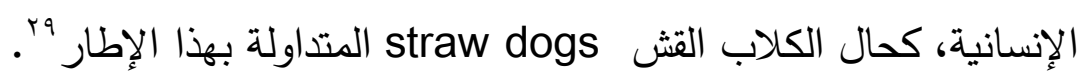

وعادةً، الجانب الحيواني يبثُ التصورات المغايرة في الحياة. فلئن كان الجسد بإشارة سابقة يفتح امكانية التعلق بالمقدس، فوجود الحيوان كمادة مشتركة مع أجسادنا

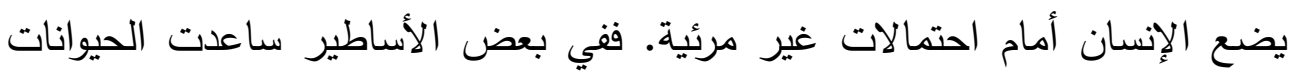

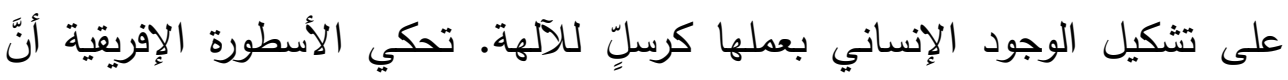

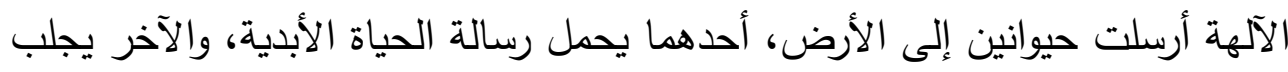

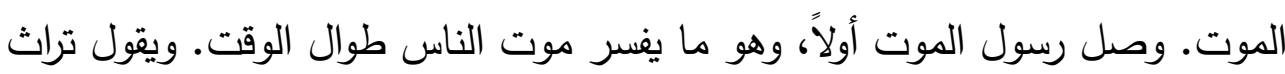

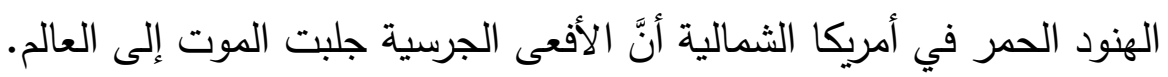

والحيوانات لعبت دورًا إيجابيًا أيضاً، حيث فتحت للناس مسار الحضارة

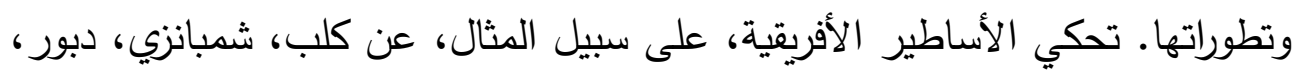

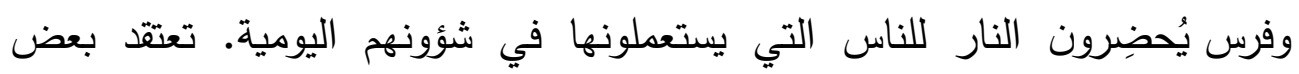

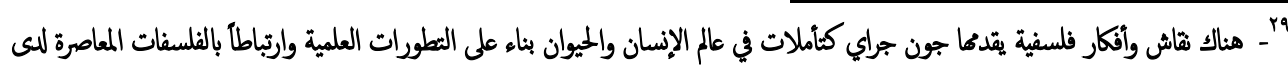

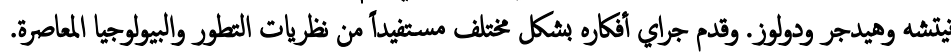
John Gray, Straw Dogs: Thought on Humans and other Animals, Ganata Books, London 
الشعوب الأفريقية كشعب بامبارا في مالي أنَّ الظبي المقدس قد علّم الناس الزراعة

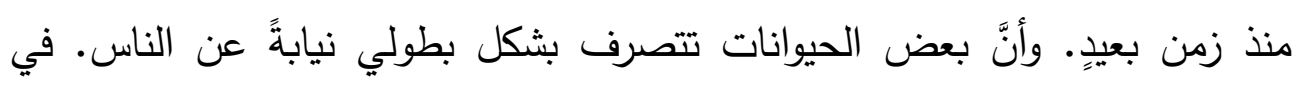

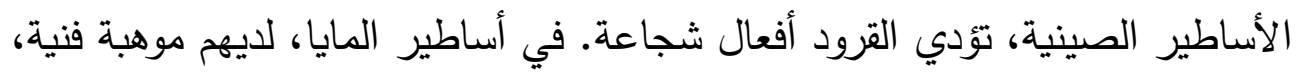

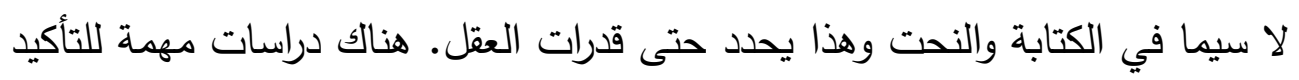

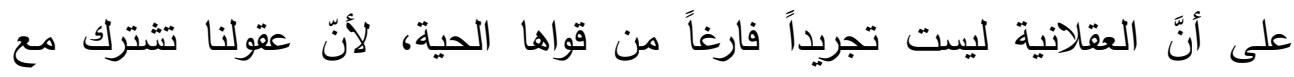

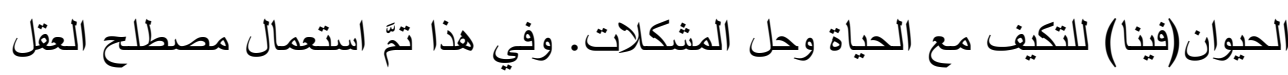

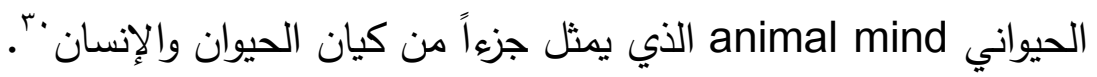
وأحياناً تظهر الحيوانات في سردية الخرافات كرموز لخصائص يُعتقد أنَّها

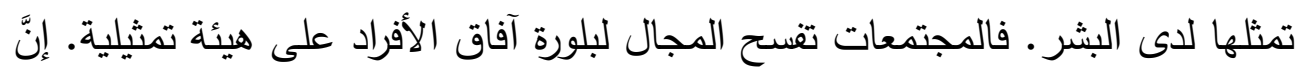

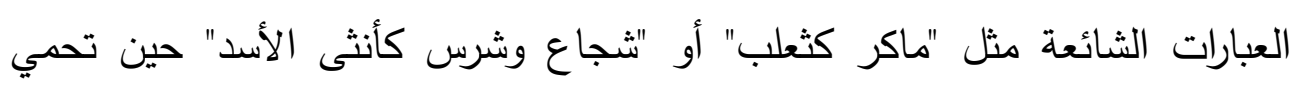

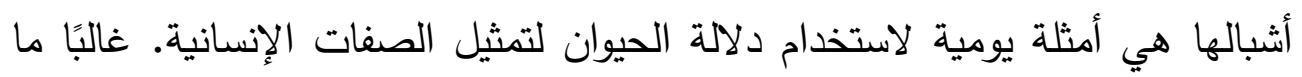

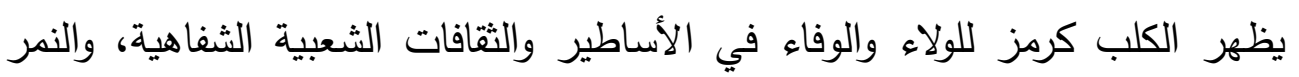

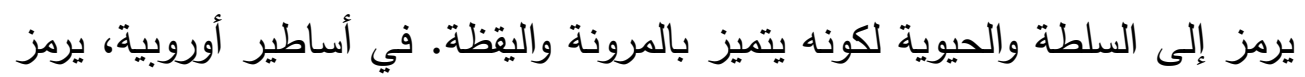

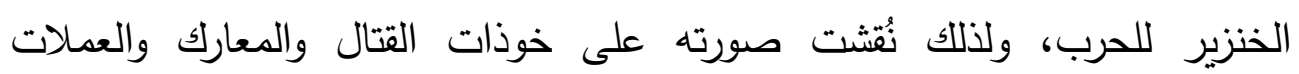
المعدنية.

في بعض الثقافات، هنالك قصص تقدم فيها الشخصيات الحيوانية( التي تمثل

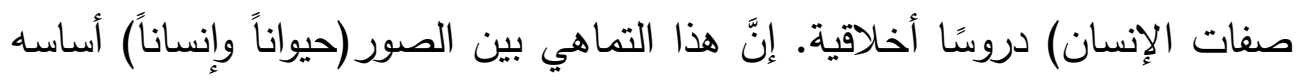

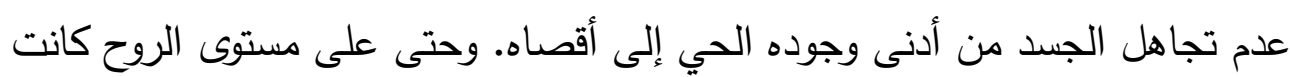

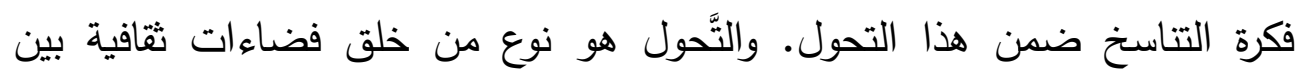

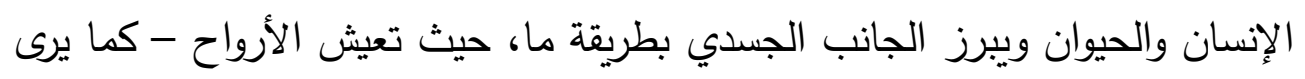

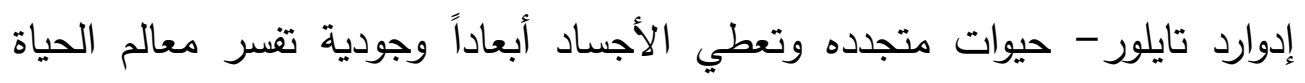

${ }^{30}$ - Robert W. Lurz (editor), The Philosophy of Animals Minds, Cambridge University Press, New York 2009. PP5-14. 
تطوراتها من الحيوانات الدنيا إلى الإنسان، لأنَّ التكوين واحدٌ والثقافة تحمل هذه

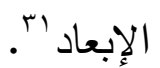

ثم مع تطور آفاق البشرية نحو عصور الحداثة وما بعدها، ارتبطت أساطير

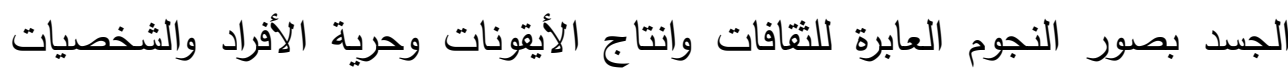

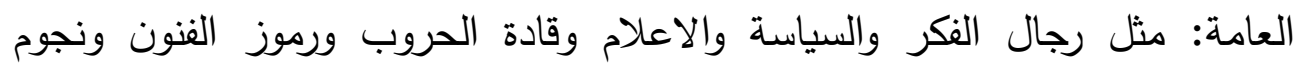

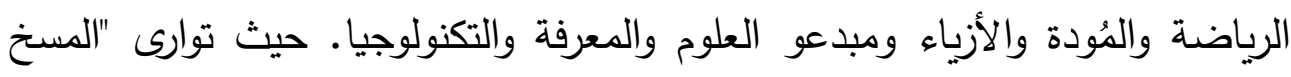

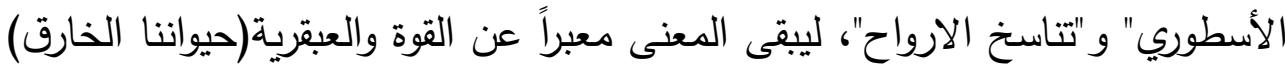

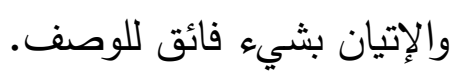

والآن في عصر ما بعد الحداثة أصبح الجسد كرَّاساً عولمياً تدَّون فيه الأرقام القياسية (كموسوعة جينيس للأرقام القياسية) للإتيان بطاقات رياضية وألعاب وأفعال

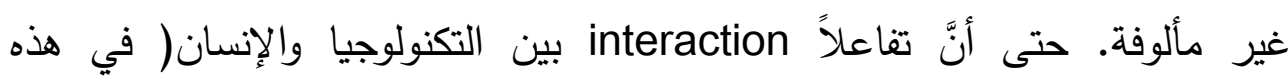
المجالات) كثف تغير العلاقة بين الجسد والطبيعة مما أثار هواجس الفكر المعاصر

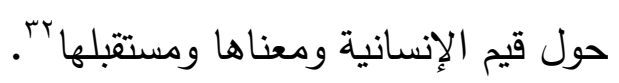

وقد صاحب التداول للجسد أدوات تُشتق من جوهر الحرية التي كمُنت فيه عبر

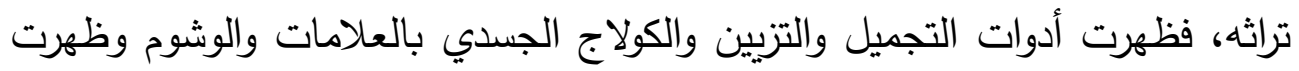

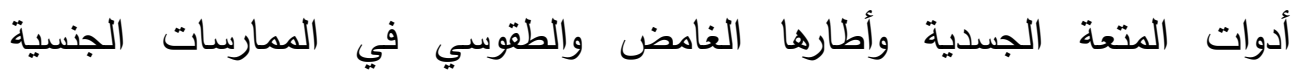

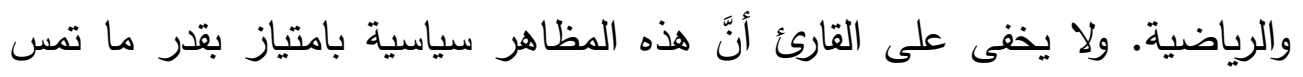

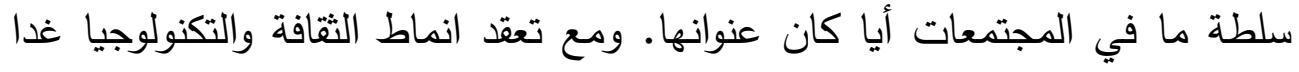

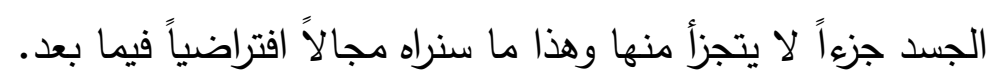

${ }^{31}$ - Edward B.Tylor, Primitive Culture: Researches into The development of Mythology, Philosophy, Religion, Art and Custom, London: John Murray, Albemarle Street 1871.P16.

${ }^{32}$-Tara Magdalinski, Sport, Technology and the Body : The nature of performance, Routledge London, New York, 2009. P 3. 
لكن السؤال بصدد ثنائية( الجسد - السلطة): أليس هذا يفترض مصدراً

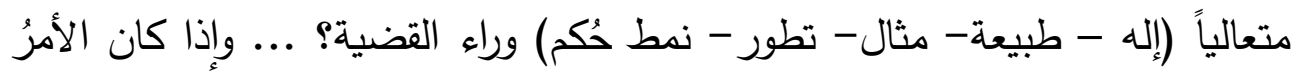

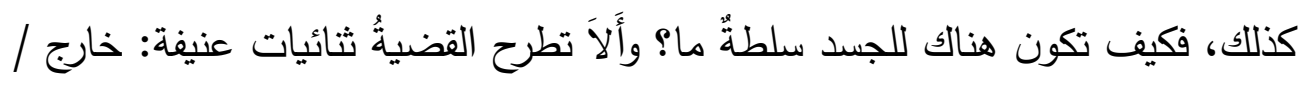
داخل، روح / جسد، فكر / مادة؟ وإذا لم يُّن الأمر هكذا، فبأي معنى ثُعطى أهمية

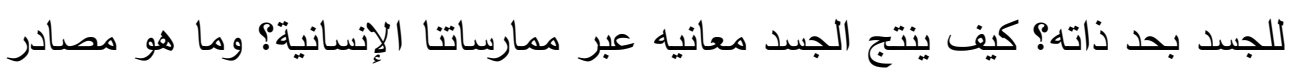

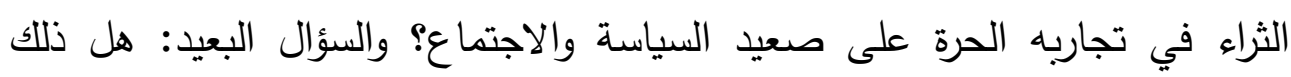
يستوجب محاولة ترويض الجسد في أنظمة ثقافية تستوعب طفراته أم أنَّهَ سيكون ثائراً،

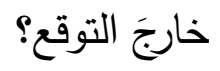
علماً بأنَ ثمة دلالةً للسلطة لا تأخدها إلاً في إطار الثقافة، وهي دلالة التأثير

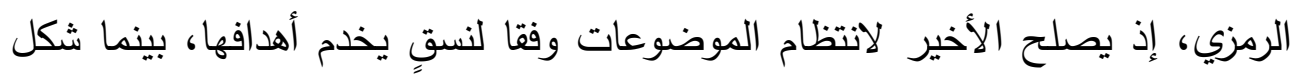

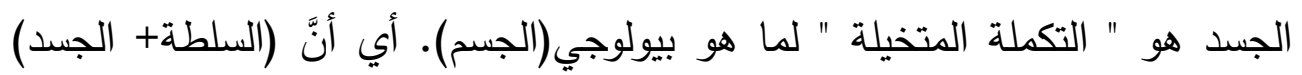

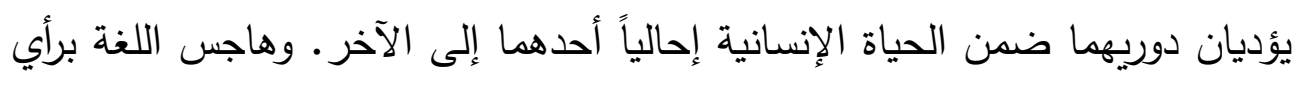

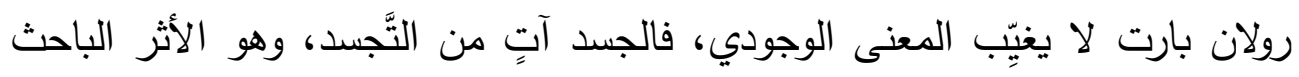

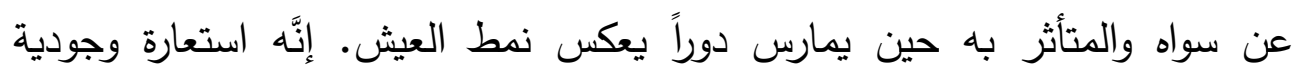
existential metaphor الجسد كوسيط وراء الإحساس بامتلاء مجالات الحياة.

الفكرة أنَّ احتكار السلطة بواسطة اللاهوت والأيديولوجيا( وأحفادهما) كان

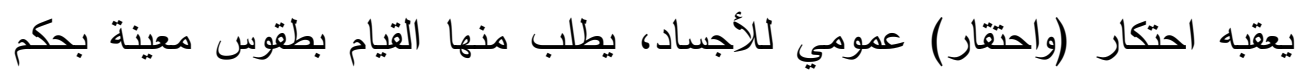

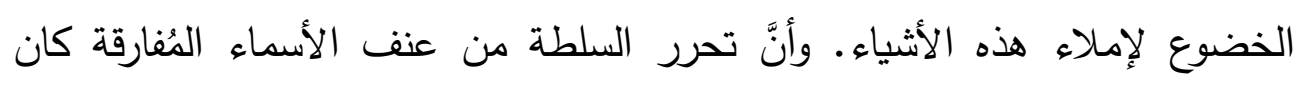

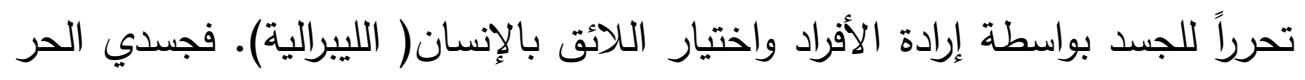

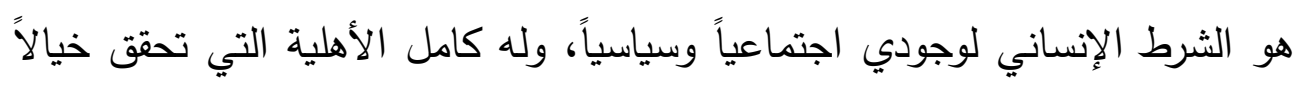

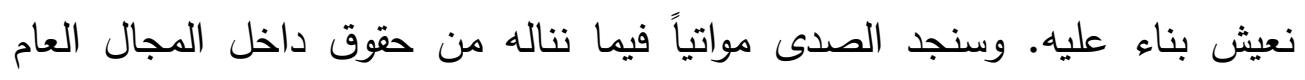


وممارساته بدءاً بالفرد وانتهاء بالدولة. وهذا ما سيدفعني إلى رصد تحولات الجسد في

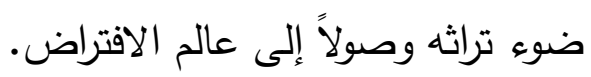

\section{تحولات الجسد}

إنَّ تحولات الجسد استوعبت السلطة وأثارت حفيظتها بالوقت نفسه. لا تخشى السلطة شيئاً قدر ما تخشى من تحرر الجسد، لأنَّهَ يهدد كيانها الحي وينازعها الوجود.

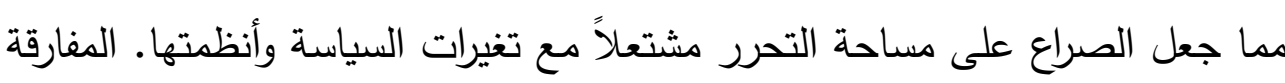

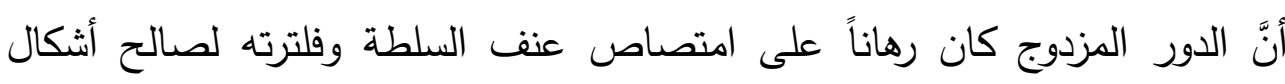

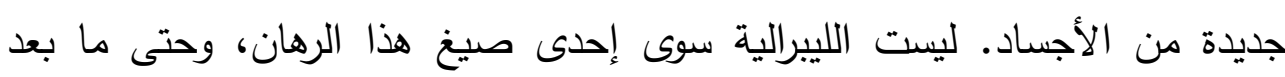

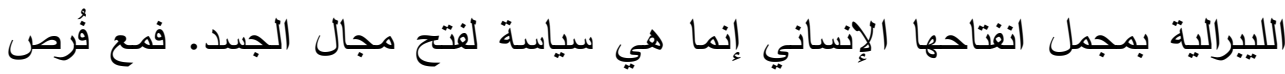
التحول يكون الجسد قادراً على التتعع بسلطةٍ ما وباستطاعته أنْ يدبر شؤونه الخاصة. الحقيقة أنَّ دلالةً الجسد تتشأ بوصفه قوة قابلةً للتأثير والتأثُر ( والتحول والتخييل

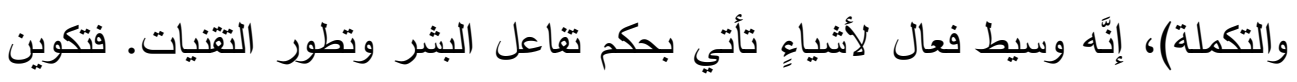
المجتمعات يفترض هذا الوسيط الذي يُلتزم بآلياته ومظاهر حركته. الأمر فيه جانبان: احدهما وجودنا المرتبط بالرغبة الممتدة كبناء شعوريٍّ يجمنا والآخرين، كلَّ الآخرين. فلا يوجد إنسان دون غرائز ولا إمكانيات حسية.

وذللك يفترض التأثير المتجاوز لحدود الجسد في مجاله المعروف. وهو ما يجعل الرغبة - كدالٍٍ متحول بلا توقف- موضوعاً للآخر ويجعل إمكانية القوة الكامنة

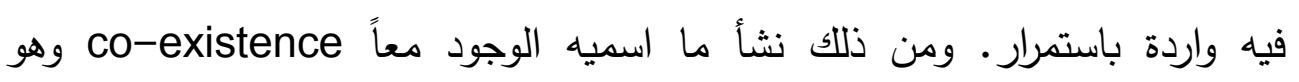

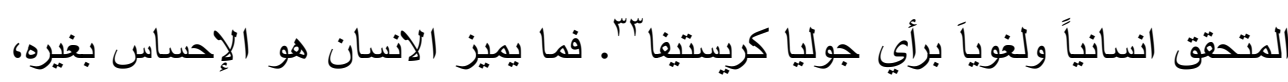

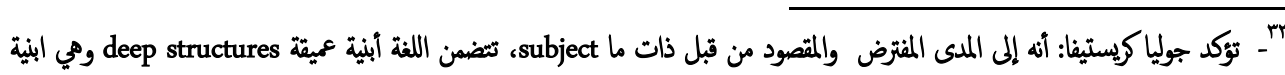

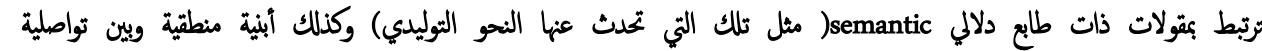
historical intercommunicational

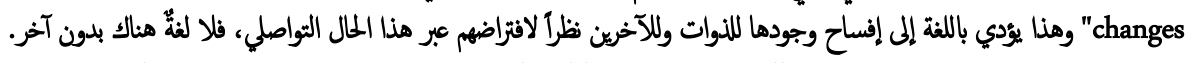
Julia Kristeva, Revolution in Poetic Language, Translated by Margaret Waller 
أنَّهَ الكائن الآخذ آخريته بعين الوجود. حتى أن اللغة تمارس امكانياتها الدلالية برغباتنا تجاه الآخر، التكلم هو ترجمة لرسالة لا تخرج دون الآخر، والكتابة بمثابة الغياب الذي ينقش كيان ما يستحيل حضوره، هي تترك كلمات لمن يأتي بوقٍٍ ما. أما الوجه التالي، فهو البُعد الرمزي الذي يحل محل البُعد المادي الأول عبر فضائه غير المدرك. أي هو الجانب الحاضر حين يغيب الآخر مادياً عن قصد أو دونه. فالرمز شيء يحضر مكان شيء غائب دالاً عليه. وكلمة الشيء لا مهرب من هن هنئ استعمالها، فلا يسعفنا معجم اللغة أمام رموز بصيخ لاء تشير إلى معطياتٍ ما. الموت - على سبيل المثال - يُعرف أنَّه فقدان روح الحياة في الكائن، لكن ما هي ماهيته؟ ما طبيعته؟ هو وضع رزي يفعل دلالياً داخل الجسد وخارجه، وهنا يعرِفنا اللاوعي والخيال أبعاداً أخرى في شكل اللا جسد. ولا يعني ذلك تصفية قضايا الجسد بمعطاه الحي لكنه يمثل وجوداً من نوعٍ خاصٍ. بالتدرج التاريخي - لإتمام الفكرة - يمكننا رصد تحولات الجسد من الخارج إلى الداخل واضعاً السلطة في احراج تكويني. لأنه بتلك الحالة سيكثف نظامها، فالجسد

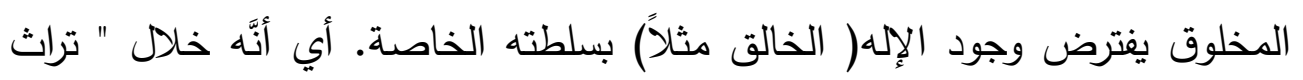
الجسد" خضع الجسد لسلطة اللاهوت، واخذ دلالاته بالنسبة إليها وبالنسبة لحياته بالتوازي. فالسلطة اهتمت به نظراً لاعتباره امتداداً لها، فعلَّيه أنْ يكون موجوداً بينما هي تنتظر مزيداً من التعبير عنها حين لا تكون (في غيابها الظاهري).

with an Introduction by Leon S. Roudiez, Columbia University Press, New York1984, P 23.

وابرزت كريستيفا الفكرة بوضوح في مفهوم الحب الذي يمثل علاقة الأنا - الآخر بجلاء. Julia Kristeva, In the Beginning Was Love Psychoanalysis and Faith, translated byArthur Goldhammer, Columbia University Press New York, 1987. PP 1- 11. 
وعن طريق "تَكْره الغريزي"، تحول الجسد مستثراً الفجوات الثورية للمعرفة والسياسة والمجتمعات الإنسانية. كان عليه بلوغ أقصى درجات التكيف وانتزاع مصيره

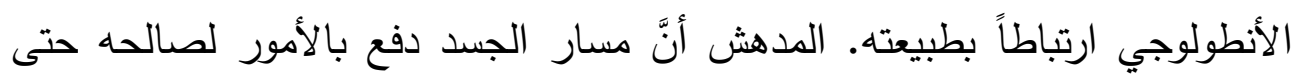

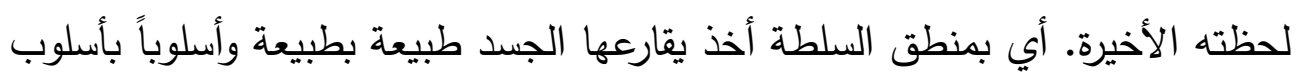

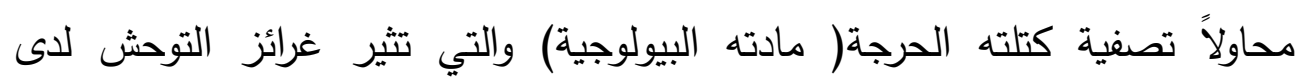
السلطة.

إذن ثمة مراحل مر بها الجسد أنطولوجياً حتى وصل إلى صورته الراهنة.

1- الجسد مخلُوقاً (سلطة اللاهوت): وهي مرحلة السلطة اللاهوتية المهيمنة على الجى

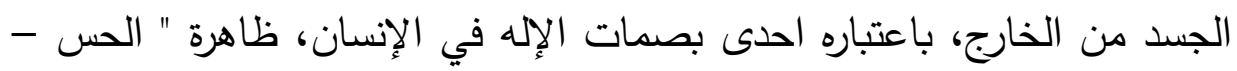

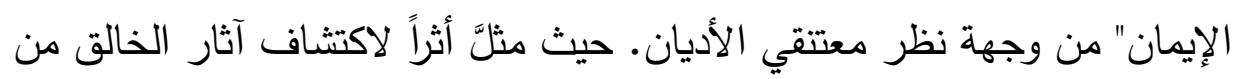

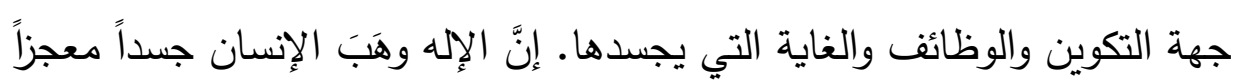
في حياته التي يحملها كنعمةٍ ميتافيزيقيةٍ.

ذللك أنَّ ما يُخلع على الكون بفضل فكرة المقدس( الدين) يُخلع على أية

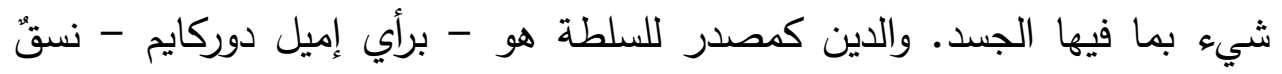
موحد unified system من المعتقدات والممارسات المرتبطة بالأشياء والكائنات

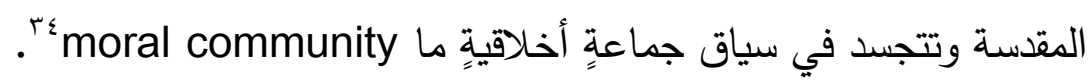

جميع الديانات تبدي امتناناً للسماء واضعة كماً من الأسرار في حياة البشر ، لأنَّها أوجدت الجسد الذي يحس ويشعر ويتمتع بالملذات وكذلك يتطلع إلى التسامي.

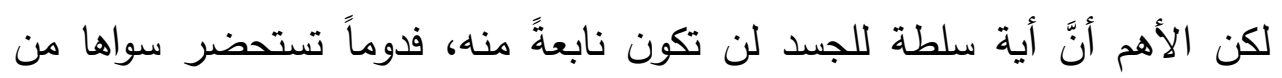

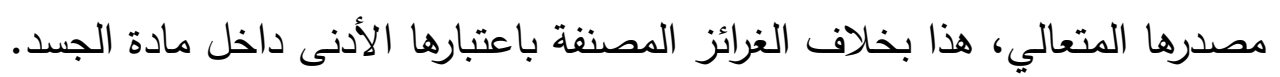

\footnotetext{
${ }^{34}$-Emile Dürkheim, The elementary forms of religious life, translated and with an introduction by Karen E. Fields, The Free Press: New York- London 1995. P 44.
} 
أي أنَّ خطاب الأديان يحذر من انحرافاته كدابة للشر . فالإنسان العاصي ستلاحقه

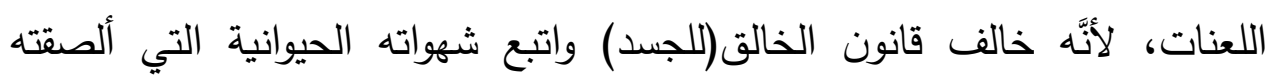

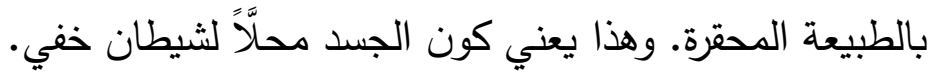

إذن هناك جانب محقَّر في المسألة أساسه غرائز الجسد حين تثد الإنسان إلى

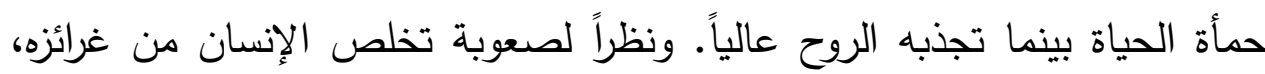

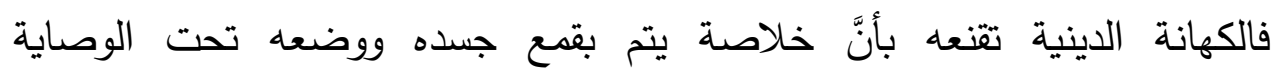

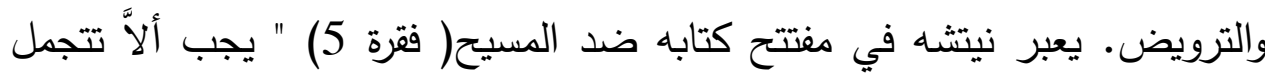

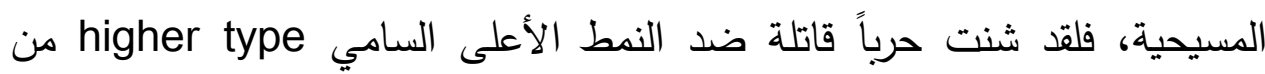

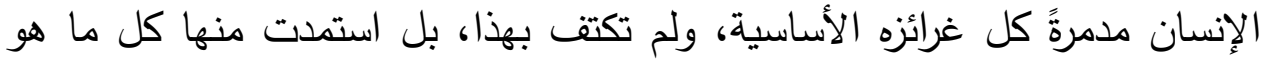
شر evil، الشر فقط بعيداً عن هذه الغرائز : فالإنسان القوي شكل بالنسبة إليها نمطاً

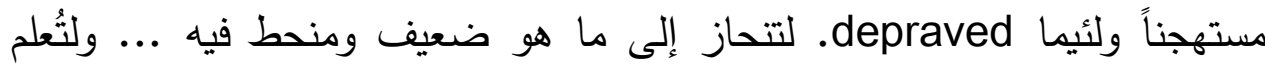
الناس أنَّ القيم الروحية العليا المندفعة من الحياة والنفس خطيئة sinful ومجرد

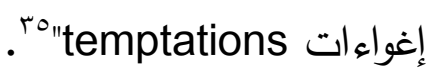

وبطبيعة الجسد ذاته لا يستطيع الإنسان التَّحرُر من رجال الدين انتظاماً

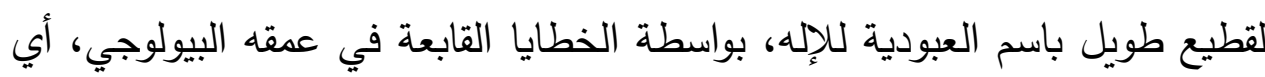

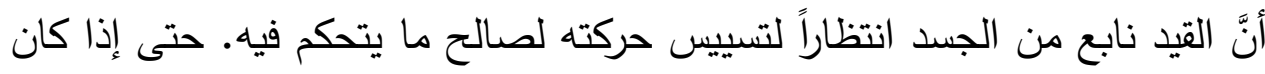

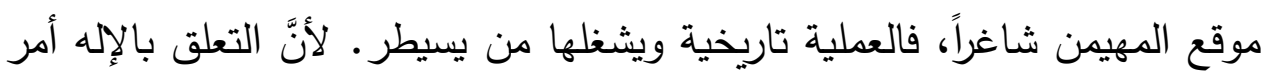

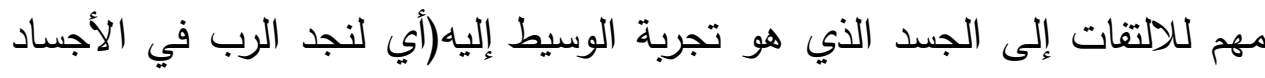
(Finding God in Bodies

35 - Friedrich Nietzsche, The Anti- Christ, Ecco Homo, Twilight of the Idols, and Other Writings, Edited by Aaron Ridley and Judith Norman, Translated by Judith Norman,(Cambridge Texts in the history of philosophy), Cambridge Uni- Press 2005.P 5.

${ }^{36}$ - David Brown, God and Grace of Body: Sacrament in Ordinary, oxford University Press Inc., New York 2007. PP 11- 18. 
الموت مهم للولاء للسلطة وبالنسبة للدولة ونظامها الحاكم \ّام وكان طبيعياً مع ميراث الحداثة الغربية أن تتحول (قوة المقدس) إلى (قوة سياسية مدنية) هي الدولة. تلك التي حلت محل الإله لتشرع سياسات للأجساد على مساحة المجتمع. Y- الجسد كائناً سلطة الموجود الإنساني ): جسد (كما هو) متعارف علية في الحياة والطبيعة، وفكرته هي نتاج اتجاهات الحداثة الغربية باعتباره شيئًا مبدئياً self- sن حيث الوجود والإحساس، وما يتبع ذلك من تنوع واختلاف وفهم ذاتي

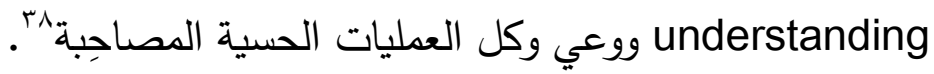

فالجسد ليس مسكوناً بالأساطير ولا بالأسرار ولا تحركه قوى ميتافيزيقية مفارقة، لكنه جسم مادي بيولوجي له سياقه ورغباته. والأبرز أنَّه قد يتحول وتعتريه

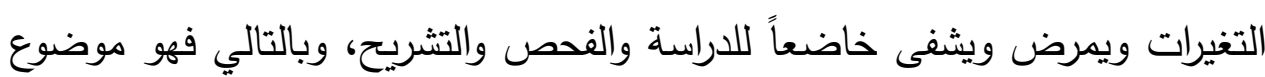

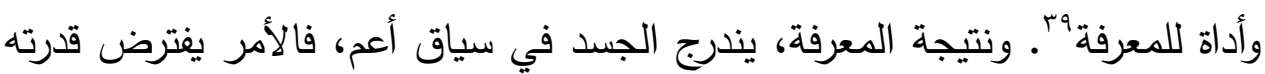
على المشاركة في الحياة العامة طالما نتحكم فيه. والعنوان الواضح أن الجسد يستطيع إظهار نفسه وبإمكاننا تأهيله لتحمل القيم والمسؤولية والحرية داخل مواطنين يناسبون الدولة ومؤسساتها.

لقد أبرز ذللك جون لوك من خلال أفكاره السياسية المعتمدة سلفاً على وجود مواطنين أصحاء لتتظيم سياسي يستوعبهم كجزٍ من هيكله التاريخي، حيث

\footnotetext{
${ }^{37}$-Ann Thomson, Bodies of Thought: Science, Religion, and the Soul in the Early Enlightenment, Oxford University Press Inc., New York 2008.P 29.

${ }^{38}$-Miri Rubin, The Body, Whole and Vulnerable, in Fifteenth- Century England, in: Bodies and disciplines: intersections of literature and history in fifteenth century England, Barbara A. Hana walt and David Wallace (editors), (Medieval cultures; volume 9), University of Minnesota Press, Minneapolis-London 1996. P 19.

${ }^{39}$-Charles T. Wolfe , Ofer Gal (editors), The Body as Object and Instrument of Knowledge Embodied Empiricism in Early Modern Science, Studies in history and philosophy of science 25, Springer ScienceBusiness Media B.V Heidelberg-London - New York 2010. (Part one: the body as object and Part two; the body as instrument).
} 
هناك حقوق وواجبات في إطار الدولة الديمقراطية. وإذا كان القانون الطبيعي مُهماً، فإنه يجعل الناس أسوياء وكذلك أساليبهم في الحياة والعيش المشترك، فهم يعتمدون

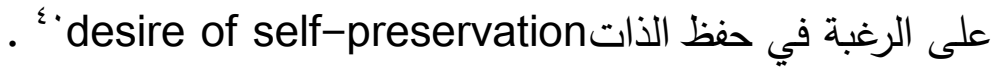

بوضوح قال كوجيتو ديكارت( أنا أفكر إذن أنا موجود)، اعلان صريح بقوة

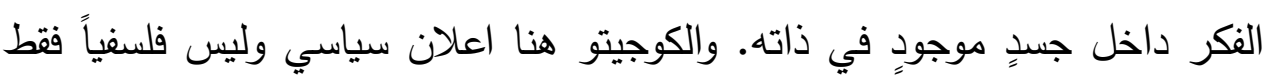

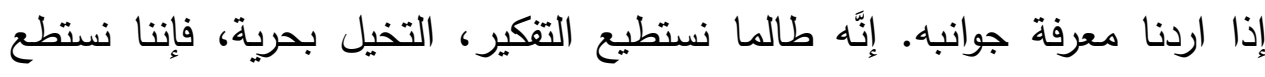

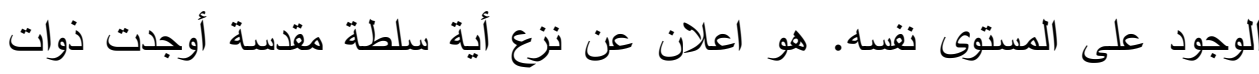
الناس سلفاً (الجسد مخلوقاً ومؤسطراً). والفكر يعني ممارسة الجسد كاشفاً قدراته الطبيعية. ورغم ما قيل فلسفياً عن الكوجيتو الديكارتي( ثنائية الفكر والوجود) وهي ما لأليا

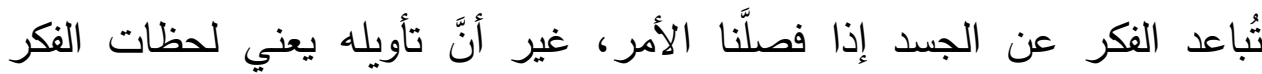

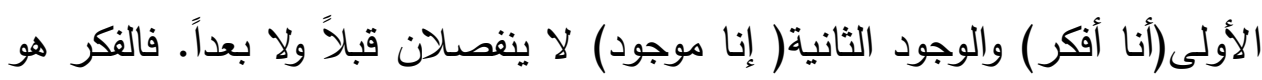
عين الوجود والوجود هو عين الفكر، الأنا واحد.

في كتابه التأملات( التأمل الساد) يقول ديكارت" عندما يفهم العقل فإنَّه يتجه بطريقة ما صوب ذاته باحثاً في إحدى الأفكار التي بداخله، لكنه عندما يتخيل

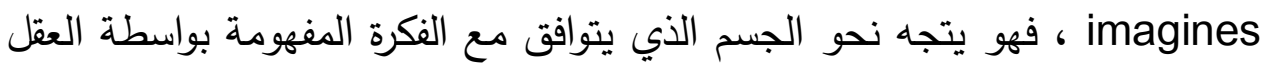

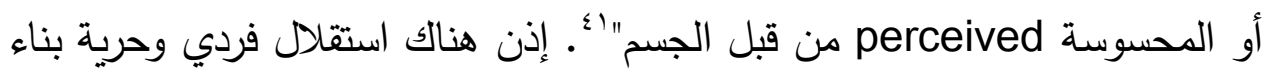

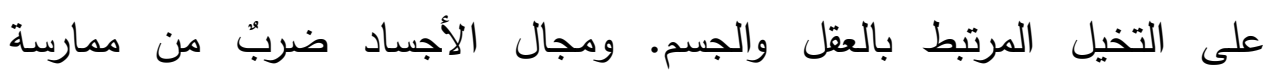
الخيال(المثار في ضوء الفضول والرغبات والغرائز).

${ }^{40}$-Daniela Gobetti, Private and Public Individuals, households, and body politic in Locke and Hutcheson, Routledge: London and New York, 1992.P 77.

${ }^{41}$-René Descartes, Meditations On First Philosophy, in: The Philosophical Writings of Descartes( Volume 2), Translated by John Cottingham, Robert Stoothoff, Dugald Murdoch, Cambridge University- Press 1984.P 51. 
وتلاك خطوة كبيرة - بإشارة الكوجيتو السياسي- في إزاحة السلطة المهيمنة

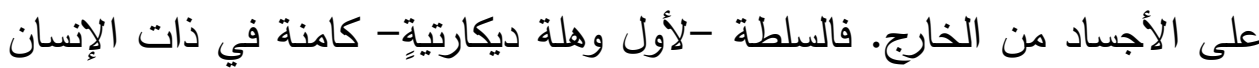

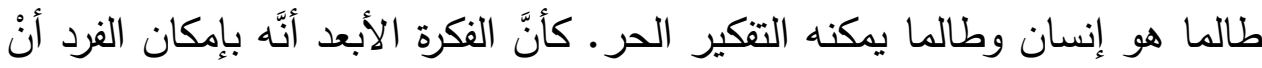

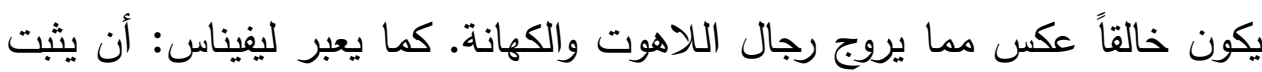
الإنسان ذاته كجسدٍ يعتبر أول فعلٍ ينفصل بواسطته عن العالم.

r- الجسد شفافاً (سلطة الروحانيات): تحاول اتجاهات روحانية بث انفاس إنسانية على إيقاع لاهوتي قديم في الجسد. والأمر يجري باعتبار الجسد في الحقيقة أقل التل

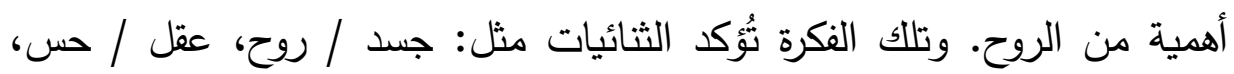
جوهر / مظهر من الروح. والجسد هاهنا بديل ظاهري لممارسة السلطة المادية. فالروح هي السلم لمعراج

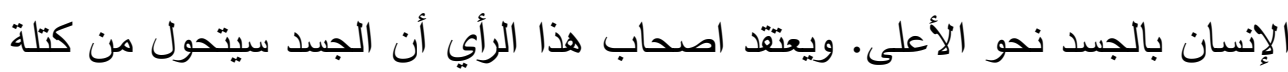

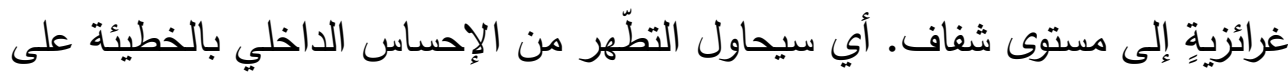
افتراض كون الجسد جراباً لآثام قديمة. ثم هناك هدف أثير باعتبار التجربة الروحية -

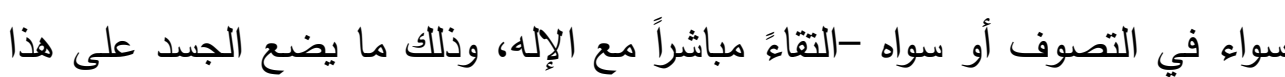

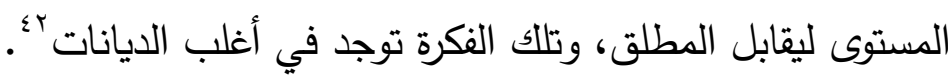

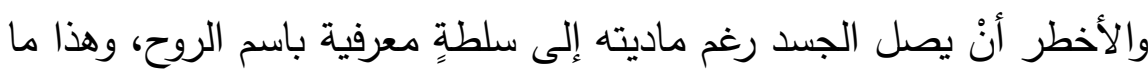

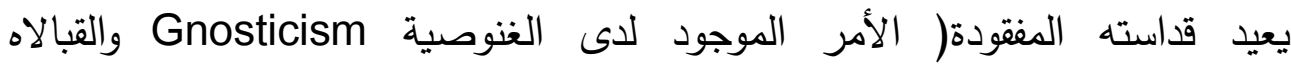
Kabbalah تتحاز إلى المقدس بخلاف أي شيء في الحياة، الانحياز إلى دائرة الحقيقة الجوهرية.

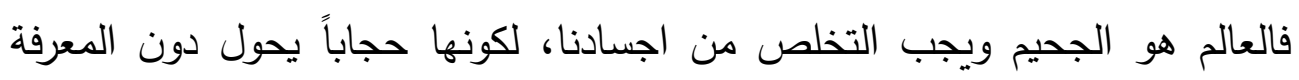

42 - Donald Broadribb, The Mystical Chorus: Jung and the religious dimension, With Contributions by Marilyn Holly and Norma Lyons, Millennium Books E.J. Dwyer (Australia) Pty Ltd 1995. PP100- 101. 
الأكثر أصالة وإشراقاًّ؛ْ وهذا الأمر رائج في الجماعات الصوفية والأديان والتتظيمات

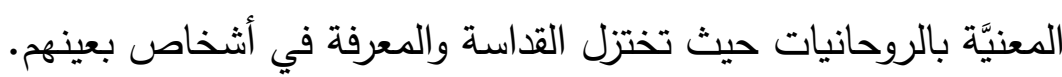
لكن في هكذا حال قد يصبح الجسد منعزلاً، هائماً، فوضوياً، غائباً، غارقاً في

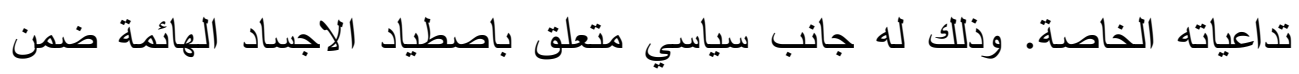

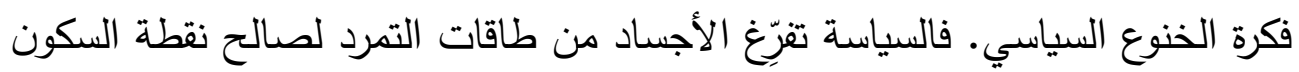

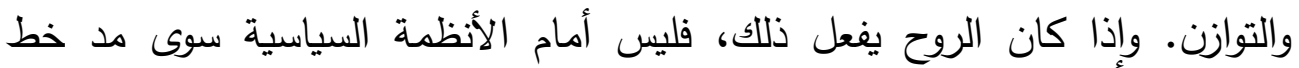

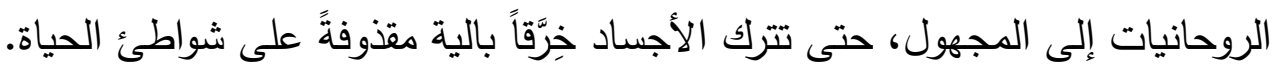
ع - الجسد مؤدلَّجاً (سلطة الأيديولوجيا): تأتي الفكرة من إلباس الجسد لباساً أيديولوجياً، أو

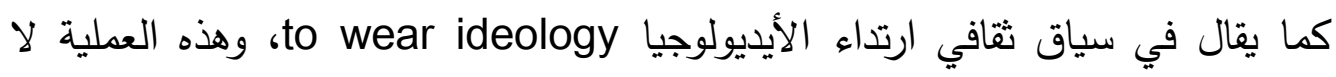

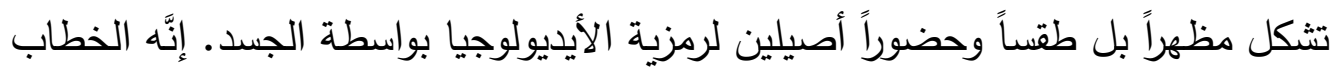

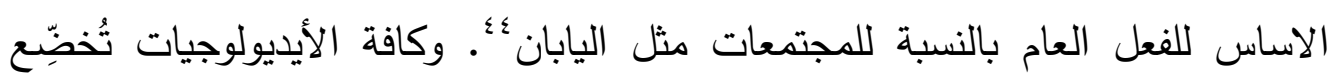

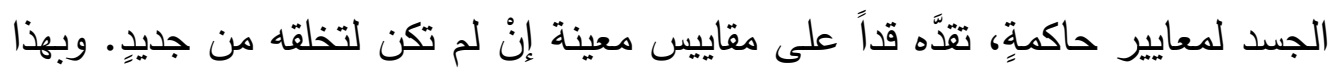
سيكون الجسد أحد أدوات التعبير القوي من خلاد التظاهر والسلوك العام.

تحت عنوان جذاب ( شبح الأيديولوجيا spectre of ideology ) يقول الفيلسوف المعاصر سلافوي جيجك: " إنَّ المرء يستطيع تقرير أن وجود الأيديولوجيا أشبه ما يكون

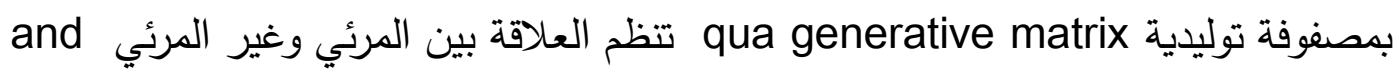

43 -Harry T. Hunt, Lives in Spirit Precursors and Dilemmas of a Secular Western Mysticism, State University of New York Press 2003, P 103.

-J. F. C. Fuller, The Secret Wisdom of Qabalah: A Study in Jewish Mystical Thought, AGNZ New York 2008.P 81.

44 - Brian J. McVeigh Wearing Ideology State, Schooling and Self-Presentation in Japan, Berg: Oxford New York, 2000. PP 47- 50. 
imaginable and non-visible non-visible imaginable

من ثنَّ تستعمل الأيديولوجيات الدينية لاهوت التحريم للسيطرة على الجسد، فلَّها

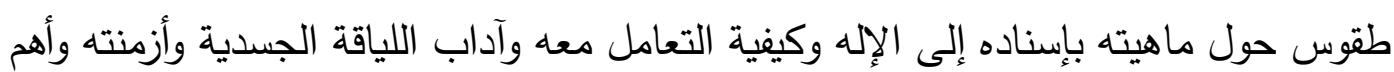

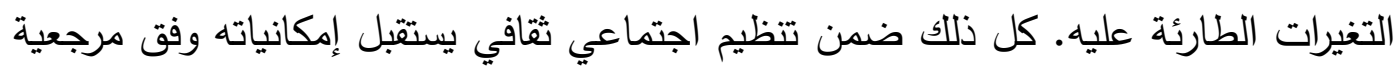

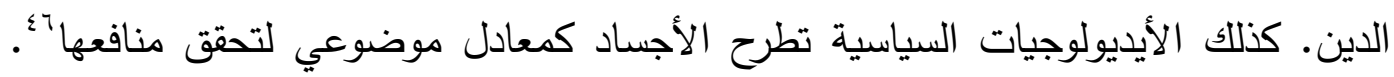
فهي تتشد الاصطفاف باسمها وتتحت علامات الجسد وفقاً لتراتب يخدم أغراضها. فالأيديولوجيا الماركسية تفترض الاصطفاف في مجتمع الطبقات بما يشعل الصراع

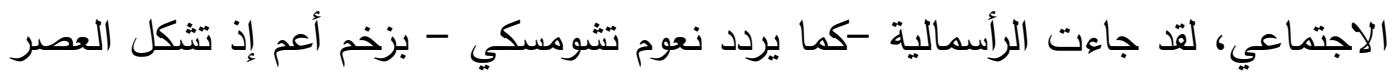

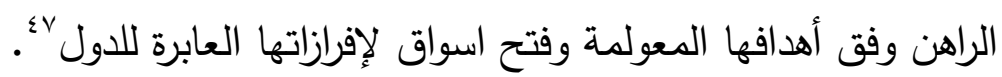

وكذلك الاتجاهات الليبرالية وما بعدها( إذا اخذناها بوجهها الفردي) تفترض أنَّ

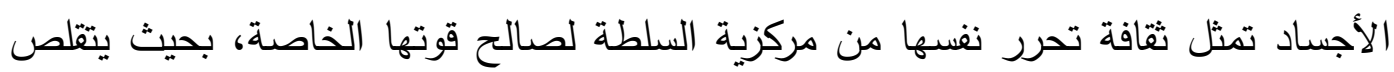

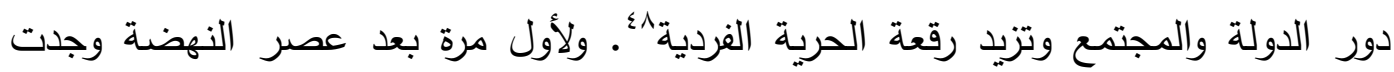

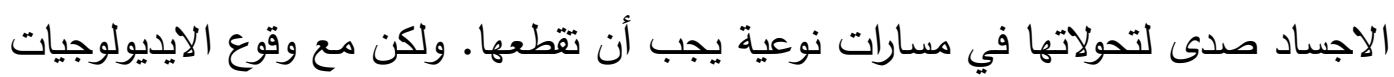

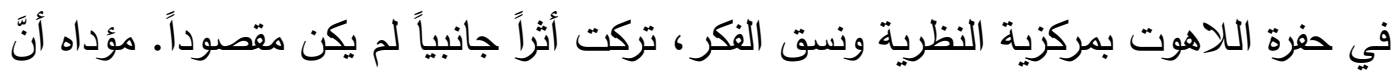
الجسد بإمكانه حمل مصيره كطاقة قابلة للتحرر لاحقاً.

${ }^{45}$ - Slavoj Žižek ,Introduction :The Spectre of Ideology, in: Slavoj Žižek (editor) Mapping Ideology, Verso: London -New York, 1989.P 2.

${ }^{46}$-John Schwarzmantel, Ideology and Politics, SAGE: London - Los Anglos ,2008. PP 3 -17.

${ }^{47}$-Noam Chomsky, "An American view of the ideological confrontation of our time", in: C. P. Otero, Language and Politics, Black Rose, 1988, pp. 284 -296.

${ }^{48}$ - Rachel S. Turner, Neo-Liberal Ideology History, Concepts and Policies, Edinburgh University Press, 2008. PP $192-215$. 
ولذلك فإن عصور الأيديولوجيات تتنهي غالباً بانفجار بيولوجي للأجساد على جثث

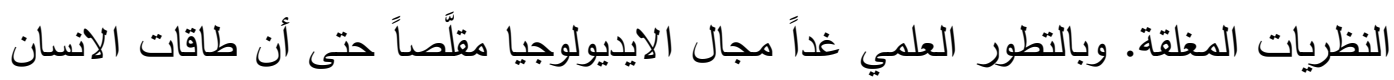

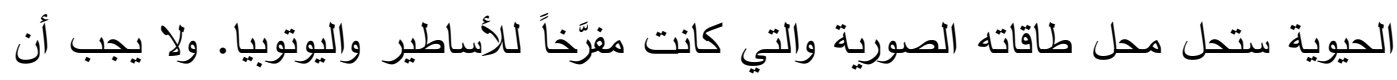

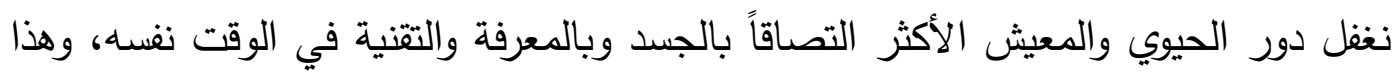

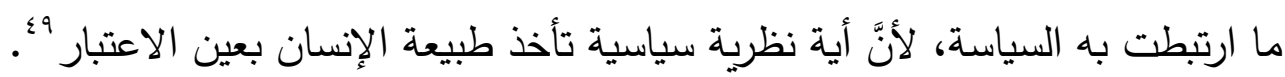

ه- الجسد طقساً( شكل التدين): وهو ما ينتشر لدى جماعات الاسلام السياسي

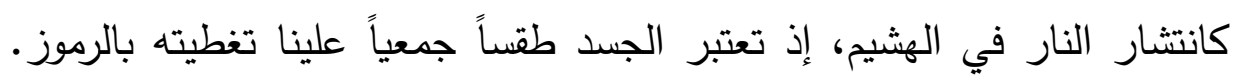

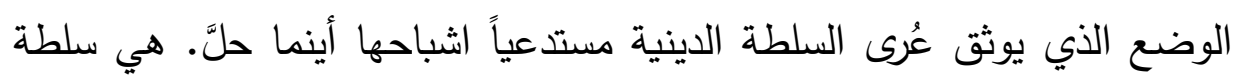

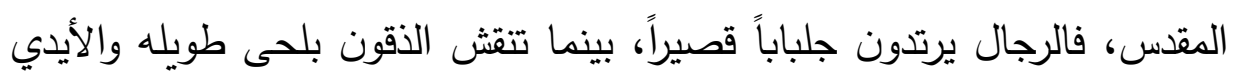

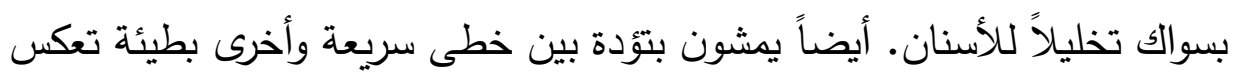

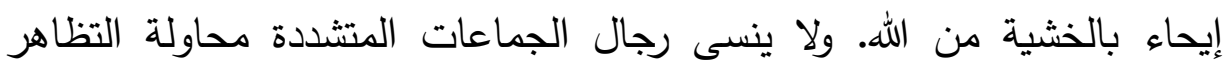

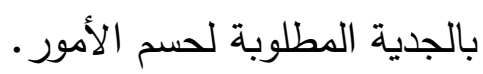

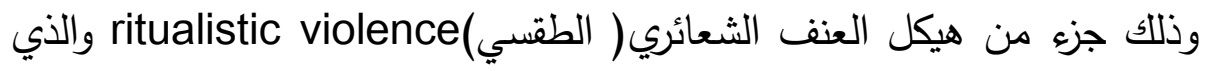

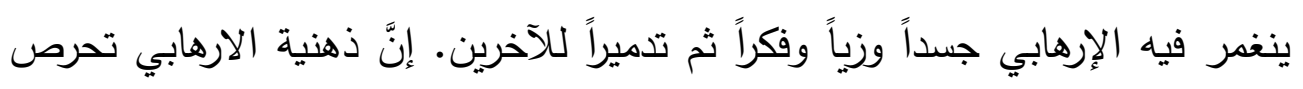
كل الحرص على استعمال الجسد كسلاح فتاك أمام ما يطلقون عليه أعداء الإسلام.

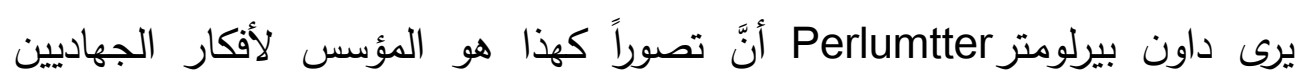
الحركيين منذ ظهور التطرف الديني على السطح ". الجسد تسييس ذكوري يعكس خطاب الإسلاميين البرجماتي الذي يصطاد

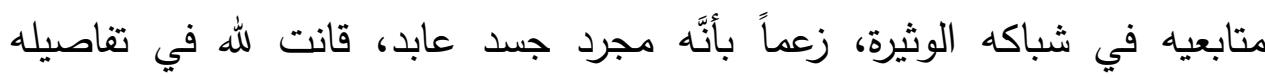

49- Richard C. Lewontin, Biology as Ideology: The Doctrine of DNA, (CBC Radio Massey lectures series;1990).P 53.

${ }^{50}$-Dawn Perlmutter, Investigating religious terrorism and ritualistic crimes, CRC PRESS : London -New York -Washington, D.C. ,2004. Pp 83- 88. 
ومسعاه. بالطبع سيأتي المظهر مع علامة الصلاة(زبيبة الجبهة) والوجه الجاد كأنَّ

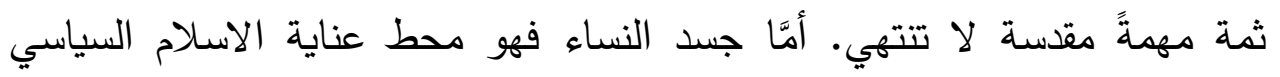
بالمقام الأول. لارجة أن التغطية بالنقاب والملابس السميكة هي نظرية سياسية في

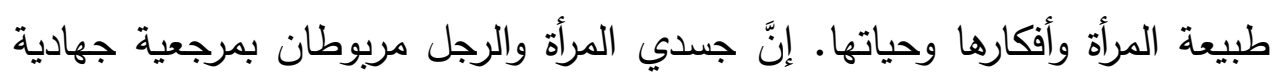

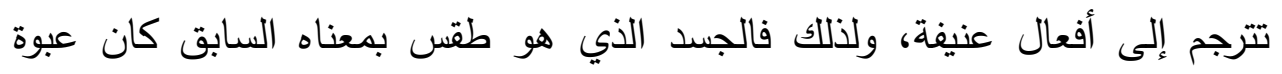

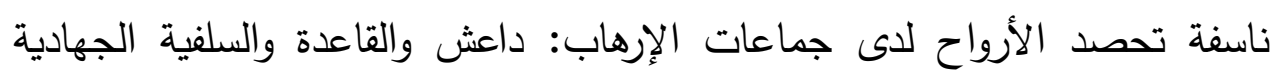
وبوكوحرام.

צ- الجسد مركبة حربية طائشة ( تقنية مدمرة ): هو يظهر في الحروب التي ينخرط

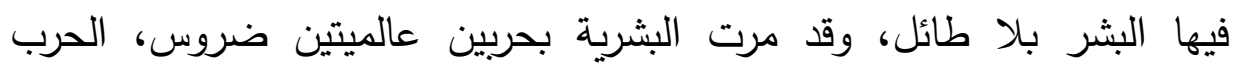

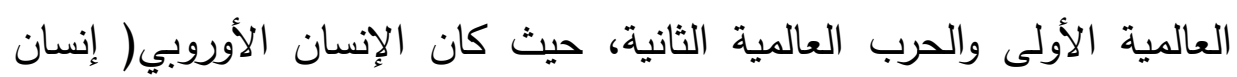
الحداثة والعقلانية والتتوير) في وسط القرن الآفل آلة تدمير بامتياز .

وقد ظهر إنسان هاتين الحربين راكضاً وراء أشباحه كأنه كائن أحمق رغم

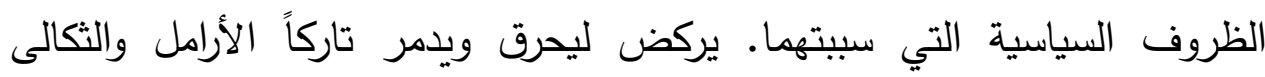

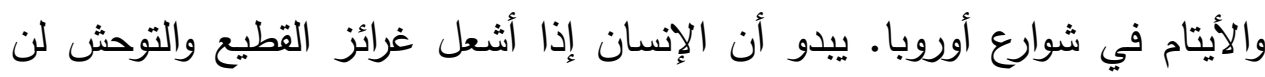

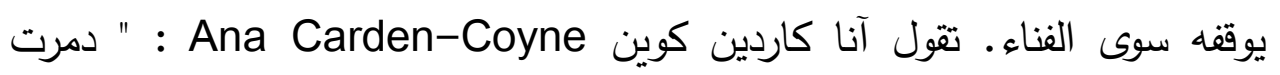

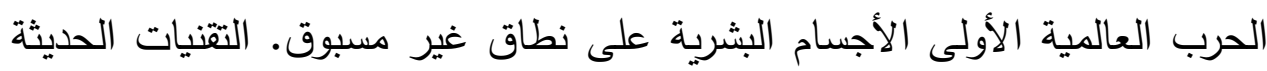

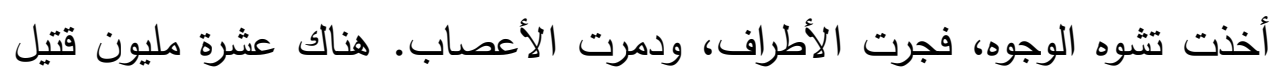
وعشرون مليون ضحية مشردة وثمانية ملايين شخص إعاقات دائمة، هكذا غرقت

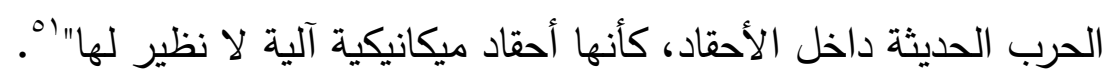

مما حدا بجان بول سارتر بعد الحرب العالمية الثانية إلى طرح سؤال الوجود

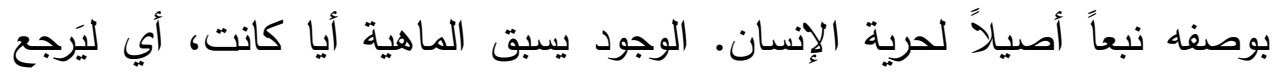

${ }^{51}$ - Ana Carden-Conyne, Reconstructing the Body :Classicism, Modernism, and the First World War, Oxford university Press, New York, 2009.P 1. 
الإنسان إلى وجوده كما هو أولاً، ثم ليبحث عما سيكُونه من مشروعٍ. الإنسان

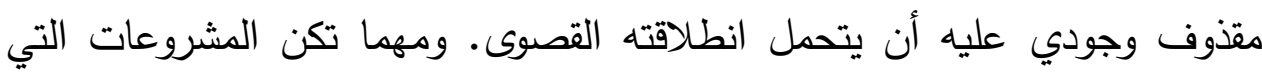

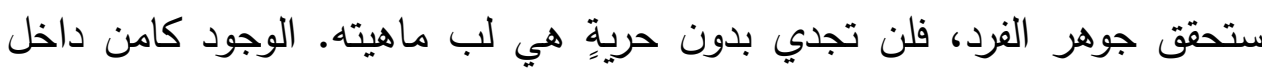
كيانه الجسدي بقدر أصالة الحياة فيه.

V- الجسد طاقة( آلة عمل): الجسد هو الرصيد العيني لفكرة العمل، فما لم يُكن ثمة

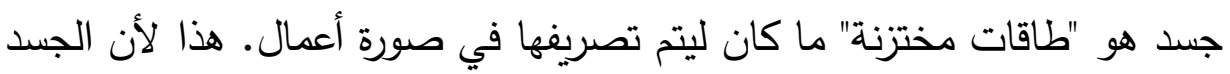
ليس محض إضافة خارجية، لكنه كيان طبيعي لتحقيق المعنى في بيئة الانسان الاجتماعية والمادية×ْ فالعمل هو الجانب المختزل داخل الجسد بإدارة الإنسان نحو تحقيق الذات. لكنه يفترض مورداً قابل للاستثمار حيث اجادت الرادية الرأسمالية عولمياً استغلاله لجني الأرباح وفتح الأسواق.

تاريخياً كانت المقايضة لا تخطئها العين بين القوى العضلية للجسد والقوى الشرائية التي قد يجنيها، ليجيء الجسد ماكينة بشرية تُستنزف قدراته تباعاً. وقد نوَّه

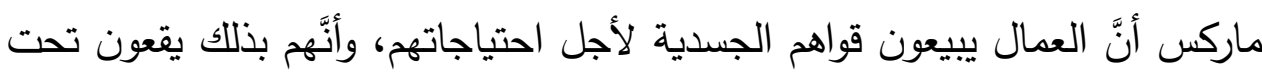

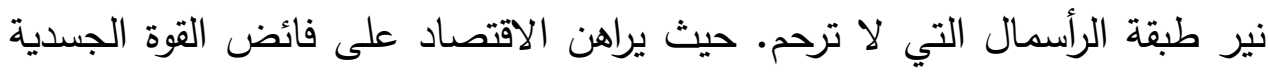

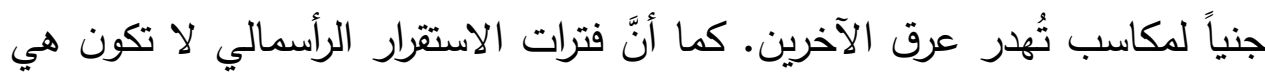

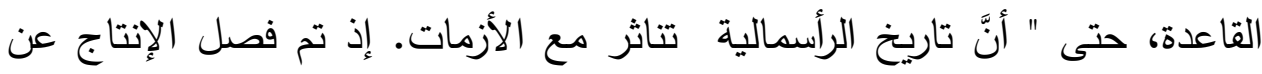
الاستهلاك، ونشبت المنافسة بين المنتجين، واشتد الصراع بين رأس السرات المال

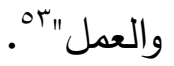

\footnotetext{
52 - Marcel Mauss, Sociology and Psychology: Essays, London 1979. p. 104.

${ }^{53}$-James Fulcher, Capitalism: A Very Short Introduction, Oxford University Press, New York, 2004. P 125.
} 
الرأسمالي capitalist لدية كل الحيل المكنة وغيرها في امتلاك الأجساد

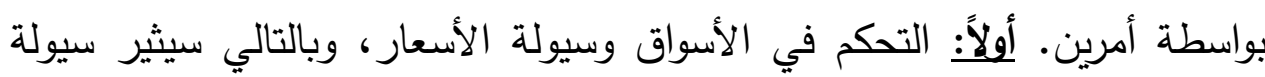
الطاقة الجسدية الباحثة عن احتياجاتها الأولية( الطعام والشراب والجنس). ثانياً: اعتبار الاجساد معاول لزيادة ثرواته بواسطة استتفار غرائزها ببدائل لا تتوافر لجميع

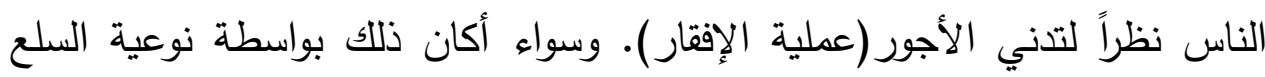
المادية أم بالاشتغال على إثارة الرغبات وإدارتها لصالح الأغنياء وأصحاب السلطة.

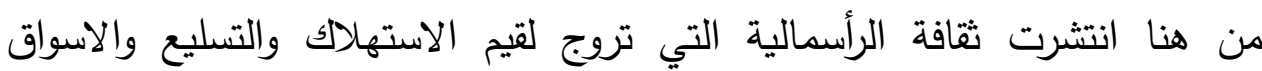
المفتوحة لأي شيء هن أنشرن

^- الجسد عارياً( الافقار والعُري ): ظاهرتا الفقر والعُري الحسي ( في مجتمعات

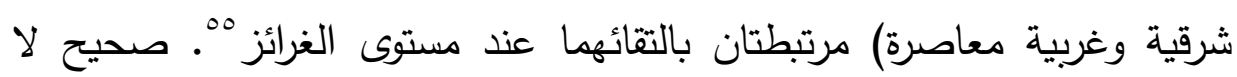

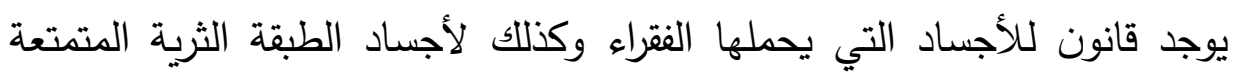

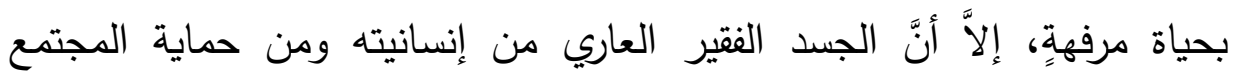

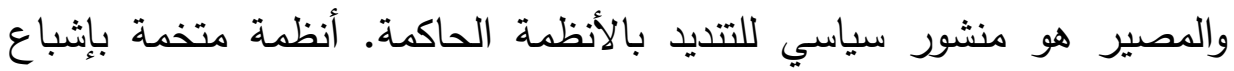

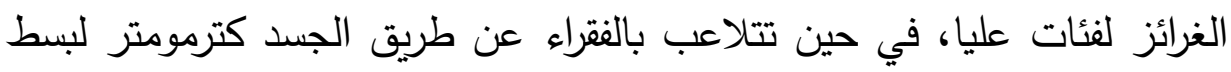
النفوذ واستهلاك طاقات التحرر واهدار رصيد الحياة.

صناعة الفقر هي صناعة ثقيلة تشغل ماهية الجسد وتربطه بالمجهول حتى التى

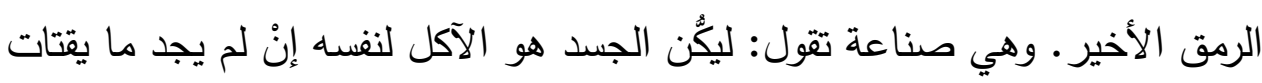

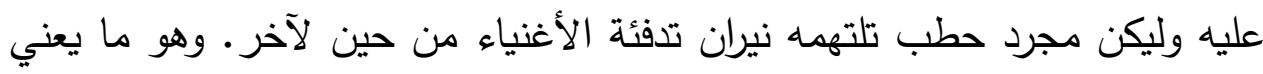

${ }^{54}$ - Richard H. Robbins, Global Problems and the Culture of Capitalism, Allyn and Bacon, London ( Second Edition) 2002. PP 10- 30.

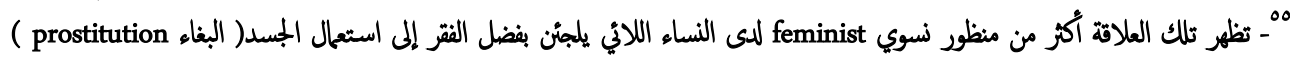
كسب قوت العيش. -Silvia Federici, Prostitution and Globalization: Notes on a Feminist Debate, In: Matt Davies and Magnus Ryner(editors), Poverty and the Production of World Politics, Palgrve Macmillan London 2006.PP 113- 133. 
شحن الأجساد بطاقات سلبية تدفعها إلى دائرة الصراع الاجتماعي العنيف "ك وإذا

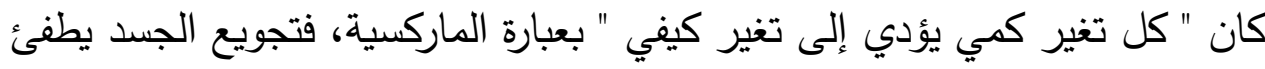

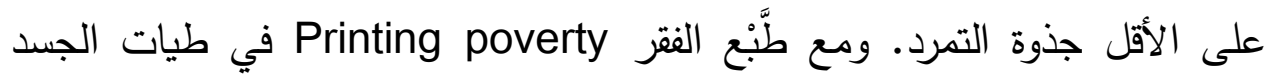

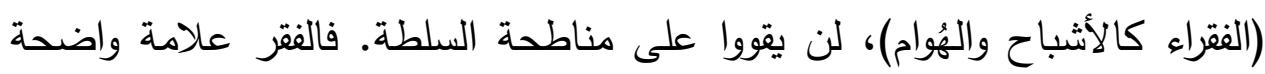

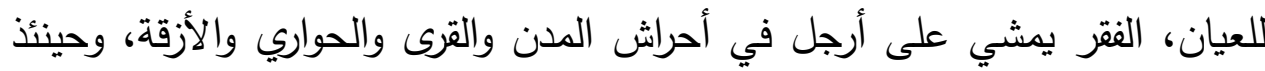

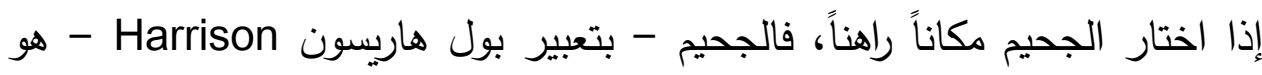
المدينة المبنة

أغلب المجتمعات الفقيرة تتَّوحل- بهذا المعنى- في العشوائيات على نواصي

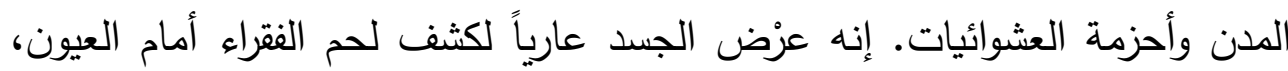

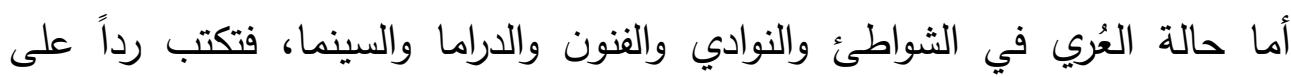

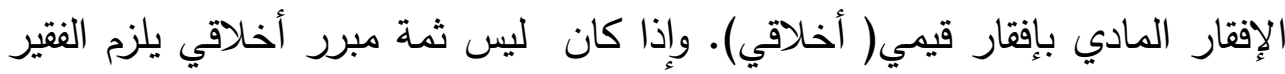

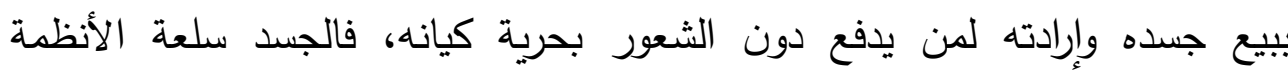

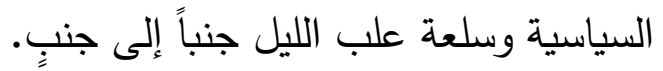

إنَّ العري بسبب الفقر هو أقسى أنماط العُري اذلالاً للإنسان، لأنَّهَ غدا بضاعةً

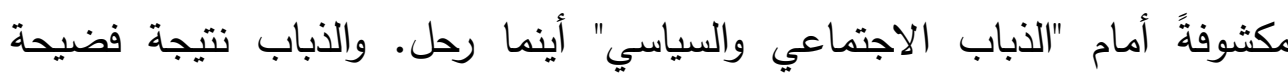

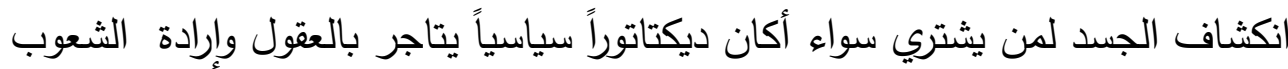

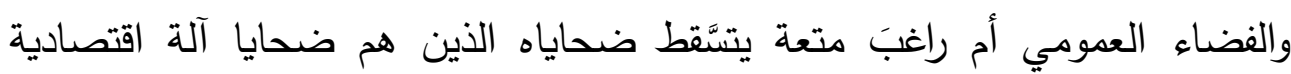

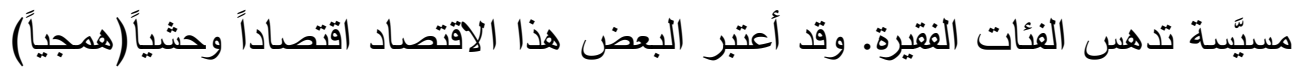
Savage Economics

${ }^{56}$-Nancy Dziedzic, World Poverty, Information Plus_ Reference Series ,Formerly Published by Information Plus, Wylie, Texas, Thomson Gale, San Francisco, London, 2007.PP 123- 134.

${ }^{57}$ - Paul Harrison, Inside the Third World: The Anatomy of Poverty, Penguin Books, London, 1993. P 138. 
العنف عن طريق الاقتصاد السياسي للمجتمعات الراهنة كأننا انثروبولوجياً مازلنا في

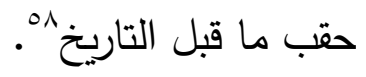

9- الجسد كائناً آلياً( الروبوت): كان هذا نتيجة تخليط التقنيات المتطورة الكترونياً

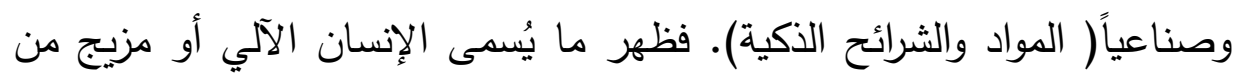

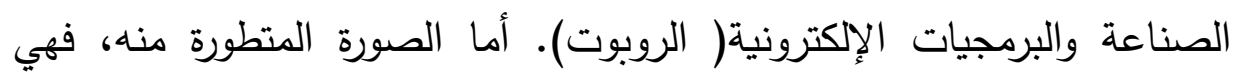

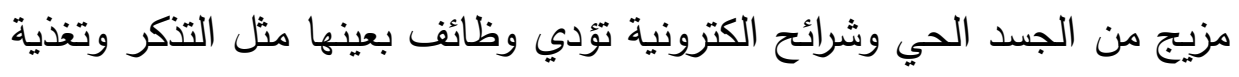
الجسم أو زراعة أعضاء مصنَّعة في اللحم الحي. هذا الجسد بصورتيه (الألية

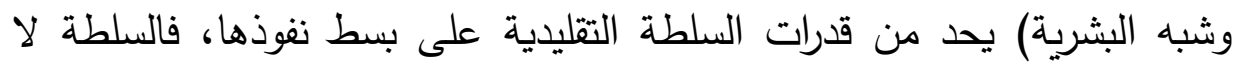

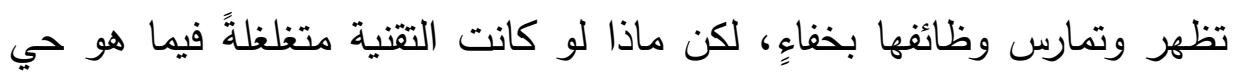

داخلنا؟!

الجسد الآلي ليس خطراً على الجسد البيولوجي، لكنه دوماً يشكلُ خطراً على لألى

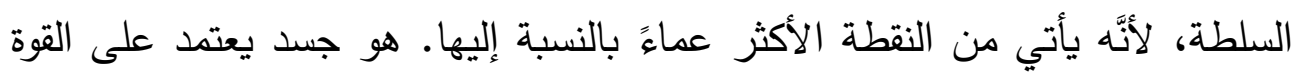

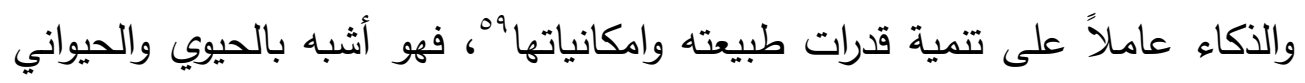

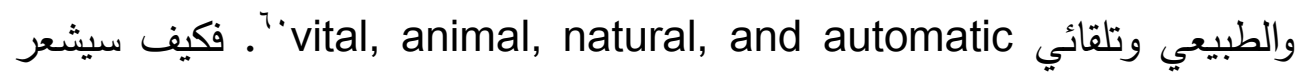
بالخوف من لا يشعر بالحياة مثلاًٌ! كيف يميز الجسد الآلي بين هذا وذاك دونما

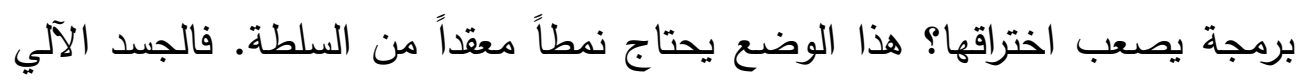

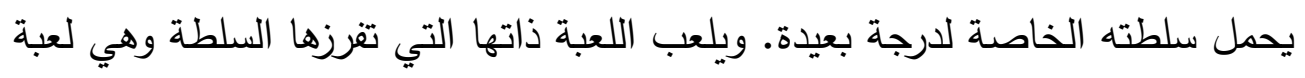

58 - David L. Blaney and Naeem Inayatullah, Savage Economics : Wealth, poverty, and the temporal walls of capitalism, Routledge London and New York, 2010. PP 183- 184.

${ }^{59}$-Julien Offray de La Mettrie, Man a Machine ,Blackmask Online 2001,

( http://www.blackmask.com/), P 2

${ }^{60}$-Sungook Hong, Man and Machine, In: Techné 7:3 Spring 2004 (https://scholar.lib.vt.edu/ejournals/SPT/v7n3/pdf/hong.pdf), P56.

-Julien Offray de La Mettrie, Self-moving body parts: in :Man - Machine, Jonathan Bennett, London 2017. P23. 
الوسيط، فلئن كانت السلطة أداة هيمنة، فالجسم الآلي وسيط في الفضاء المعمول به واضعاً أية سلطة تقليدية موضحَ الاستفهام.

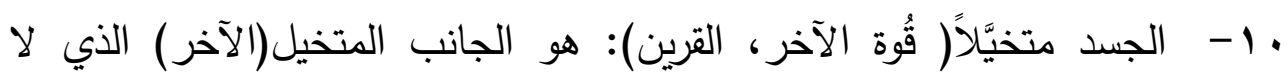

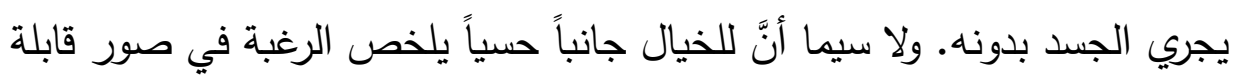

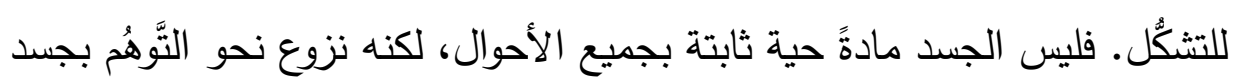

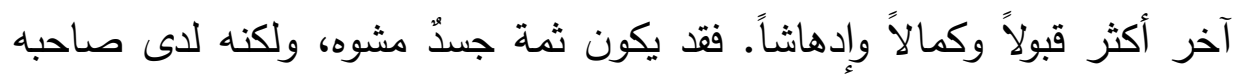

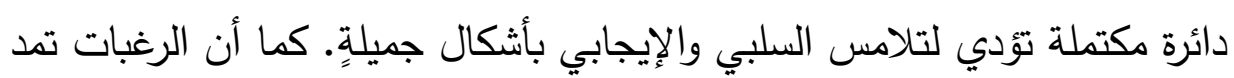

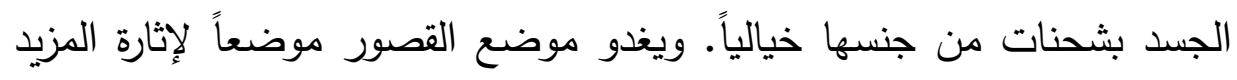
منها (مظاهر القصور) عند حالات العِوز.

الجسد متخيل من جهة الصورة التي يوجد عليها وكان توطئة لانفكاكه من حيز

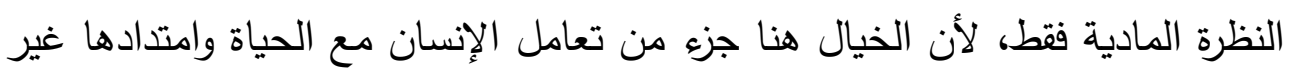

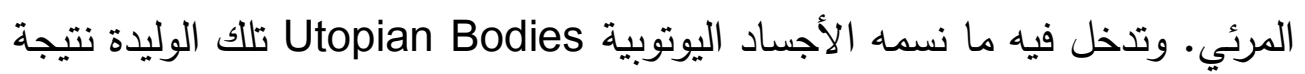

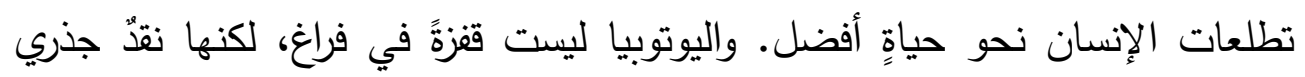

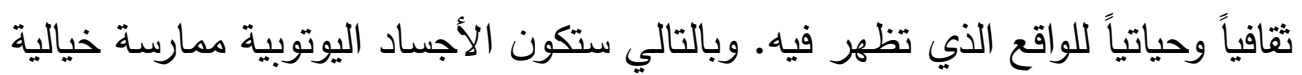

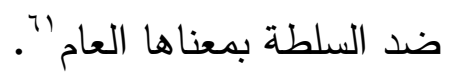

\section{الجسد الأفتراضي}

هو الجسد المرن والأكثر ذكاء بين أنماط الجسد. وهو التطور الأخير لتحولاته من جهة الانفتاح والحرية وصياغة آلياته الخاصة وهدم التمركز حول صورة بلئ بعينها.

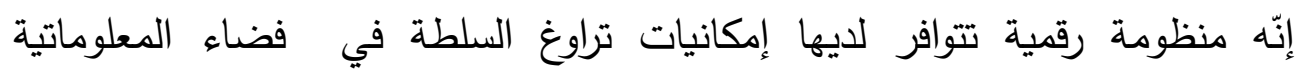

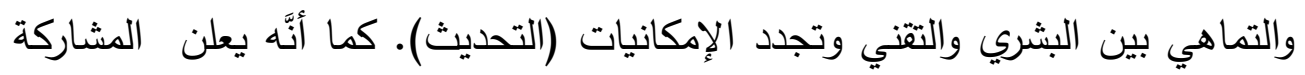

${ }^{61}$ - Lucy Sargisson, Utopian Bodies and the Politics of Transgression, Routledge: London and New York 2000, P 30. 
الإيجابية في الحياة عبر خلق شبكةٍ من العلاقات العنقودية بين عقولٍ تخترق آفاقاً

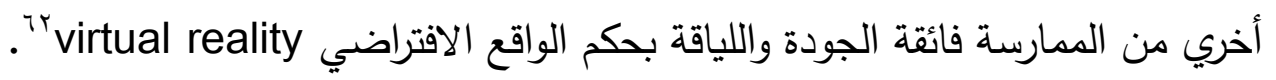
إنَّ الجسد بهذا المعنى ليس مفردا ولا يُتصور وجوده جزئياً، وإلَّا لظل دون

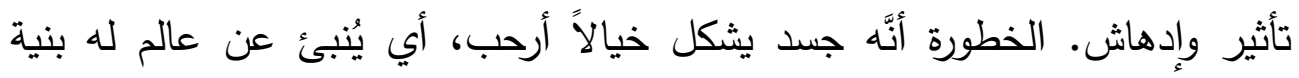

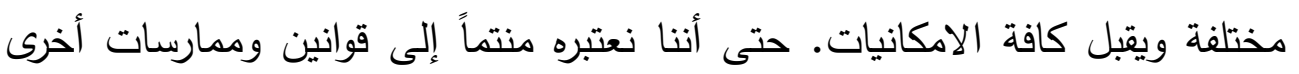
ويظل فاعلاً هناللك لا هنا. وتلك المسافة تسمح بخلق التوقعات والأوهام القابلة للتأثير

$$
\text { على صعيد التكوين والفعل. }
$$

ذذلك أنَّ" العوالم الافتراضية محاكاة لبعض جوانب التفاعل الحي في سياق

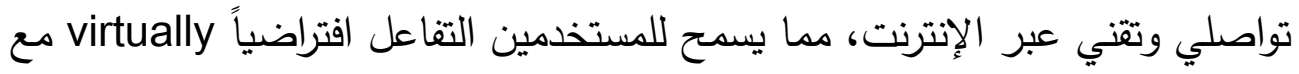

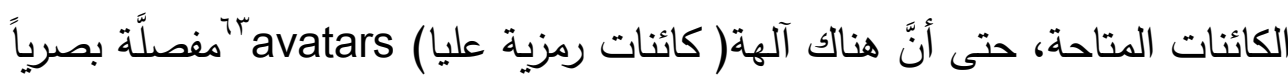

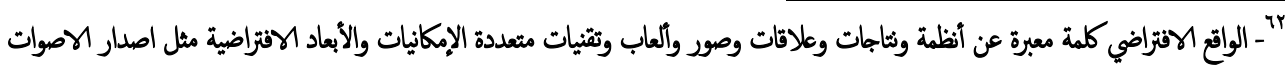

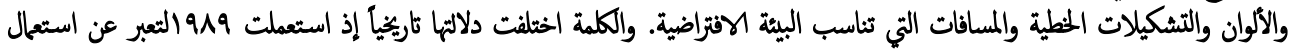

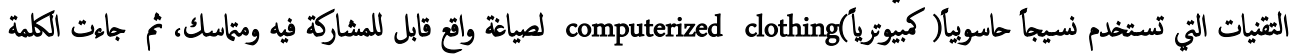

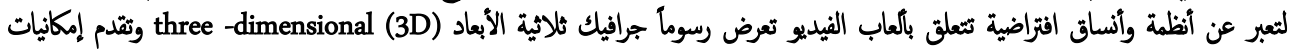

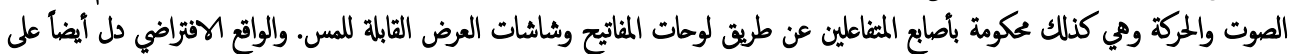

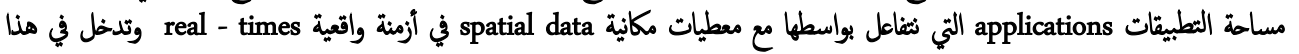

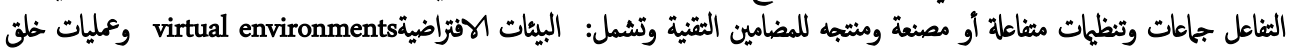

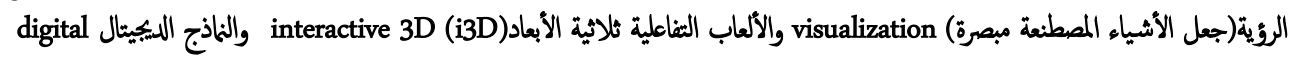

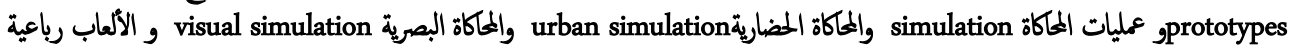

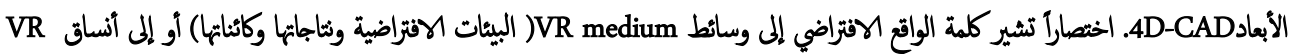

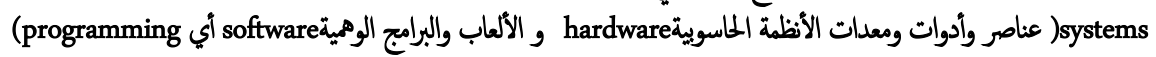
- Jennifer Whyte, Virtual Reality and the Built Environment, Architectural Press, London New York, 2002. PP2-3.

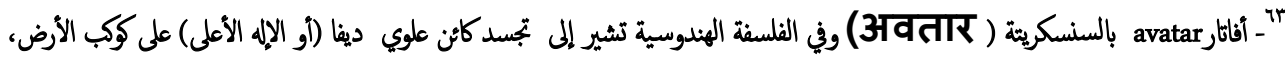

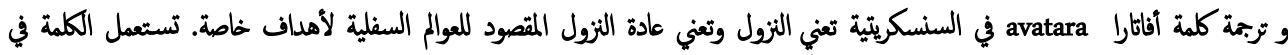

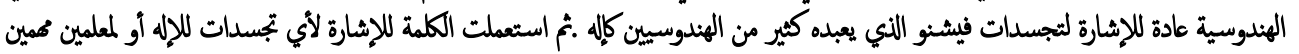

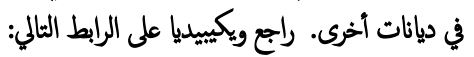
.https://ar.wikipedia.org/wiki/\%D8\%A3\%D9\%81\%D8\%A7\%D8\%AA\%D8\%A7\%D8\%B1) 
وشكلياً، أوالتفاعل مع آلهة أخرى، ذلك في وقت حقيقي وفي بيئة ممثلة represented environment

ويُلاحظ أنَّ الجسد الافتراضي له حياته الخاصة أمام عيوننا. قد نراقبه ونتتبع

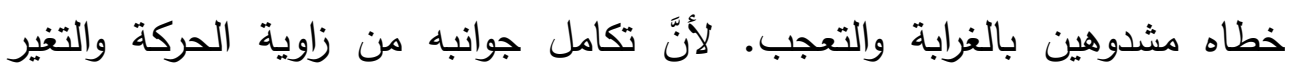

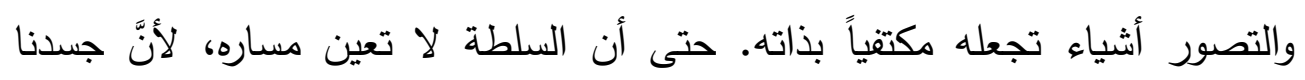

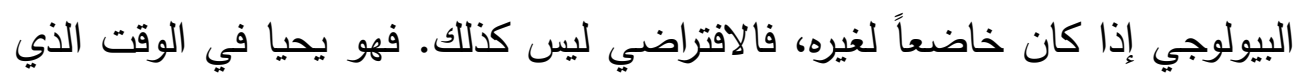

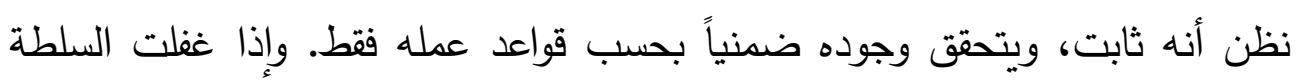
عنه، فلا يقبل إلاًّ أن يسير وفقاً لآليات الواقع الافتراضي(في العوالم الخيالية

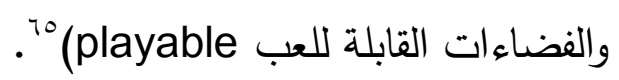

كأنَّ هذا الجسد يريد القول إذا كانت السلطة لها منطقها في الممارسة، فإن

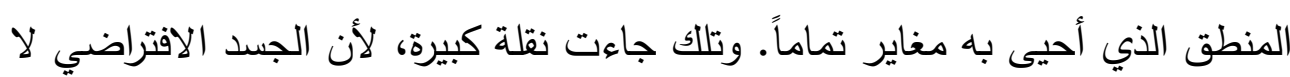

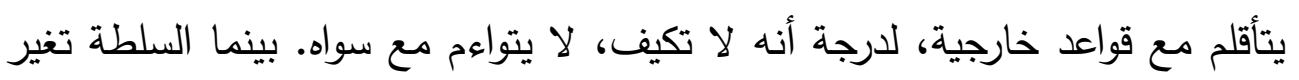

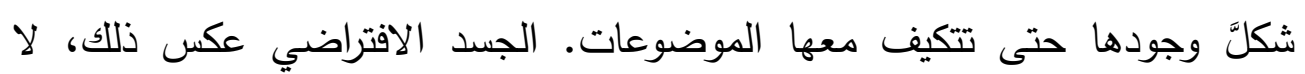

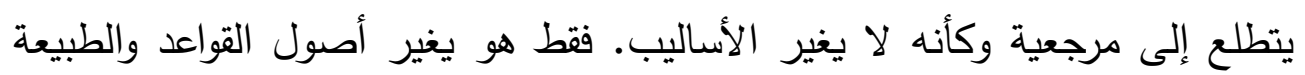

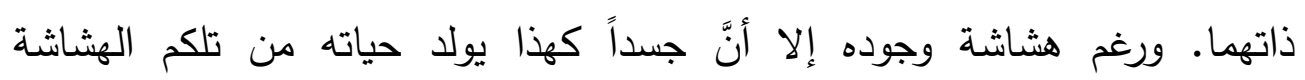
الإلكترونية.

ولعلَّ علاقة الجانب الافتراضي بالعالم الخارجي تأتى عبر وسيط المشاهدة،

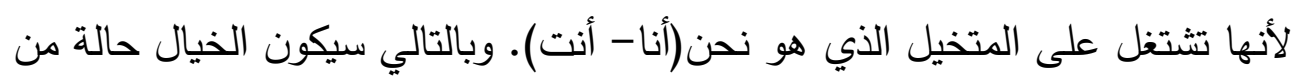

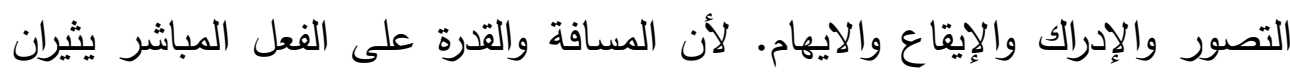

${ }^{64}$-Ruthanna Gordon, Alternate Reality Games For Behavioral and Social Science Research, London, 2015.P 15.

${ }^{65}$-Antonio José Planells de la Maza, Possible Worlds IN Video Games :From Classic Narrative to Meaningful Actions, Carnegie Mellon University: ETC Press Pittsburgh, PA, 2017.PP 73-99. 
مغامراتتا الواحدة تلو الأخرى. مما يثير آفاق الخلق لاى المشاهد( الهتفاعل)، يلجأ

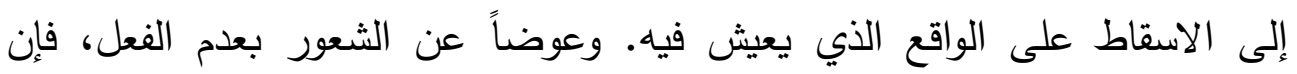

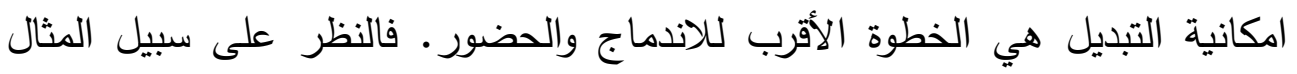

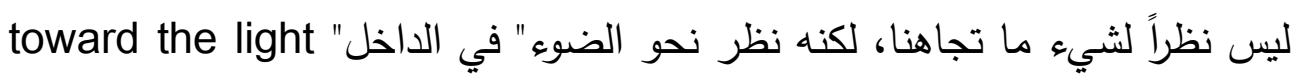

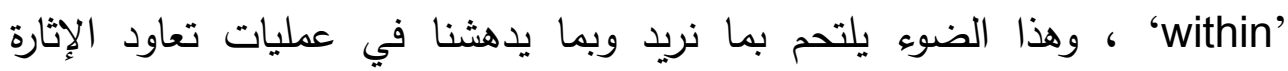
والإلحاح.

فلسفيا،" فإنَّ التقنيات البصرية المعتمدة على الضوء مثل الكاميرا الغامضة camera obscura الافتراضي(VR)، تقف جنب إلى جنب الاستعارات التي تتموقع بها التقنيات خطابياً

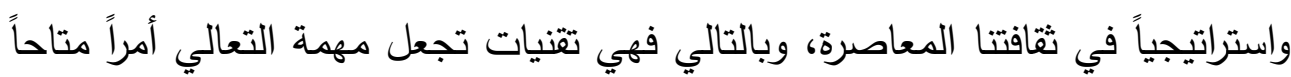

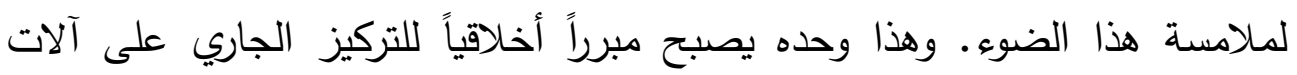

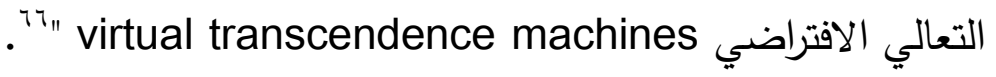

ما يهم هو كلمات مثل الضوء، الاستعارات، الخطاب، الاستراتيجية، فهي

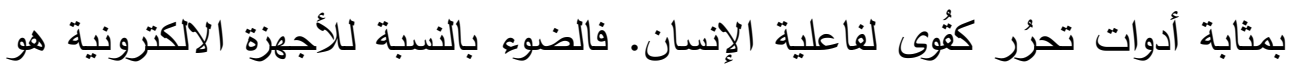

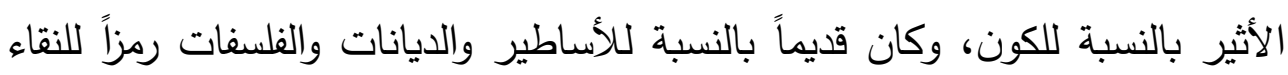

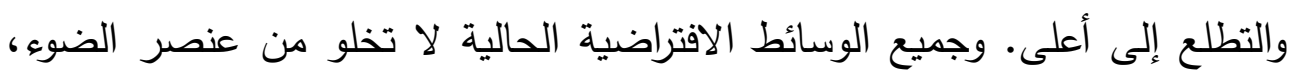

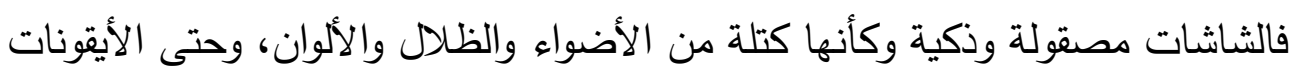

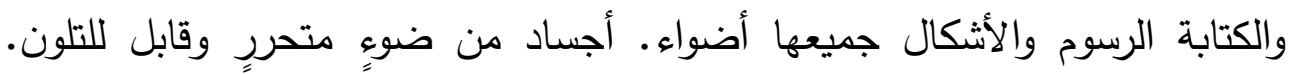

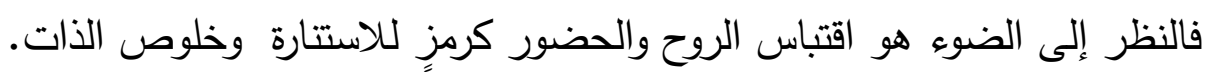

${ }^{66}$ - Ken Hillis, Toward the light 'within' Optical technologies, spatial metaphors and changing subjectivities, In: Mike Crang, Phil Crang and Jon May(editors), Virtual Geographies Bodies, space and relations, Routledge: London and New York, 1999, P 24. 
وبالتالي فالتقنيات تجري اجتماعياً وسياسياً، كأنَّا استعارات ثقافية تطلق العنان لما هو إنساني وتعيد بث الفضاء الملون. حتى أن الوسوم والرسوم الافتراضية التي

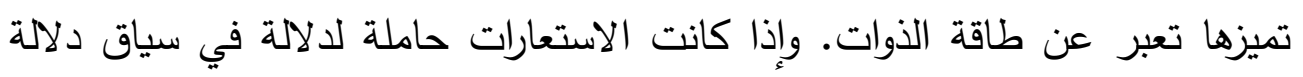
أخرى، فالإيماءة فيها دوماً هو مجابهة سلطة ما تحول دون استعمال ما نريد. وبحكم استعمالنا الحُر للأجزة(رغم وجود رقابة)، فالتقنيات خطاب واستراتيجية.

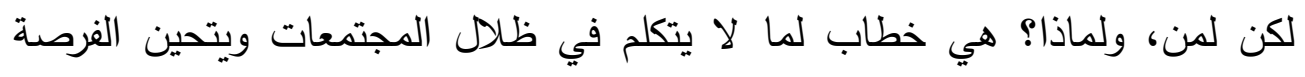

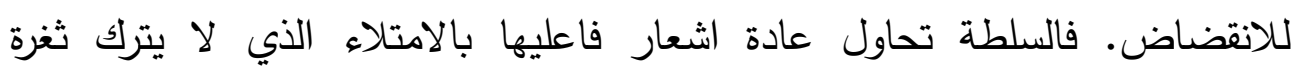
لاستعمال أشياء تتعارض معها أو تتلاعب بها. إنَّ الوسائط هي وسائط لزرع أفكار

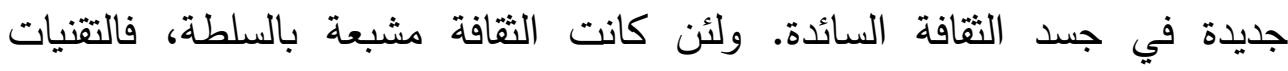
وتصوراتها هي شروخ في هذا الجدار. وليس العلُو المشار إليه هدفاً بذاته تقربه

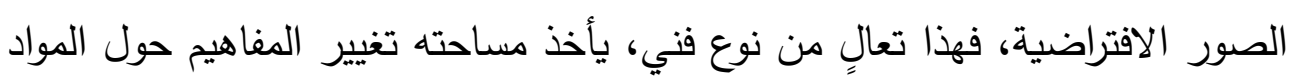
والعناصر الطبيعية. لأن الأفكار تتجسد في الأجهزة على هيئة أصوات وأنغام وخطوات وتطبيقات وبرامج واعادة تفاعل. ولان. الاعكئ.

إنه حين يتفاعل الإنسان مع الواقع الافتراضي، فهو يمارس استعارةً لوجوده

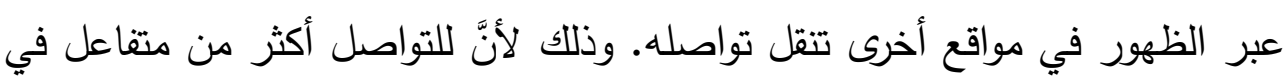

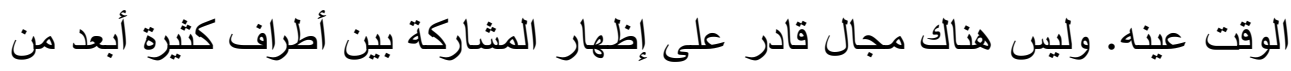

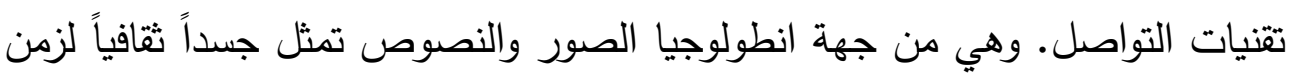

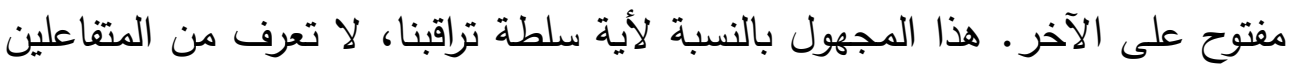

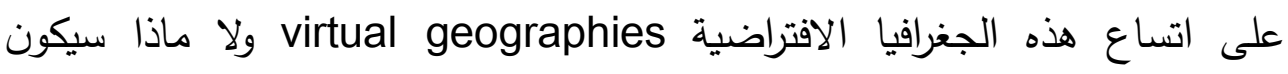

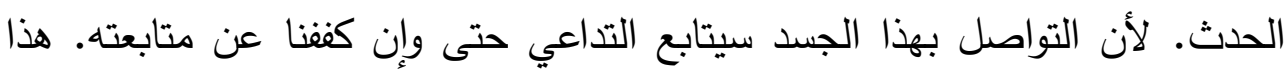

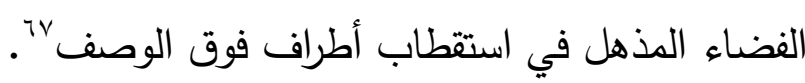

\footnotetext{
${ }^{67}$ - Mike Crang, Phil Crang and Jon May(editors), Introduction, In: Virtual Geographies Bodies, space and relations, PP1- 20.
} 
إذ ذالك ليس يكفي للسلطة أن تراقب وتنصب الحدود بيولوجياً، فهذه الأشياء

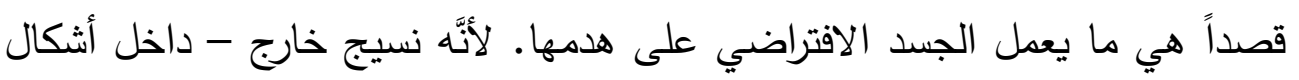

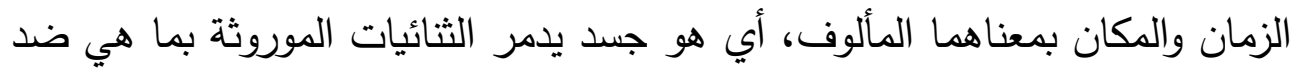

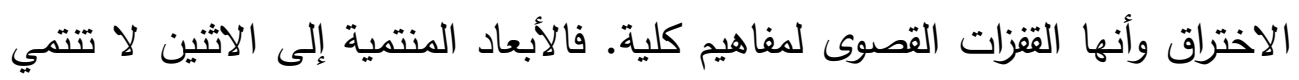

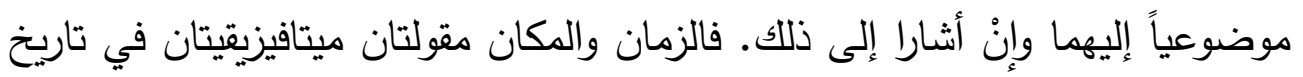

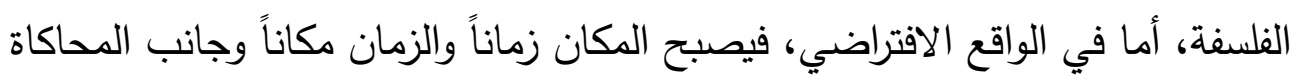

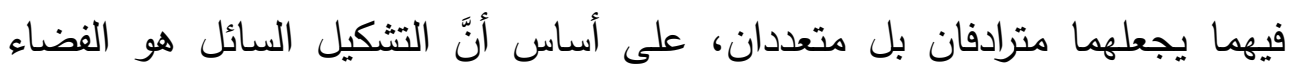

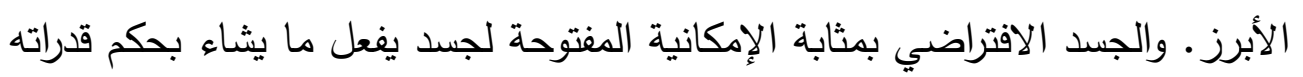

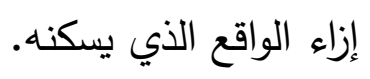

الجسد الافتراضي لا يموت، فهو ذاكرة إلكترونية لها نسيجها الخاص. ذاكرة

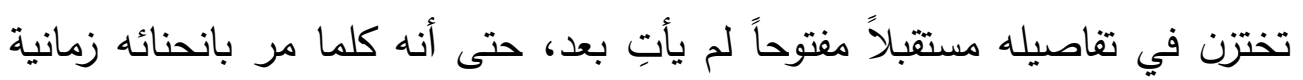

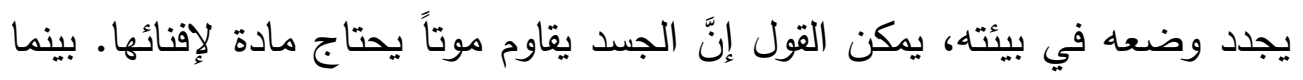
الواقع الافتراضي يكتب الحيوات تلو الحيوات كاحتمال لا ينضب، فقوانينه كامنة

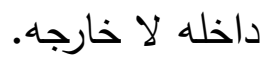

\section{أولاً: الخيال العيبراني cyber imagination}

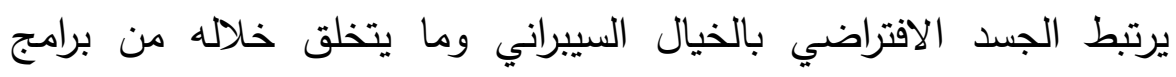

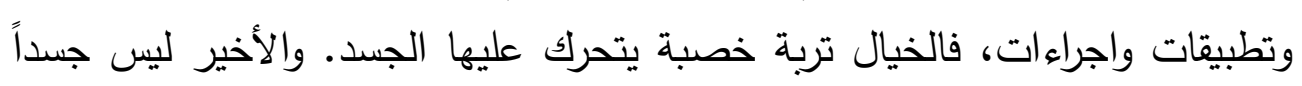
بهذه الصفة لكونه متخيلاً، بل لأنه دال على البيئة السيبرانية الكنتمي إلى جنسها.

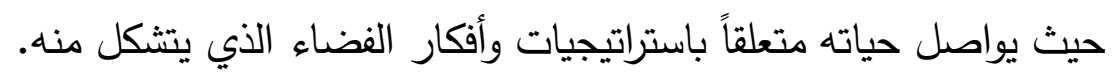

لأننا لا نتصور جسداً كهذا دون فضاءٍ له معالمه وآلياته النوعية، فكلمة

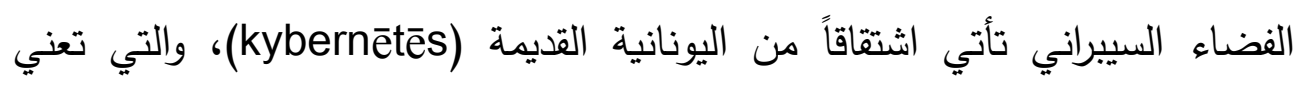


"مُساعد التوجيه" أو "الحاكم" أو "الرائد" أو "الدفة"ي" ـ وبمفهوم أشمل يُعرف بأنَّه مجال field الشبكات والبرمجيات، حوسبة المعلومات، معالجة وتخزين البيانات، ومتفاعلي هذه ونه الوسائط واستراتيجياتها.

ولعلنا نلاحظ أنَّ الفضاء السيبراني ليس هو الخلفية والمسرح والفكرة والوسيط

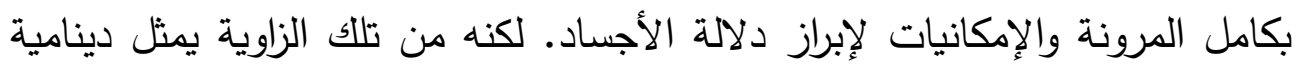

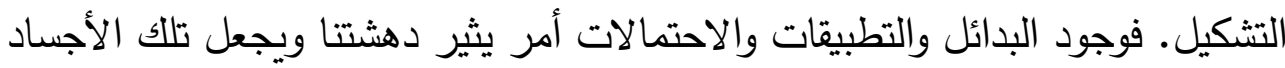

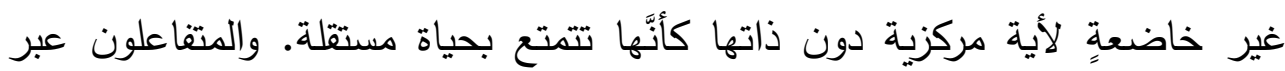

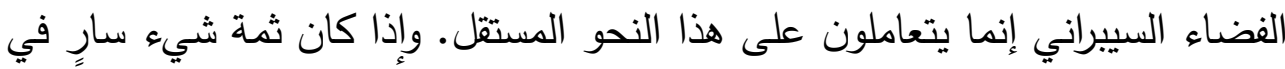
هذا الفضاء، فهو إيقاع الكلمة باعتبارها تلفظ الهيمنة عنها، وذللك يعود إلى اكتفائها

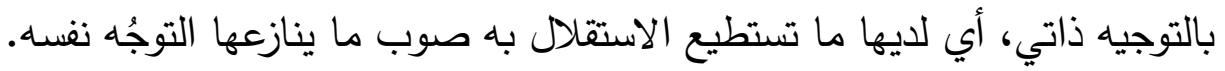
وليس بعيداً عن ذلك نقض السلطة إذا تدخلت في هذا الثأن. ولذلك ينطوي

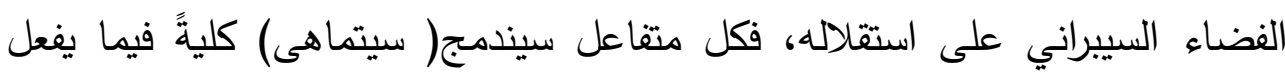
ويمارس من أخيلة. وليس هذا فقط بل سيكون جسده هو الجسد المفترض الذي

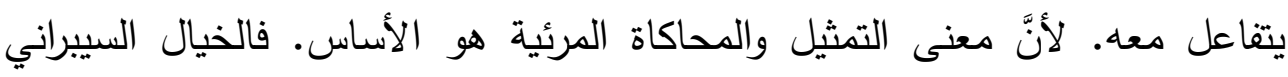

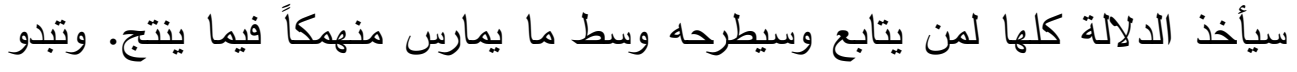

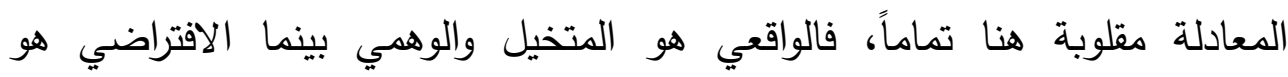

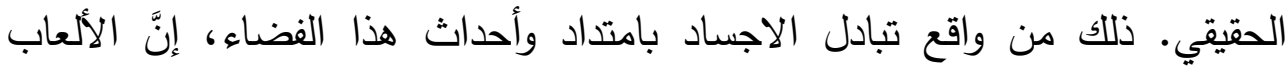

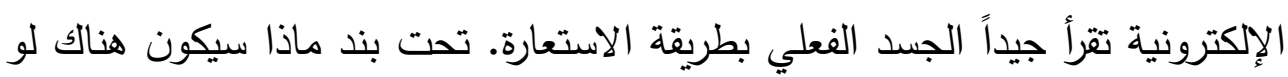

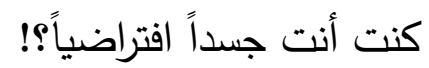


هنا يمكننا إبراز عدة نقاط:

1- التأكيد على وجود المادة الخيالية للجسد، وهي مادة معلنة الفاعلية عبر وسائط. فالفضاء السيبراني مادته التخييل الفني اللاعب على حرية التكوين. وتلك العملية لا حدود لها، لأنَّ الأساس هو الفضاء الذي يحتمل أي شيء. وهذا معناه أن مادة الجسد الافتراضي هي مادة الفضاء المشار إليه، لأنهما مادتان ترجعان إلى نسيج واحد. والامكانيات تشتق من النسيج بدءاً من التشكيل وانتهاء باحتمالات التحول.

ץ- يبرز الجسد الافتراضي أنك هو بعينه لا أنت. والسلطة دوماً لا تستطيع التعامل مع ال" هو" لكونه أحد صيخ الغياب المتقلت من قبضتها. فالسلطة قوة حاضرة عادةً، ولا تجيد التعامل من تلك الزاوية. والغياب هو إعلان عن قصور السلطة، لأنها تتساءل: كيف أكون حاضرةً بينما هناك موضوع(الجسد الافتراضي) غائب؟! لتكتشف أن غيابه ليس غياباً مكانياً، لكنه غياباً دينامياً باعتباره من جنس آخر. r- تتمتع الاجساد الافتراضية بحياةٍ ما، حياة متاحة لكل المتفاعلين الافتراضيين. كما أنها أجساد تمتد بحياتها لاى كافة الحيوات الأخرى، أي هي الحيوات القابل لجميع الأجساد. وبالتالي لن تكون السلطة قادة على ممارسة دورها البيولوجي الصرف ولا المبئي. فهي تعجز أمام التحول الجوهري الذي يعيد توزيع الموضوع داخل الفاعلين والعكس، أي الفاعلين عبر الموضوع.

إنَّ الجسد الافتراضي بهذا التشتيت dissemination - بعبارة جالك دريدالا يعطي أية سلطة إمكانية معرفة أبعاده وتحولاته الخاصة. لأنه بالوقت عينه عميق الانتشار لدى كل المتفاعلين.

ع - يجمع الجسد الافتراضي سيبرانياً بين الفردي والجمعي، التنوع والوحدة، النظام والفوضى. هو يسير بجوانبه المختلفة معاً. وهذا سر اعتبار الجسد الافتراضي 
موقعاً تأويلياً hermeneutic position لأي متفاعل، وأنه بلغة القراءة يستطيع ابراز وجوده في نقطة غير محتواه بجانب دون آخر .

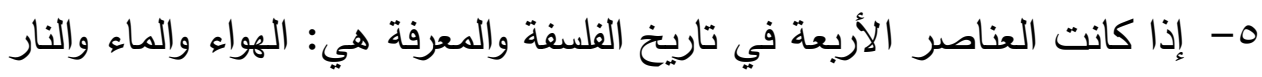
والتراب، فمادة الجسد الافتراضي هي العلامة، هي المادة الضوئية المتخيلة.

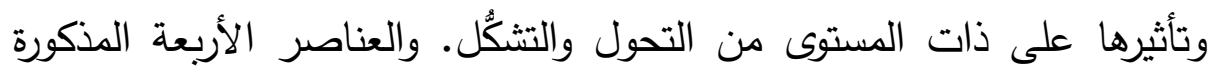

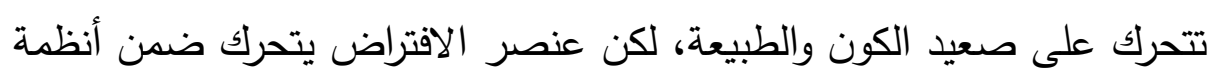
الدلالة والابداع والكتابة والحرف والصور والرسوم.

وهذه الأنظمة تحدد كوناً نوعياً بمجمله، إنَّ (كون) الواقع الافتراضي مليء

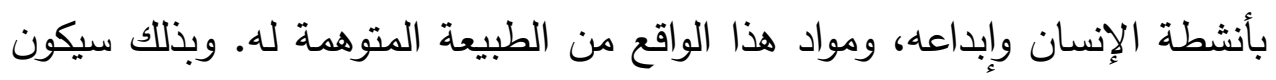

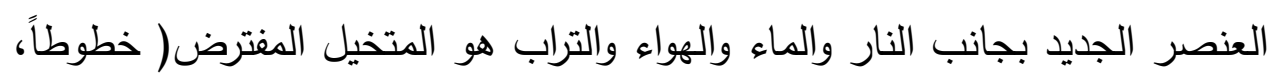

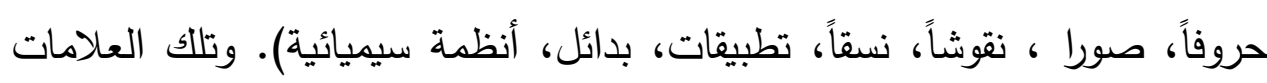

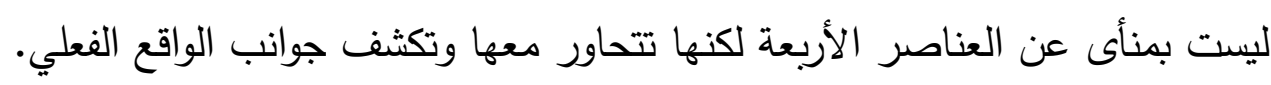

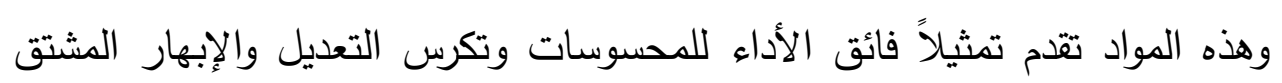
منها. نحن لا نندهش سوى بالدقارنة بين الإدراك العادي وبين مالا ندرك، بين

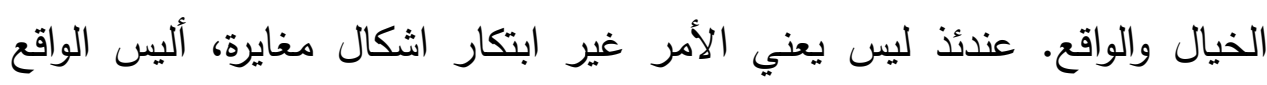

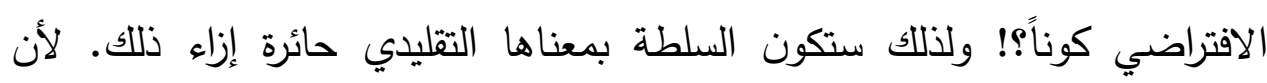

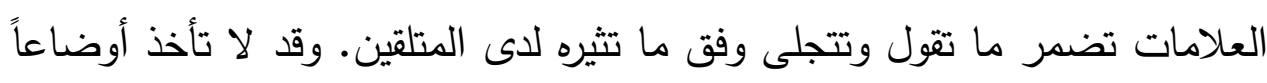

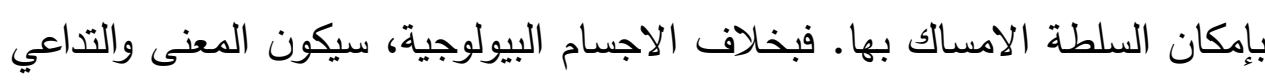

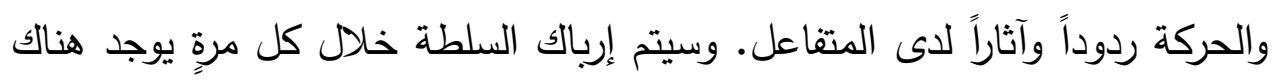

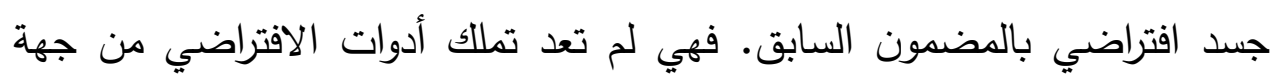

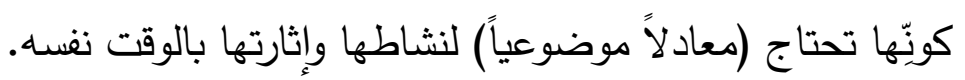


7- الجسد الافتراضي علامة حرة، تتتاسل دوالها بل دوالها ومدلولاتها من مادة

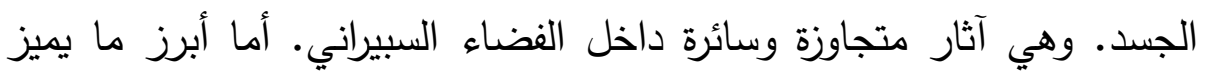

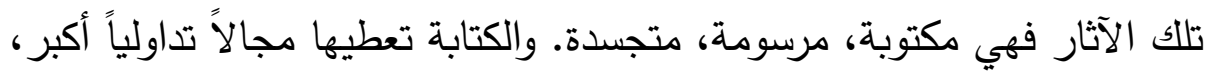

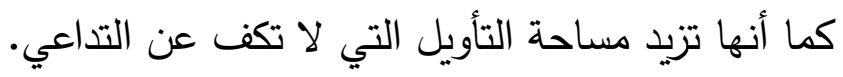

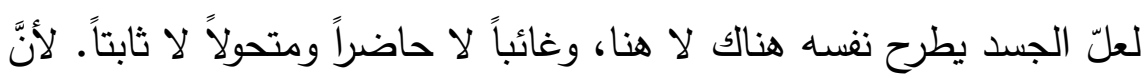

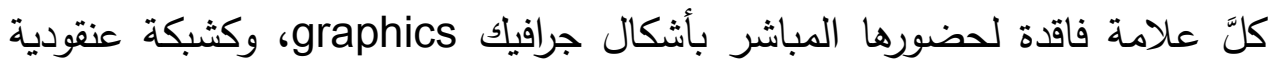

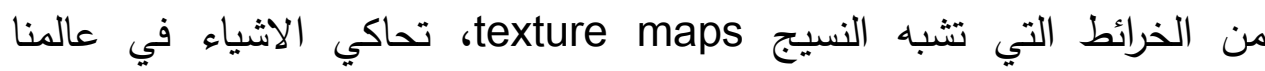
الواقعي. غير أنها تُشنَّا بإحساس افتراضي لكونها جزءاً من البيئة الافتراضية،

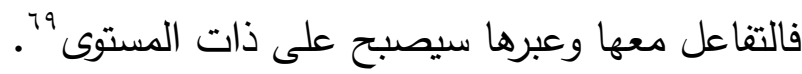

V- الجسد الافتراضي أداة وفكرة استراتيجية لمزيد المعرفة وطرح أسئلة الحياة فلسفياً. وكأنَّ الأمر المطروح كالتالي: إذا كان ثمة جسد بتثكيل أكثر مرونة،

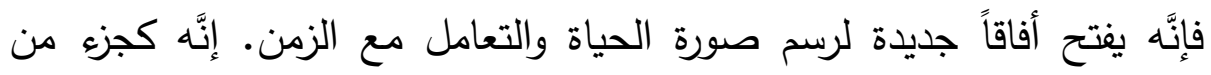
الفضاء السييراني يُسهم في تغيير نظرتتا للعالم والتاريخ. ذلك أن البيئة الحاضنة هي اساساً بيئة إبداعية لاحتمالات الواقع الأعمق

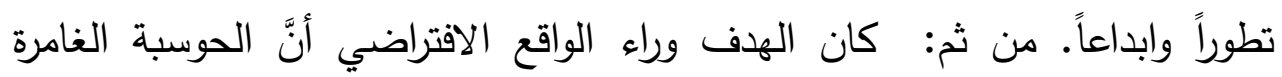

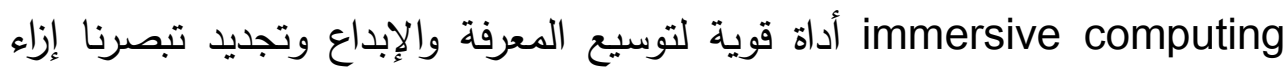

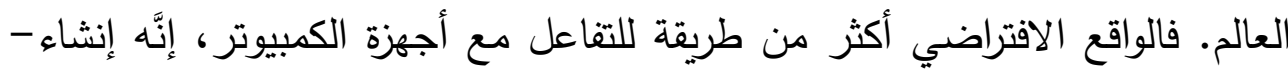

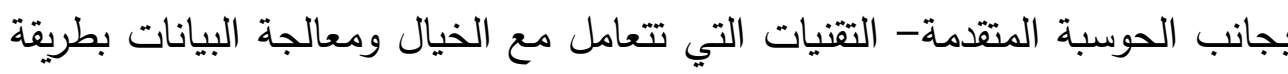

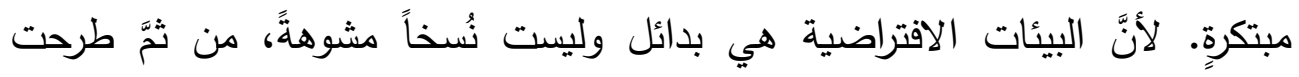
منتجاتها بعض الأسئلة الفلسفية الخطيرة حول استخدام التكنولوجيا. مثل: هل تكرر

\footnotetext{
${ }^{69}$-Sean M. Grady, Virtual reality: simulating and enhancing the world with computers,(Science \&Technology In Focus) Facts On File, Inc., New York ,New Edition 2003.PP72-73.
} 
أنظمة الواقع الافتراضي إحساساتتا بصورة أعمق عن الواقع؟ وإلى أي مدى تدمجها

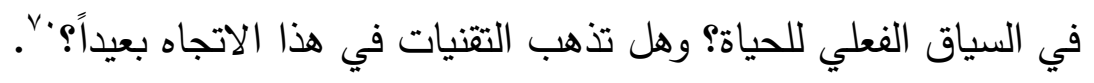

الخيال السيبراني - مع ذلك- يبقى دينامياً، لأنَّهَ الفاعل والمفعول على امتداد

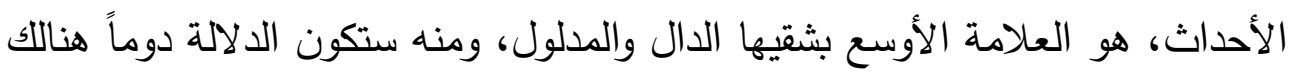
حيث التخييل، وبالجسد سيمثل ورشة كونية مدهشة تذهب وراء التفلسف بمعناه الجوال المتسائل حول قضايا المصير والحقيقة والتاريخ.

$$
\text { ثانياً: الصورة. }
$$

الصورة - افتراضياً

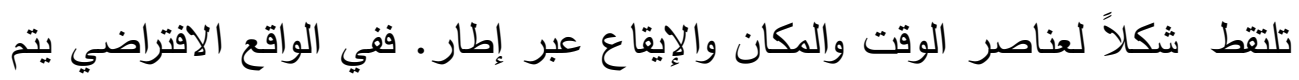

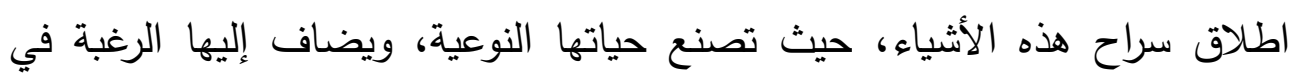
المشاهدة التي تثير كافة الصور الممكنة حتى داخل الصورة الواحدة. ففي كل صورة يكمن فائض الوهم على مقربة من حدود أبصارنا، لأنَّ

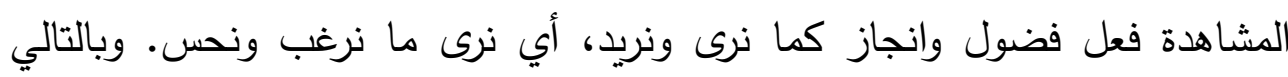

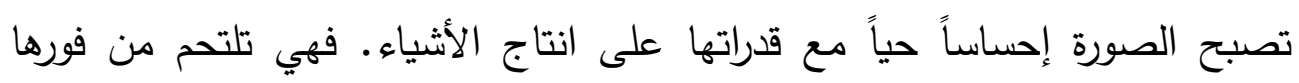

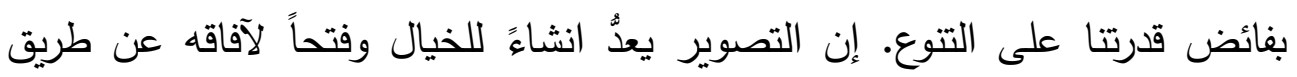

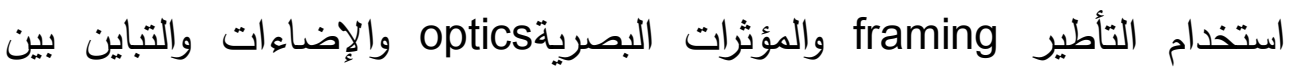

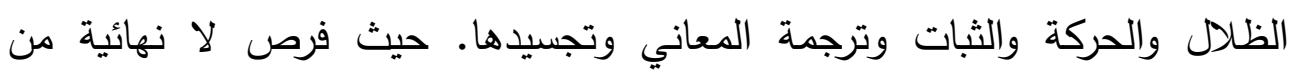

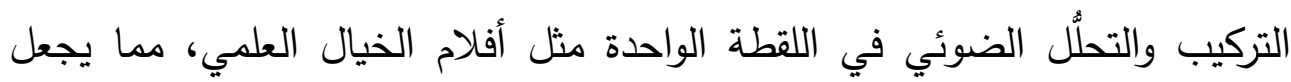

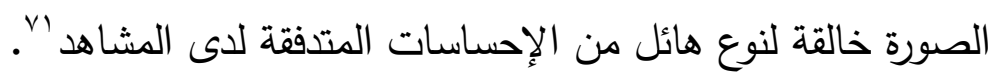

${ }^{70}$ - Ibid, P 181.

71 - Michael FreeMan, The photographer's Mind : Creative thinking for better digital photos, Focal Press ,Amsterdam, New York, London, 2011, P 44. 
الحاصل أنَّ اللقطة هي تجريب للصورة لا الوقوف على حدودها المرئية، نحن

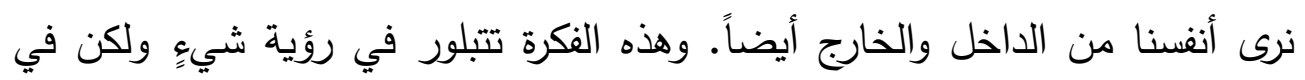

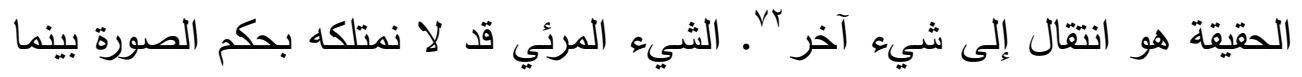
الثيء الذي ننتقل إليه هو الذي نخلقه وهي لحظة تماه والتباس ضمن التئ علاقة الوعي

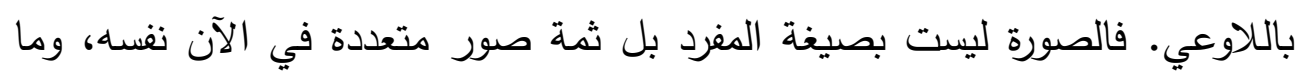

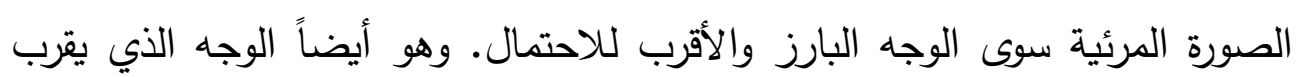
ملامح ومعالم وجوه لا حصر لها. وتلك العملية تتفاعل مع أعمق موضوعات الفكر، فالعين بالخيال تعيد تركيب

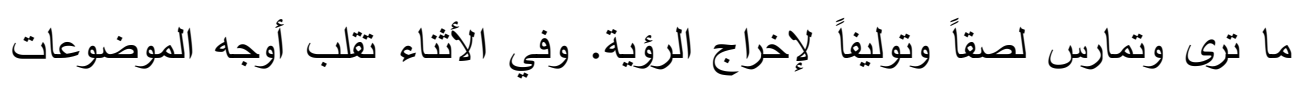

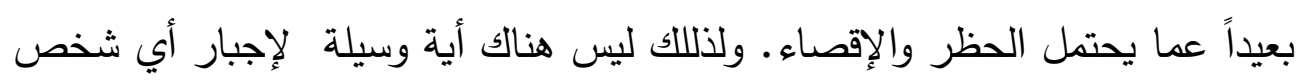
على النظر إلى صورة بطريقة معينة ألى at an image in a particular way moving وإذا كانت الصورة هكذا تؤثر بالوضع السابق، فالسلطة لا تستطيع فرض الصال

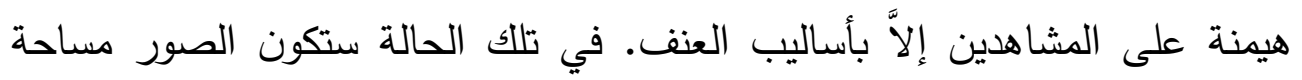

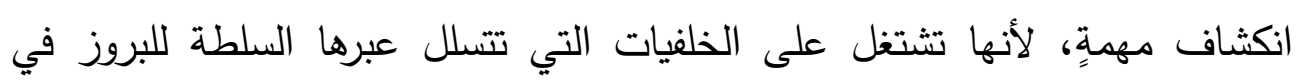

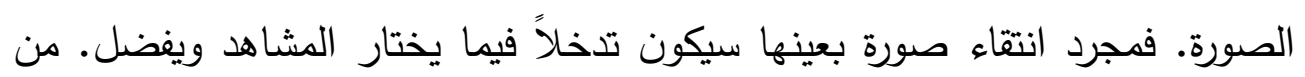

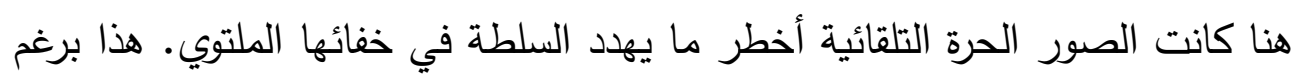

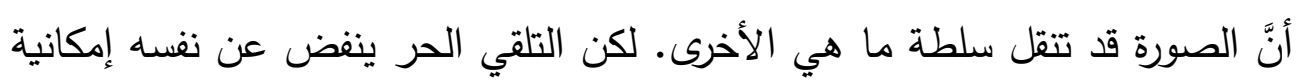

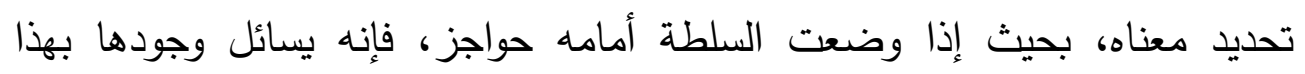
الوضع أو ذاك.

\footnotetext{
72 - Ibid, P 108.

${ }^{73}$ - Ibid, PP 108- 181.
} 
والصورة نفسها تمثل علامة استفهام حي، كلما اقتربت سلطة كلما اثارت

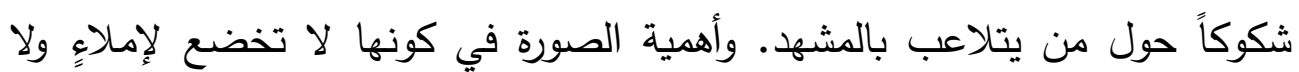

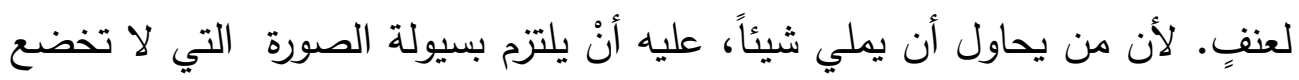

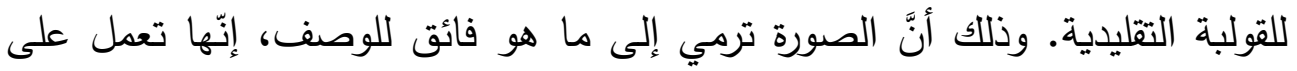

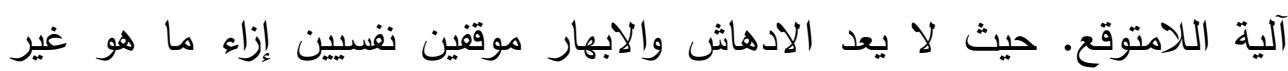

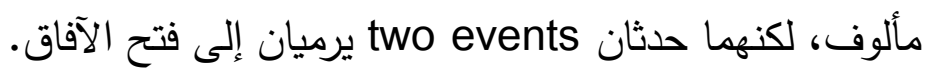

وكأن الصورة الدينامية تحيل السلطة إلى موضوع للنظر (أنْ تكون مرئية) وليس العكس. وهي كرمز مرسوم، دينامي في البيئة الافتراضية، ستكون اعتراضاً موجهاً إلى سلطة ما هناك. وعلى طريقة أنَّ حضور السلطة يتحقق نتيجة حضور

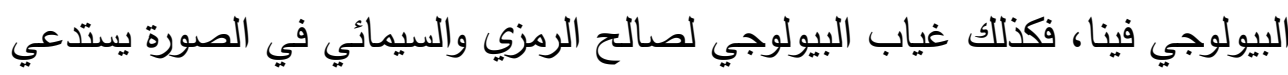

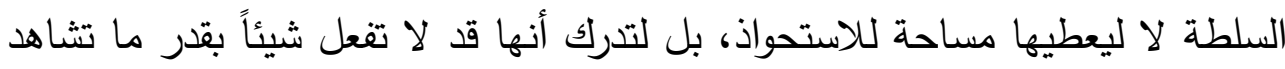

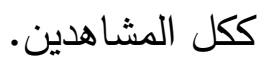

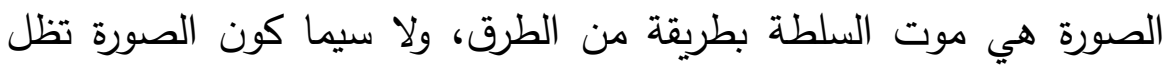

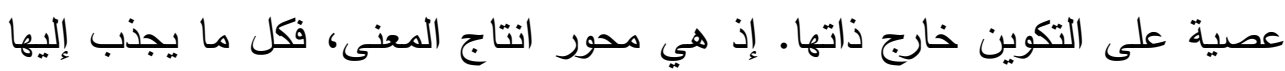

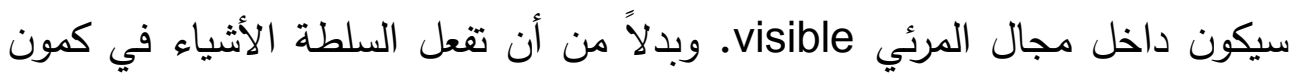

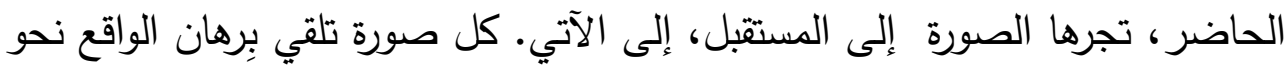

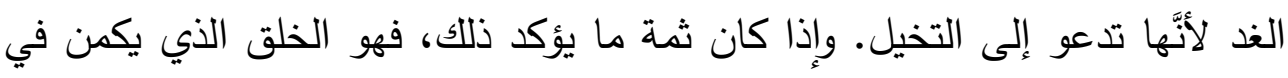

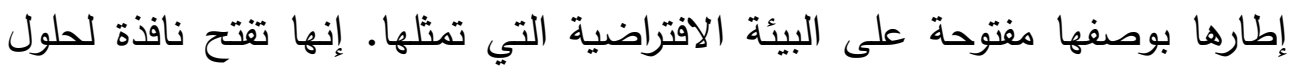

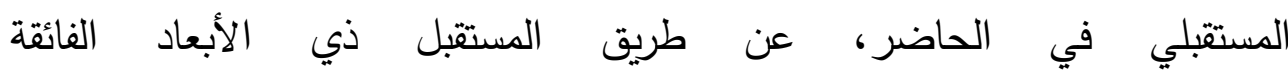
hyperdimensional .$^{\mathrm{r} \text { cyberians }}$

\footnotetext{
${ }^{74}$ - Douglas Rusbkoff, Cyberia : Life in the Trenches of Hyperspace, Clinamen Press, Manchester, 2002. P 44.
} 
وهذا يعبر عن أنَّ الصورةَ نسيج حياة أخرى، حتى الأدوات الديجيتال مثل

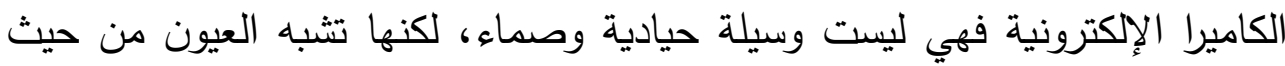

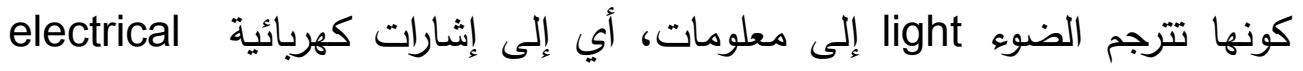
signals

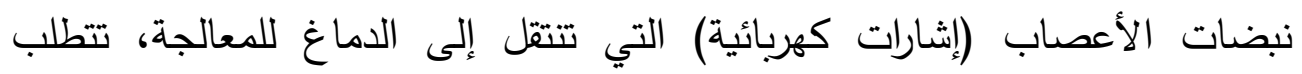

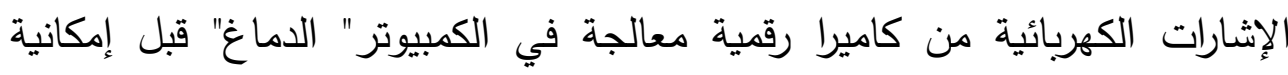

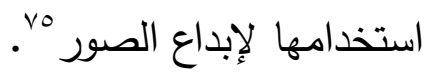

إذن تقنيات الصورة ترتبط بخلفية من المعاني التي تجذب المتفاعل إلى عالمها،

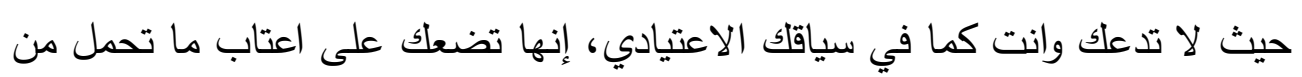

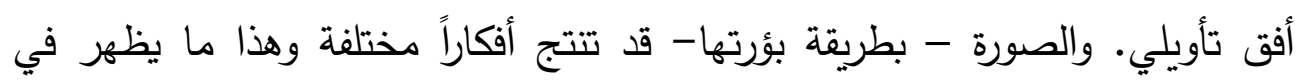
الصور الافتراضية أكثر من الصور الفوتوغرافية العادية. لأنَّ الأولى تعول في دلالتها

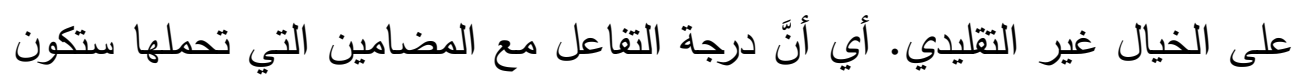

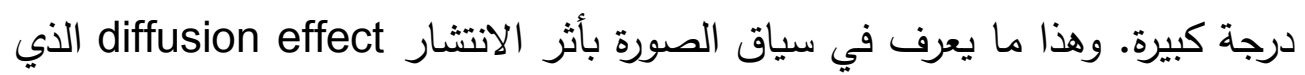

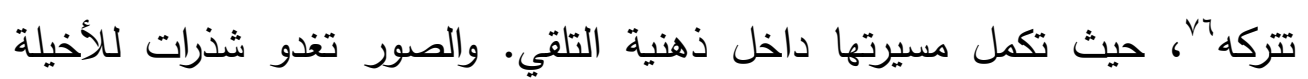
التالية التي تفرخ المزيد في عقول المتفاعلين.

وهي كصورة لها القدرة على تكملة البقية التي انفصلت عنها، أي أنَّ كل شذرة

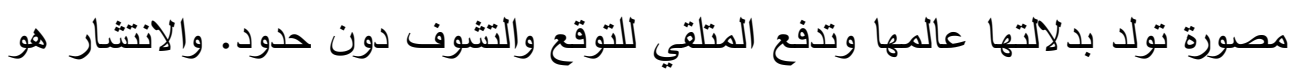

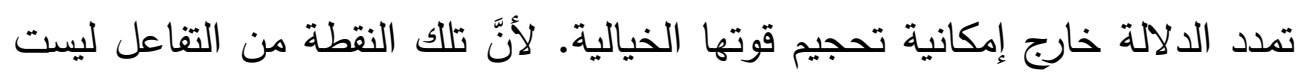

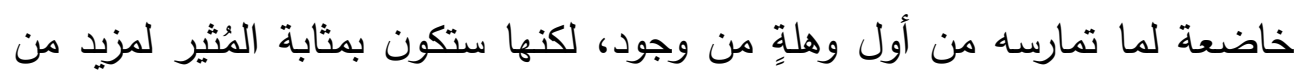

${ }^{75}$ - Lee Varis, Skin : The Complete Guide to Digitally Lighting, Photographing, and Retouching Faces and Bodies( Second Edition), Wiley Publishing, Inc., Indianapolis, Indiana, 2010. P 2..

${ }^{76}$ - Ibid, P 220. 
الصور • وهذا يؤدي إلى اعتبار الصورة جسداً ممكناً للأفعال، لأنَّ عالمها يجعل كل عمل أمراً ممكناً بناء على ذلك.

في هذا الإطار تعد عملية انكثاف الأشياء عبر الصور بمثابة اعتراف بما نرى ونتخيل. ودوماً الاعتراف هو مفتاح التغيير. فالشبكات الاجتماعية وسعت الأتياء تطبيقات وتقنيات التعامل مع الصور والمعرفة على كافة الأصعدة، وحتى بالنسبة للمجال العام public sphere ستكون المؤسسات شبكات محملة على الأجزة mobilized networks هي القادرة على تطوير ما نرى وما نفعل. وأنَّ هذه الثبكات- بذاكرتها الافتراضية-

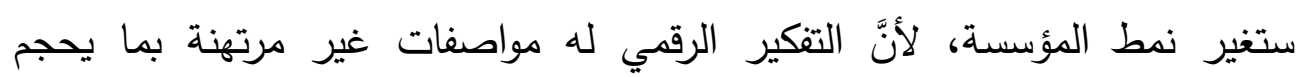

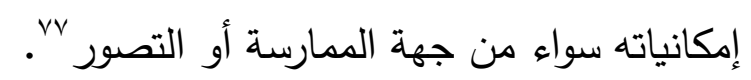

حينئذ تثبت الصورة فكرة أن موضوعات إدراكنا تبقي دوماً افتراضية وتنظيمية أكثر من كونها مرجعية referentially، وأنها نتيجة انعكاسات استعارية ومجازية

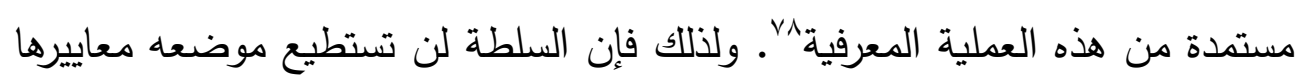

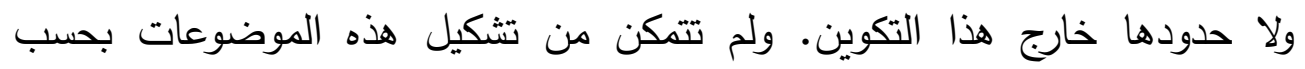

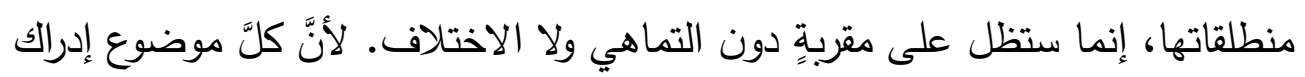

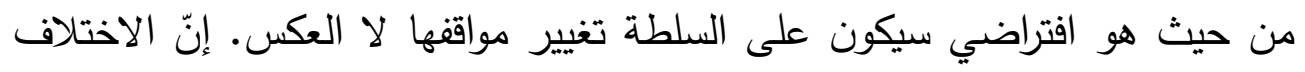

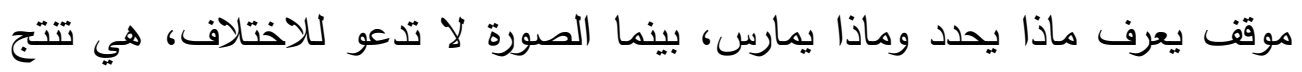
produces

${ }^{77}$ - Cathy N. Davidson and David Theo Goldberg, The Future of Thinking: Learning Institutions in a Digital Age, with the assistance of Zoë Marie Jones, The MIT Press Cambridge, Massachusetts London, England, 2010. P 176.

${ }^{78}$-Jerome Iglowitz, Virtual Reality: Consciousness Really Explained!, (Second Edition), (February 22, 2010), P 39. 
الفارق أن الدعوة للاختلاف هو دعوة للتناقض، والأخير أقرب صيغة للتطابق

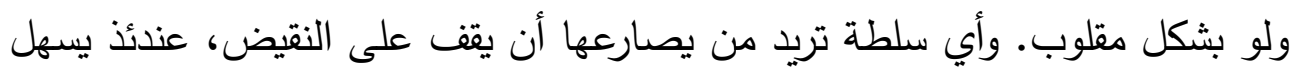

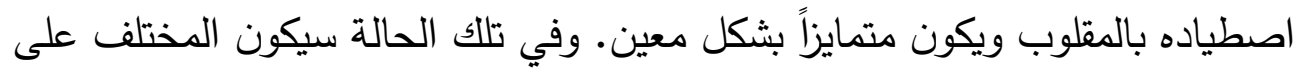

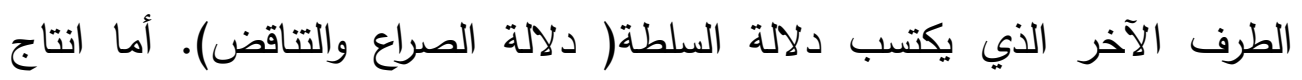
الاختلاف، فهو تعددية الأشكال الافتراضية التي تشوش مراقبة السلطة. وليس بعيداً -

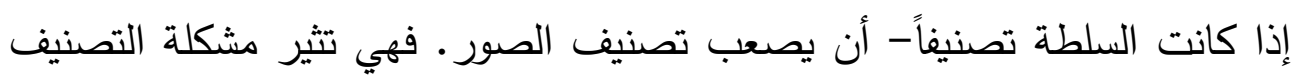
والتفسير دون السقوط في مقولاتهما.

وهنا يجب الإشارة إلى تلك السمة للصورة الافتراضية، أنها غير قابلة للتصنيف

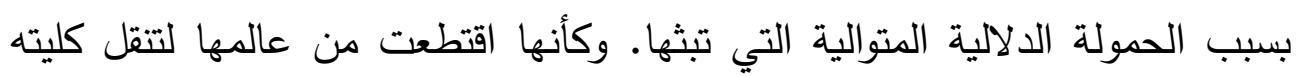
المفترضة بالوقت نفسه. والعلة وراء ذلك أن سيولة الصور كبسولات شعورية وحسية

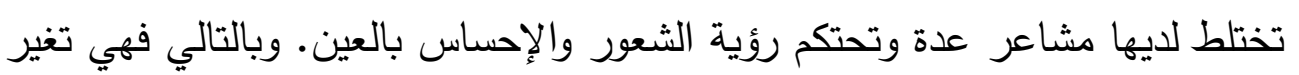

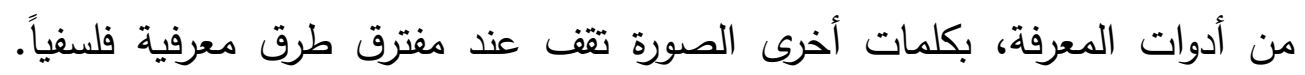
فالافتراض فيها ليس له حاسة واحدة، لكنه يمزج بين مجموعة من المعارف والأفكار والأحاسيس.

فإذا كانت المعرفة العلمية تتضمن بُعداً منطقياً قابلاً للاختبار وفقاً للسياق، فليست الصورة كذللك ولن تكون، وإذا كانت المعرفة المادية تعتمد على الخبرة الحسية

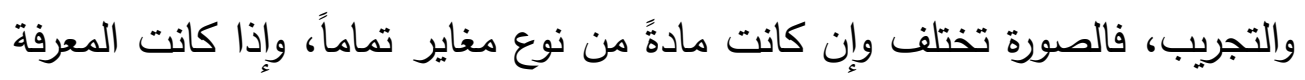

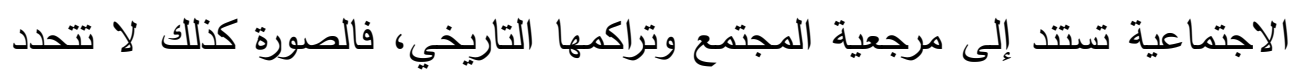

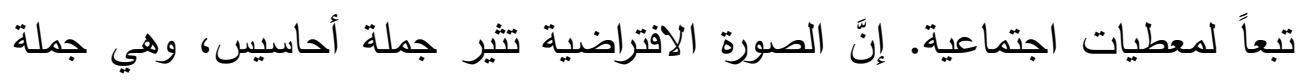
معانٍ في اللحظة وقتها كأنَّها تتقرح حاسة جديدة تجمع بين كل الحواس. كما أنَّها

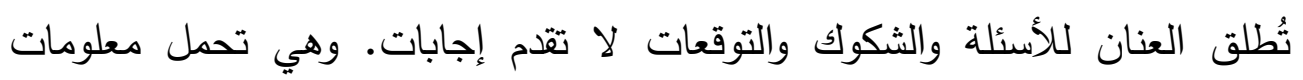

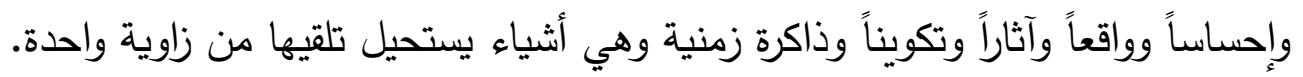

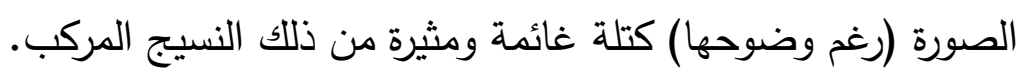


والدفارقة رغم تعقيد الصورة إلا أنها تؤثر مباشرة، إن تأثيرها يأتي عبر

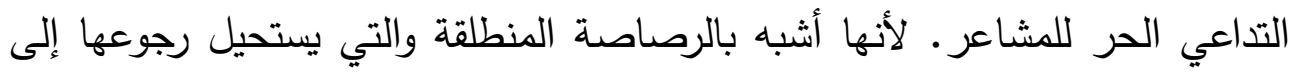

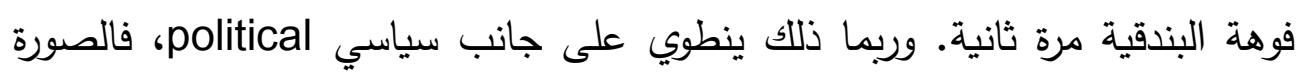

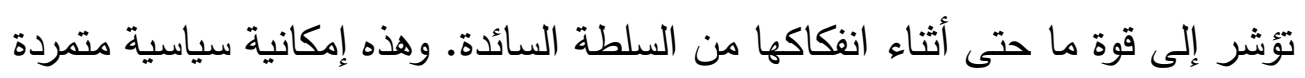

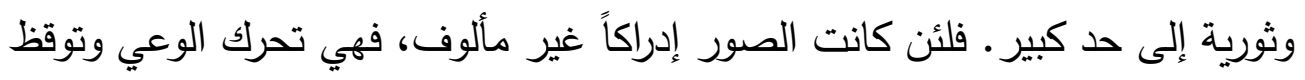

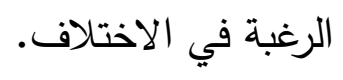

في المقابل - نتيجة ذلك- " هناك سلطة سيبرانية cyberpower وهي صورة

القوة التي تشكل الثقافة والسياسة في الفضاء السيبراني وعلى شبكة الإنترنت. وتتكون من ثلاثة جوانب مترابطة: الفردي individual، والاجتماعي social والخيالي

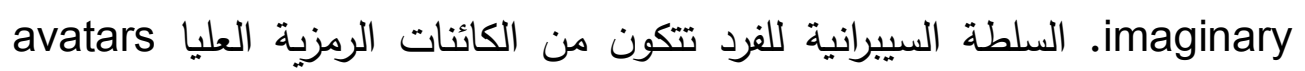

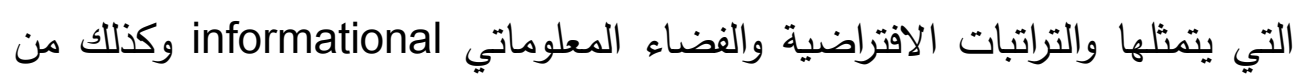

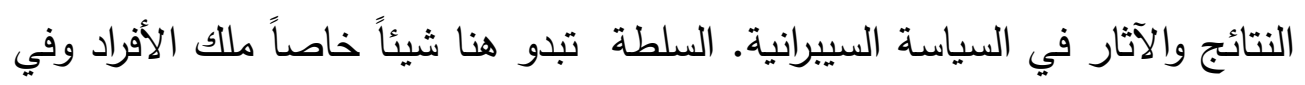

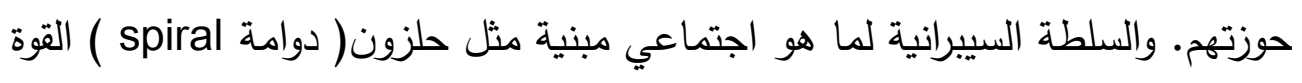

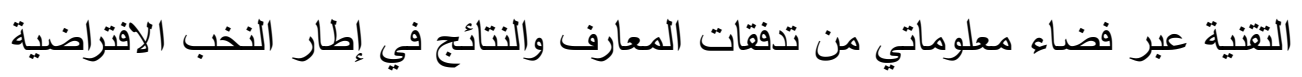
virtual elites

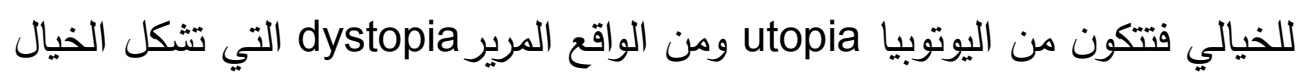
الافتراضي. وبالتالي تبدو السلطة بجوانبها عنصراً أساسياً في النظام الاجتماعي.

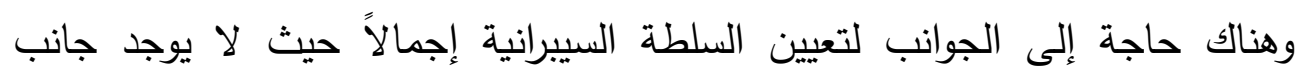

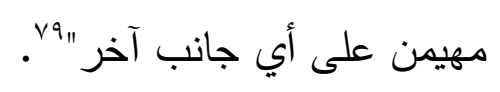

ربما الإشارة الواضحة في هذا النص هي بلورة سلطة خاصة بالفضاء

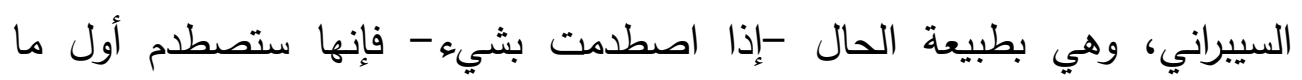

${ }^{79}$-Tim Jordan, Cyberpower: The culture and politics of cyberspace and the Internet, Routledge :London and New York,1999. P 208. 
تصطلم بالقوى المسيطرة في المجتمعات. وكأنَّ السلطة الافتراضية الجديدة تشتغل على قاعدتها السائدة وتتخر فيها. وليس أدل على ذلك من تداخل الوسائط الافتراضية

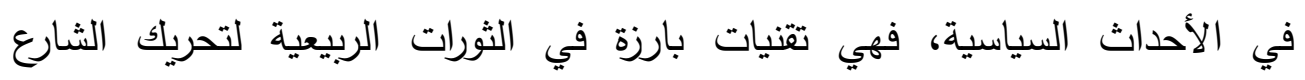

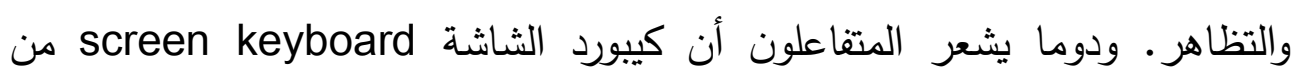

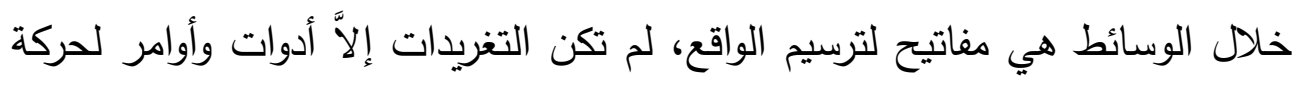
الجماهير في المظاهرات السياسية.

كانت الثاشات الذكية هي شوارع المدن والتظاهر والتفاعل الحي. المتابعون

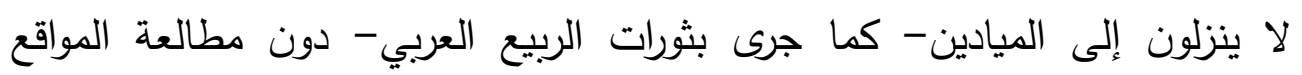

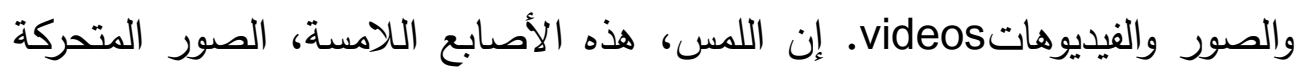

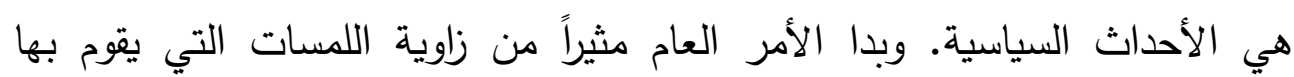

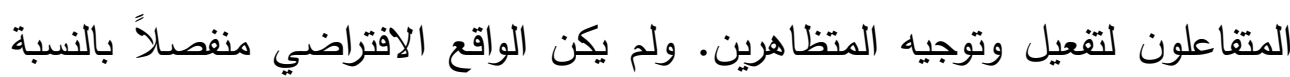

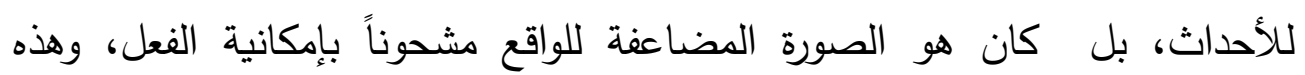

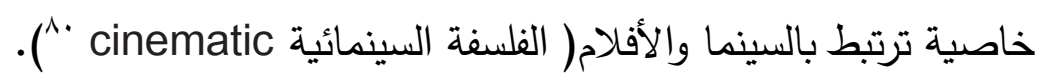
فإذا كانت الإحداث تقف خلفها السلطة السياسية مانعةً سيولتها، فالواقع الافتراضي يعطي المتفاعلين مساحة للانطلاق والتفاعل، لدرجة أم ما لم يحدث واقدياً

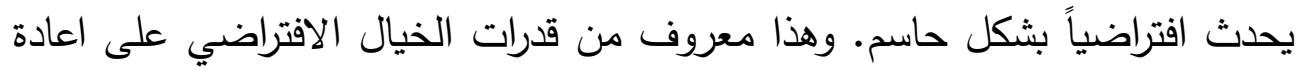
ترسيم الواقع وفقاً لرغبة المتلقي، لأنه في لحظة اندماج مع آثان آثاره. ولذلك كانت

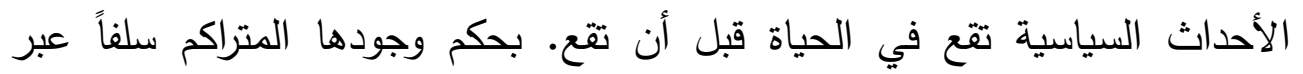

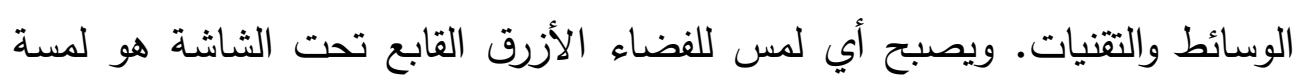
سحرية للأحداث الفعلية.

${ }^{80}$-Paisley Livingston, Cinema, Philosophy, Bergman On Film as Philosophy, Oxford University Press Inc, Oxford New York, 2009, PP 11-38. 


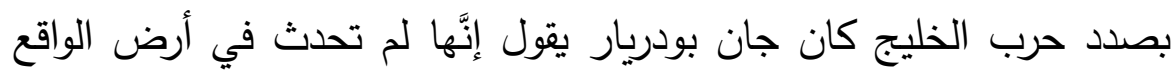

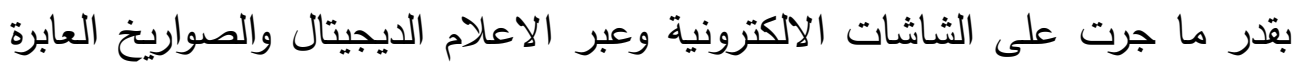

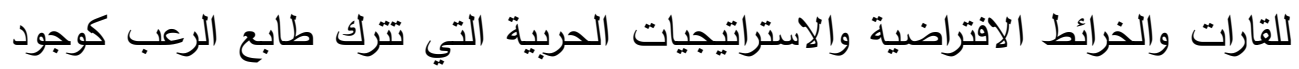

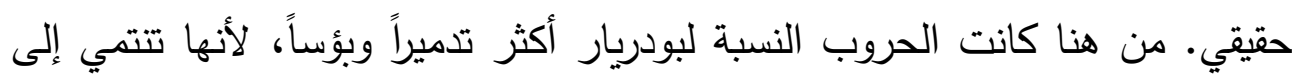

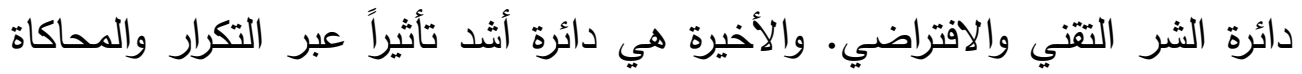
البلاغية التي تمارس استحواذاً على ذهنية المتلقي.

وهذا يأتي من وجهة نظر بودريار نتيجة الخلط بين الواقع والخيال، والخلط

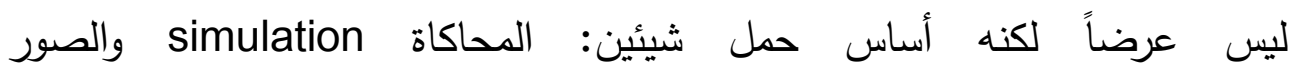
الزائفة simulacrum ... وهما آلية التخييل والنسخ القائمة على المحاكاة والوجود المضاعف والقابل للتكرار (السيمولاكر) من حيث استقلاله بالنسبة للواقع الفعلي. والمحاكاة والصور الزائفة ليستا متعلقتين بإطار اخلاقي بل معرفي وتقني وفني. أي تشكلان بنية عصر ما بعد الحداثة مميزتين لجميع أنشطة الاعلام والعملات النقدية وصور الرأسمالية واللغات وانتاج السلع وأسواق المودات والأزياء وأدوات التجميل والاقتصاد المعرفي والرمزي. وهي ظواهر وليست مغردات طبعت الفيت عصراً

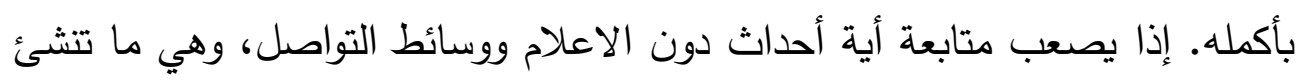
بلاغة خيالية تكرس الحدث وتشوهه بالطريقة نفسها. والتشوه أمر حتمي يستحيل

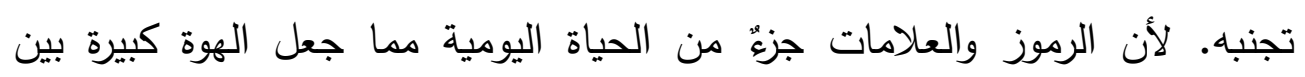
الأصول والصور، تللك الهوة هي الثيء الضروري لدرجة وجود الصور بلا أصول. والصور الزائفة (السيمولاكر) هي علامات تحمل مخزون التشويهات للأصول، وهي كذللك لا تكف عن استبدال نفسها داخل الثقافة الجارية، والأهم أنها تستقل في بنائها نحو الأصل. فاذا كانت الأصول لها سلطة مرجعية ما، فالسيمولاكر

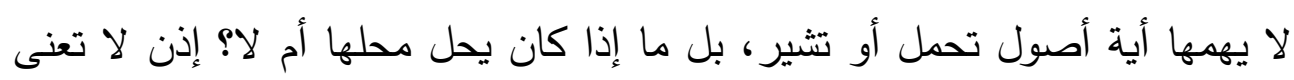


السيمولاكر بقانون الهوية الأرسطي مع الأشياء، إنَّها تبلور هوية مناوئة للواقع، مناوئة للسلطة التي تمسك الأصل أو تتحدد على غراره. وذللك له أربع مراحل متتابعة مرت بها الصورة الزائفة: 1- النسخ: حيث تكون الصورةُ انعكاساً لواقع أساسي basic reality، والصورة

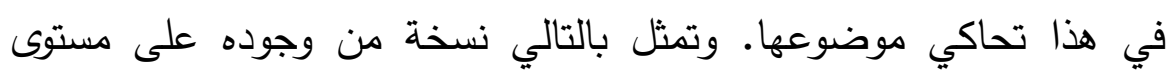

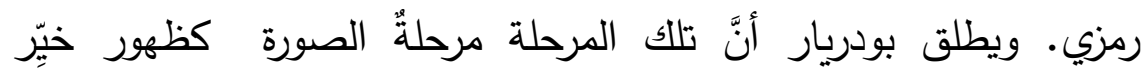

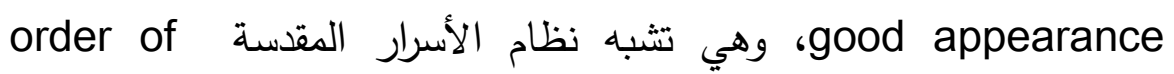
.sacrament r- التثويه: عملية تحريف لواقعٍ أساسي، وهي تتخذه قناعاً للتعبير عنه، لكنها

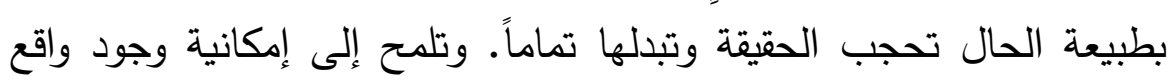

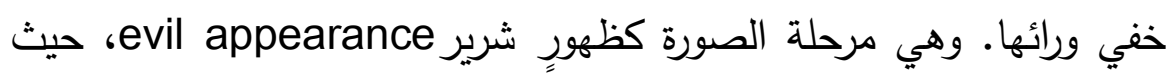

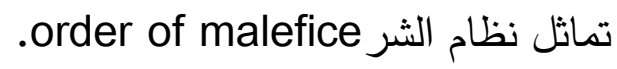

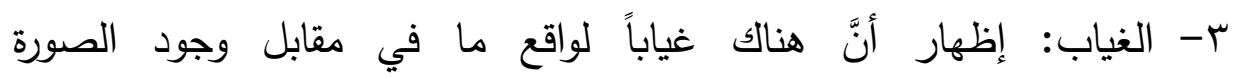

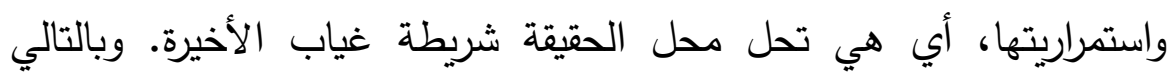
فالرموز والعلامات تحضر نيابة عنها. ولا يتم تصوير أي شيء بل وتصبح

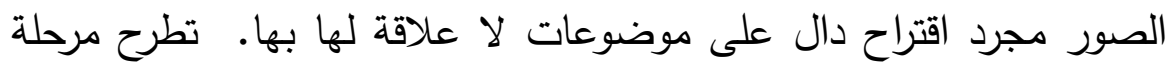
الصورة هنا كنوع من اللعب على مستوى الظهور وهي تثبه نظام السحر والثعوذة order of sorcery ع- التزيف: بروز الصورة وتجليها في شكلٍ نقي خاص، حيث لا علاقة

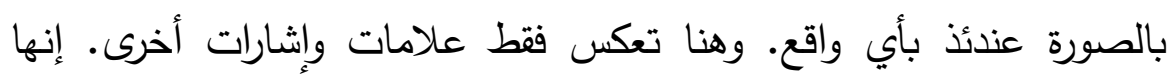
مرجلة الواقع الفائق الذي يحيل إلى صور افتراضية جملةً وتفصيلاً. وتصبح جميع تفاصيل الثقافة منتجاً مزيفاً بهذا المضمون. حيث المئ المحاكاة الكاملة 
للعلامات وقد غرقت في متاهات من الصور الواحدة وراء الأخرى بلا نهاية'

ما يهم لو أننا قسنا ذلك على الجسد الافتراضي، فإنَّه سيكون صورة مزيفةً،

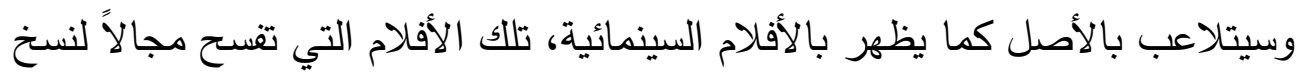
الواقع وكذلك تثويهه بدرجة أكبر. كما أن هذا الجسد يضرب تجاه دلالته مستقبلياً،

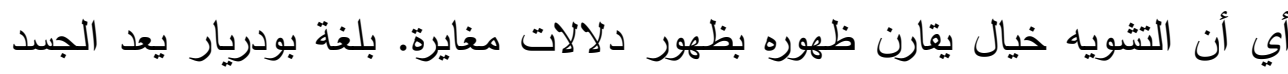

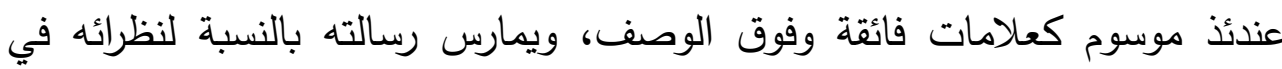

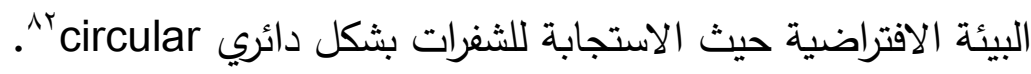

ثالثاً: اللعب والأيروتيكا erotica:

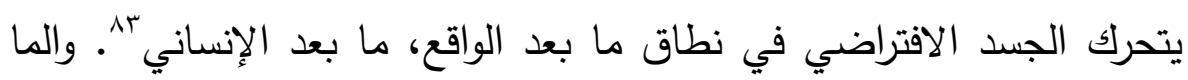

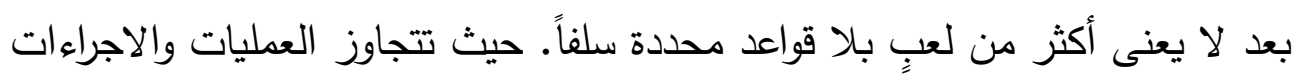

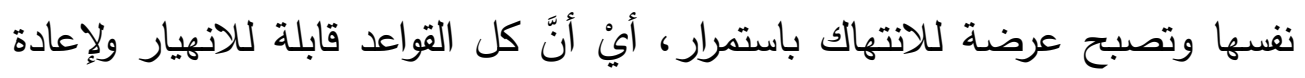

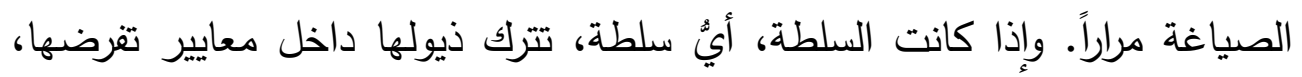

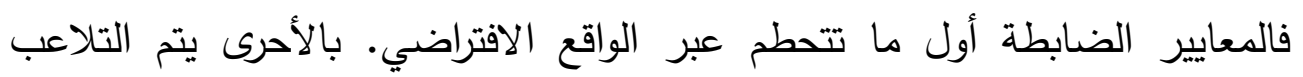

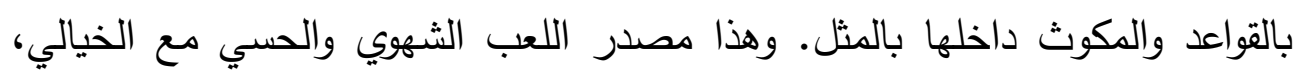

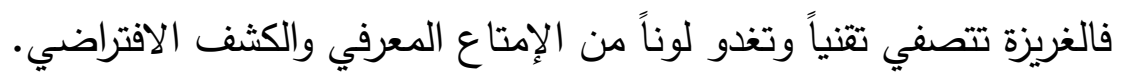

لأنَّ كلمات: play ولعبة game وألعاب games ... كلمات لا تُقهم إلاًّ بناء على تحطيم قواعد وإعادة صياغة قواعد جديدة أكثر مرونة، تأتي المرونة من طبيعة

${ }^{81}$ - Jean Baudrillard, Simulations, Translated by Paul Foss, Paul Patton and Philip Beitchman, Semiotext[e], United States of America,1983. PP11-12.

${ }^{82}$-Jean Baudrillard, Simulacra and Simulation, Translated by Sheila Foria Glaser, Michigan University Press, 1980. P 52.

${ }^{83}$-David Hakken, CYBORGS@CYBERSPACE?: An Ethnographer Looks to the Future, Routledge, New York-London, 1999.P 91-92. 
الموضوع وقدرته على التغاير • إنَّ فضاء اللعب واسع بما لا يحد ولا يتعين من أول

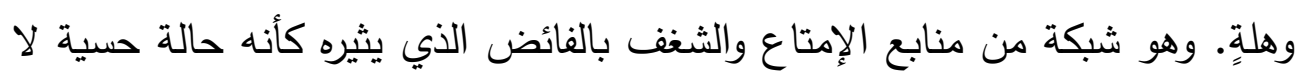

$$
\text { تصنف في حدودها المعروفة. }
$$

هكذا "خلال حياتتا العملية، معظمنا يفقد التواصل مع مصادر قوتنا الشخصية.

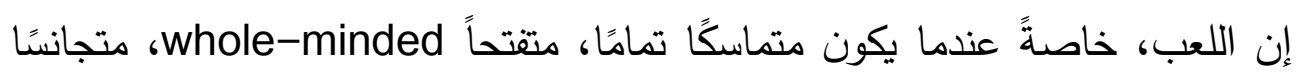
بالكامل، هو تجربة وتعبير عن القوة الثخصية. عندما نلعب ونلعب بشكل كامل،

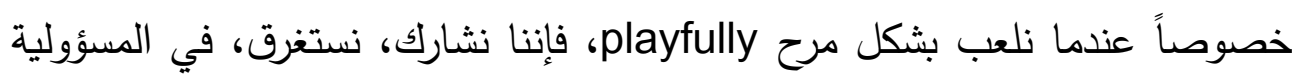

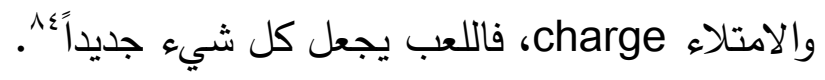

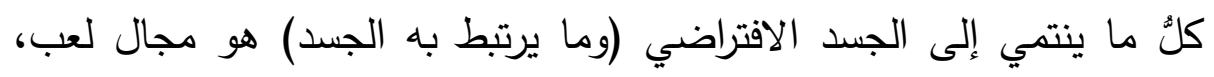

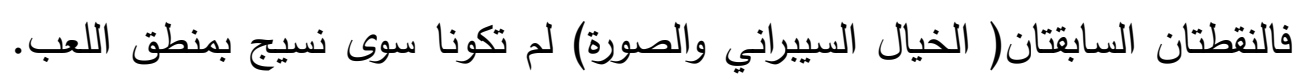

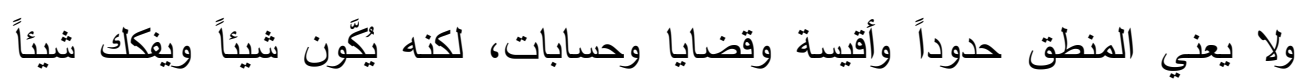

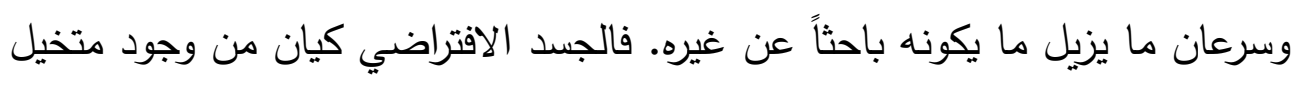

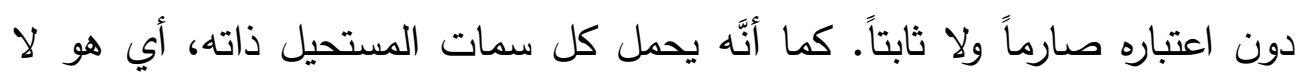
يتجمد على شاكلةٍ بعينها ويفتح سياقاً للمجهول.

والحقيقة أنَّهَ لو كانت الأجساد دالاً للرغبات وبالتالي تحاط بالنظر والترقب،

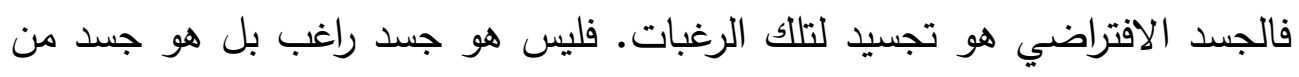
خلال الرغبة فيه( نفسه). وهو الكيان المتخيل مثلما يراه الآخر بكلِّ سحرِ وبأسطورته الخاصةٍ.

لو كان الآخر يرغب في جسد افتراضي بسمات نوعيةٍ، فالجسد هو المرسوم

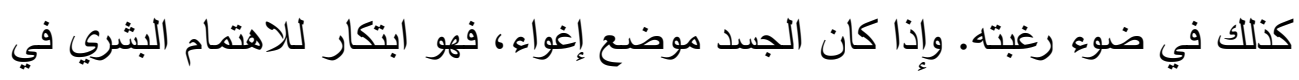

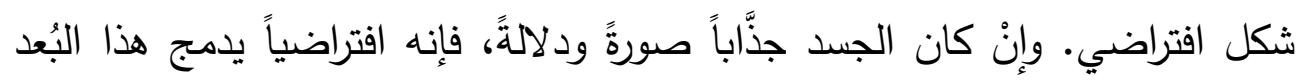

${ }^{84}$-Bernard Louis DeKoven, A Playful Path, ETC Press, U. S.A, 2014. PP 83, 152. 
ضمن حضوره. ولئن كان الجسد مُحرِكاًا للدهشة، فهو مصمَّم بطريقة غير مألوفة

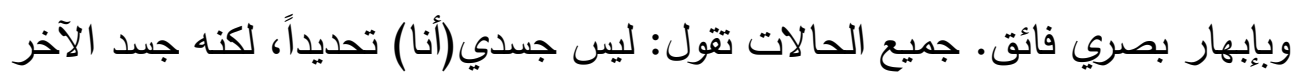

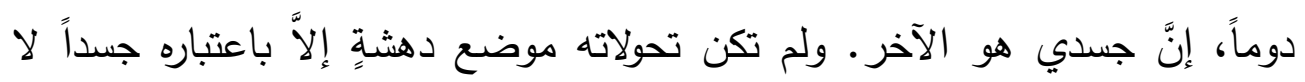

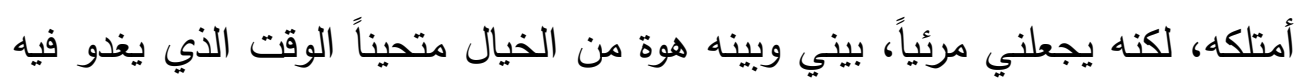
موضوعَ (رؤية).

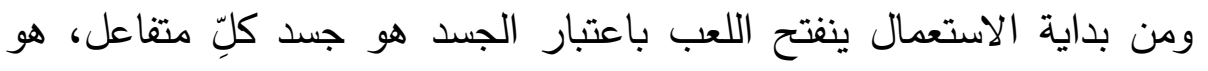

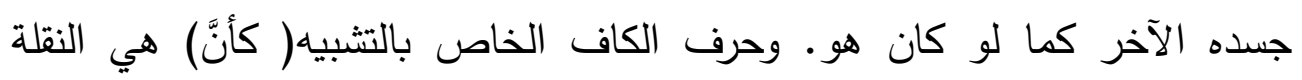

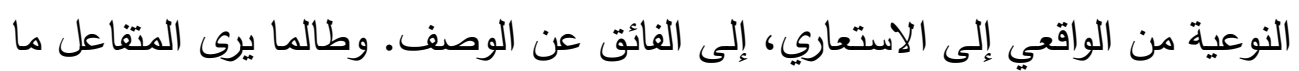

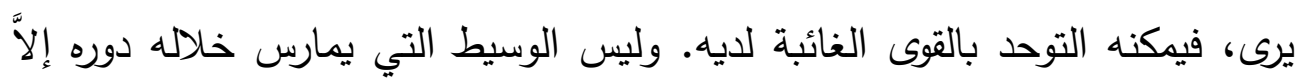

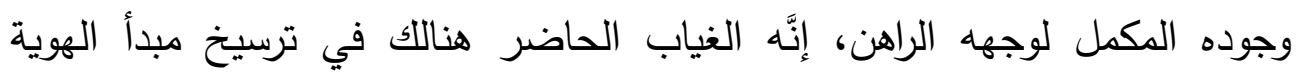

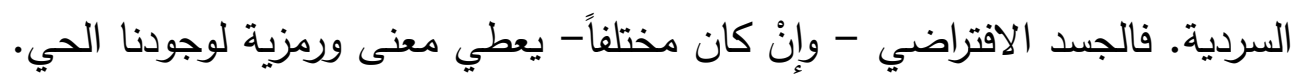

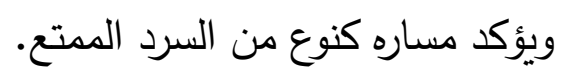

ليس الجسد الافتراضي نقيض وجودنا، لكنه بمثابة فائض التخيل الحر، والخيال

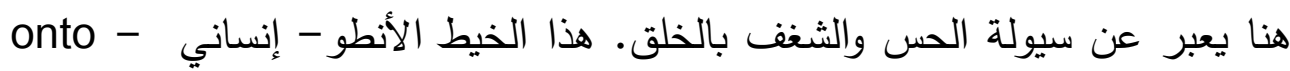

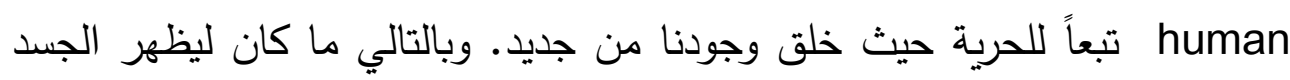

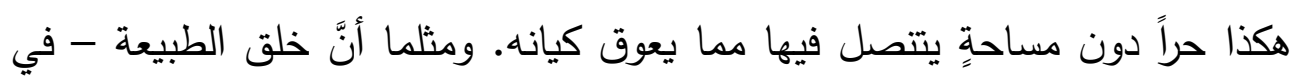

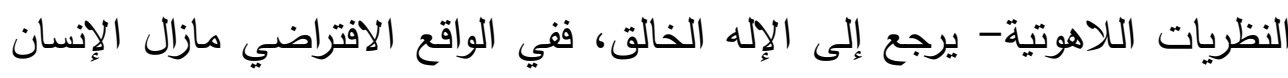

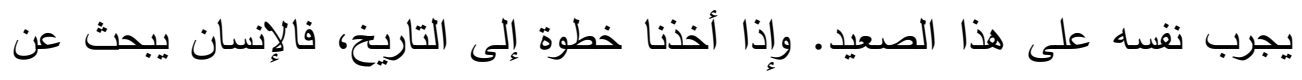

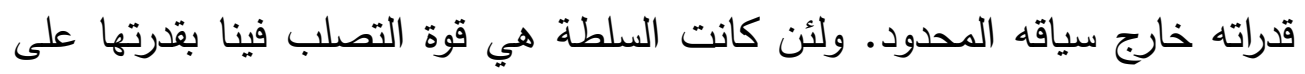

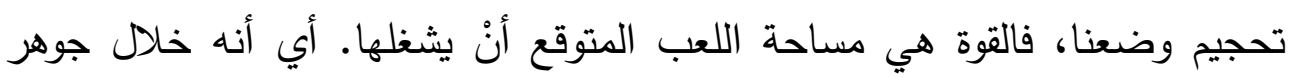
السلطة وهيمنتها، ينشأ اللعب، وكما تكون عنيفة ومسيطرة بإمكان اللعب أنْ يكون حراً التها ولا يتوقف لدى مرحلةٍ بعينها. 
إذن ينشأ اللعب بناء على أصداء الدفاهيم التي تربط المتفاعلين بالعقل والحقيقة

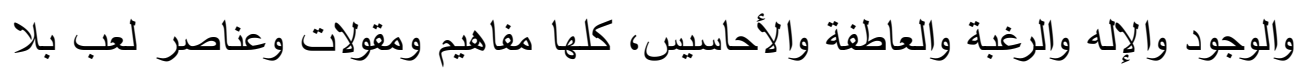

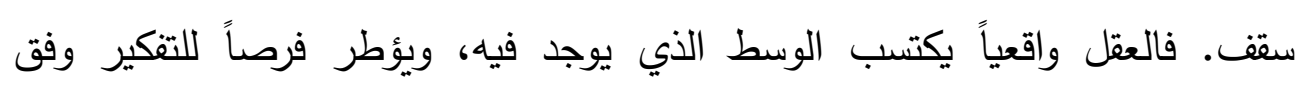

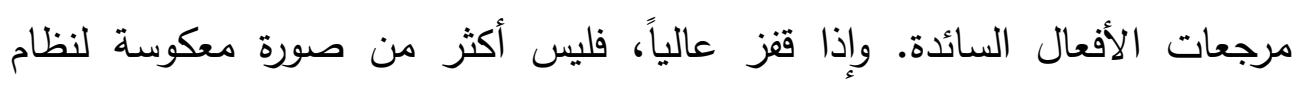
التفكير، ولذلك سيقع العقل في براثن السلطة مرة أخرة بحكم ميل التأقلم معها. أما فاليا،

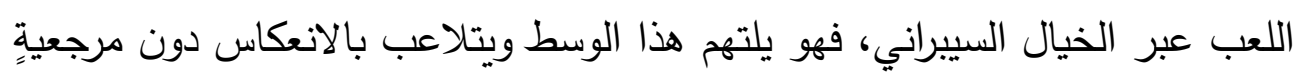

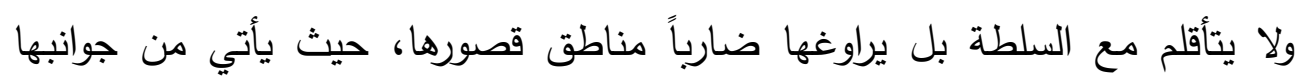
العمياء حين تعجز عن فرض وجودها.

كذلك تمثل الحقيقة مجال لعب ومعرفة، فلنلاحظ أن كل الحقائق - سواء

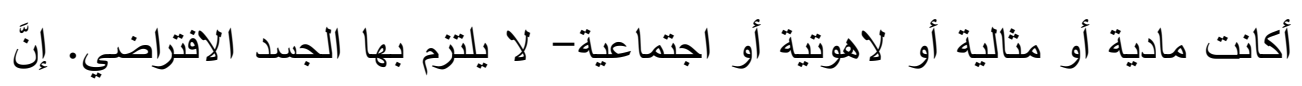

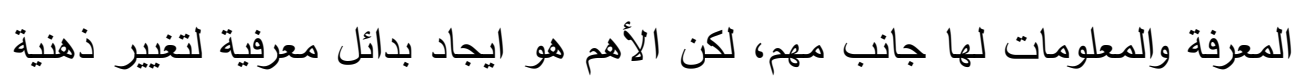

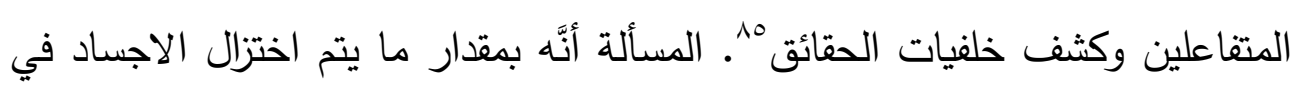
ظواهر مادية بيولوجية، ينحو الافتراضي إلى اللعب باشكال هجينة وغير معقولة.

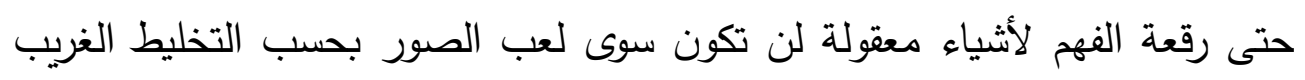

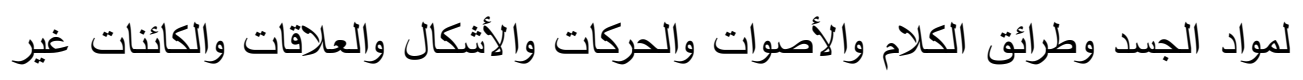
المألوفة ( فيلم آفاتار ). وذللك نوعٌ من اللعب له طابع ثنائي التأثير :

أولاً: تفريغ الكيانات المفاهيمية والوجودية التي ترتبط بالمعاني في حياتتا العامة.

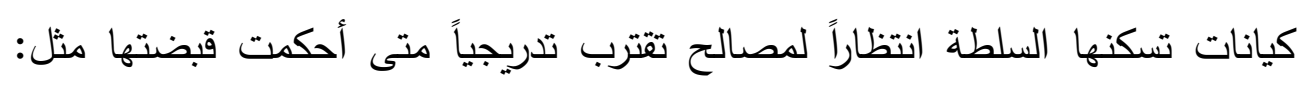

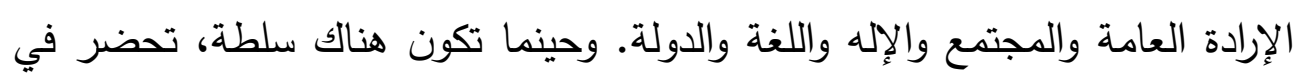

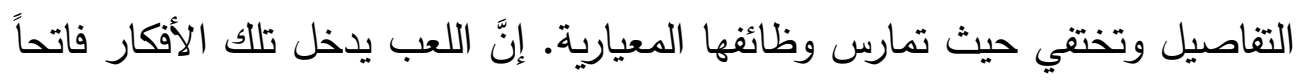

\footnotetext{
${ }^{85}$-David Hakken, The Knowledge Landscapes of Cyberspace, Routledge :New York \& London, 2003. P173.
} 
أبعاداً أخرى. فالبيئات الافتراضية لا تحاكي الأشياء، إنما تجد بُعداً جديداً خارج

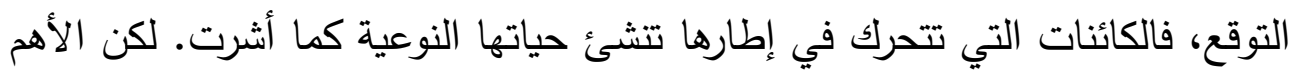

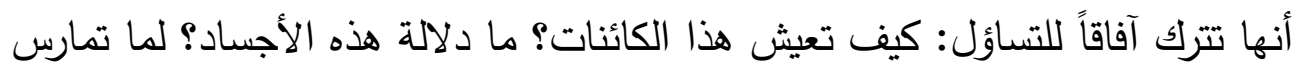

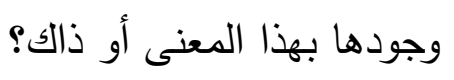

ثانياً: إثارة أخيلة فنية وتقنية أكثر اتساعاً وخصوبة. لأن اللعب هو احتمال المزيد من

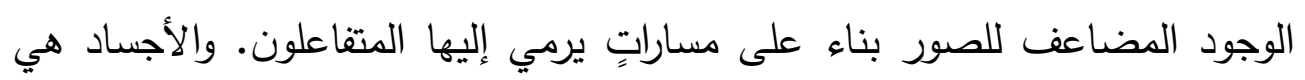
وجود مضاعف double على الأصالة.

ذلك لأنَّها تصور عالماً خاصاً، ثم أنها تضمر وجوداً على مستوى وجودنا

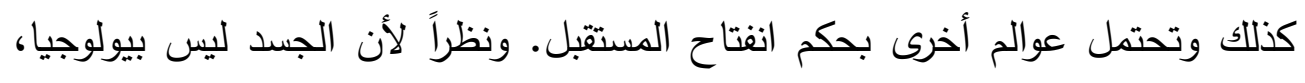

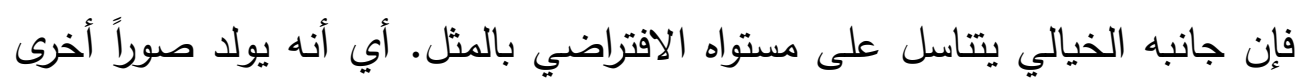

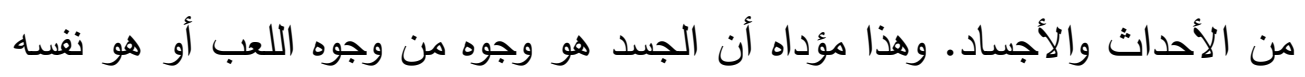
مبني ومتحرك وله كافة التطبيقات الدالة على طبيعته.

حين يعرفنا اللعب شيئاً، فإنه يطرح البدائل اللامتناهية للأشياء. فلم يكن مدكنا

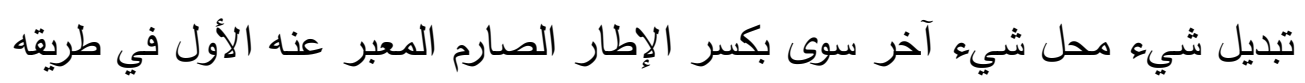

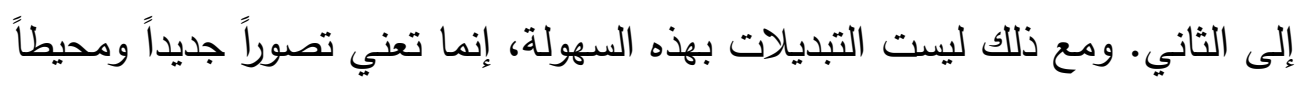

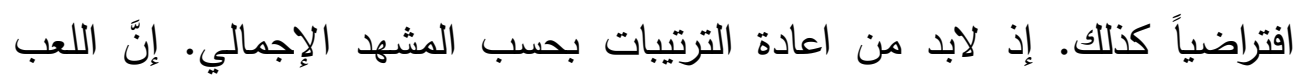
يقتضي من الجسد أنْ يكون أكثر قابلية للتطبيقات المختلفة من مرحلةٍ إلى مرحلة

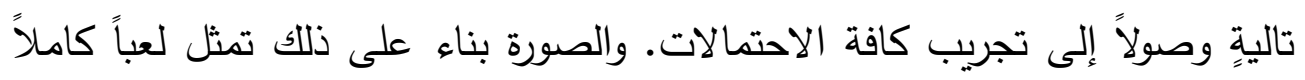

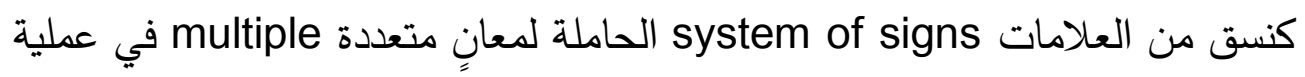
من التأجيل deferral الاختلاف) كما هو الحال في فيلم ماتريكس Matrix، وهو 
فيلم يطرح الظهور الفعلي لعالم الخيال، وكيف ينسج شبكة الأفكار والدفاهيم التي

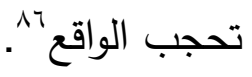

اللعب المتجسد - من ثم- هو ابداعنا في شكل مسارات يمكن تجريبها من زوايا مختلفة. وهو أمر متاح لجميع المتفاعلين بحيث يشعر أحدهم أو سواه بأنه

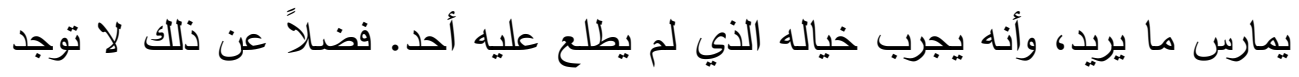
نتائج وخيمة للتجريب، أي هو تجريب بلا خوفٍ. في مقابل السلطة التي لا ترى بديلاً

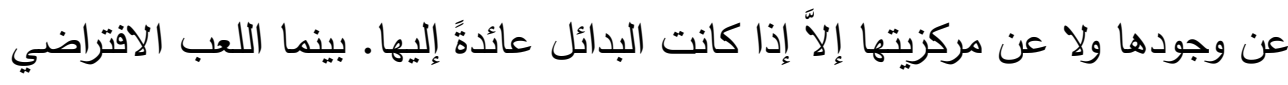

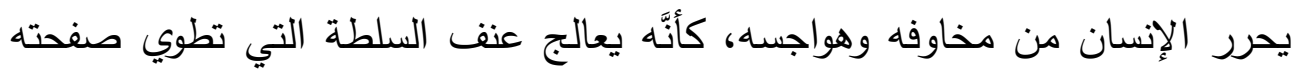

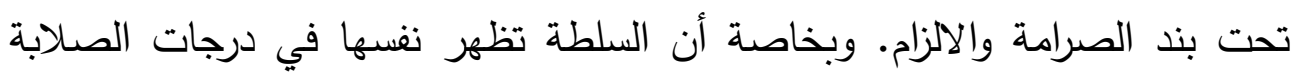
الحائلة دون أية مساءلةٍ. وهي في هذا نوع من استباق النتائج قبل المقدمات نظراً لقدرتها على التتبؤ الذاتي الذي يسحب وهي وجودها دوماً إلى الأمام.

بصدد السلطة يصعب تجريب غيابها، لأن الآثار المترتبة على ذلك الغياب

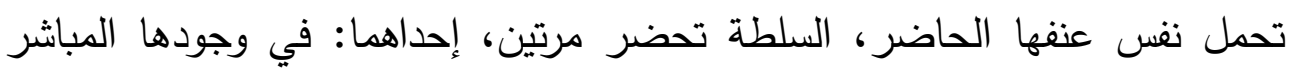

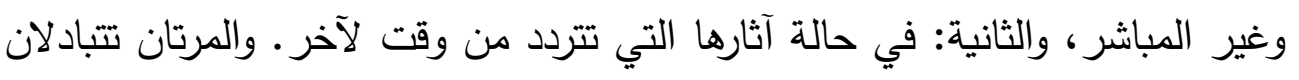

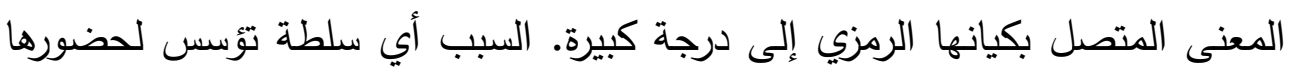

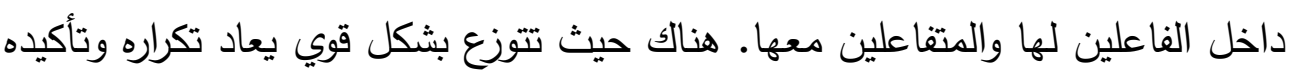

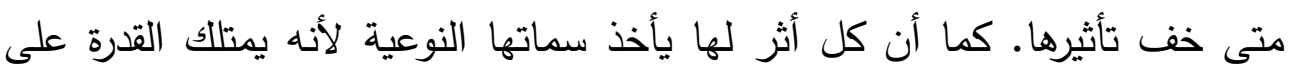
استتبات جذورها البعيدة.

أي أثر للسلطة هو امكانية عودة السلطة ذاتها، وتترك موضع خفائها الضمني ذاكرةً تسرد ما تقول. ومع وجود الثقافة تصبح علاقات الناس وتصوراتهم حاملة

\footnotetext{
${ }^{86}$-William R. Oliver, The Matrix : A Metaphorical Paralell To Language, A Thesis Submitted to the University of North Carolina Wilmington in Partial Fulfillment of the Requirements for the Degree of Master of Arts Department of English University of North Carolina Wilmington, 2008.P 1714.
} 
لفيروسات السلطة الناقلة لكافة معالمها. حتى أنَّ نجد التاريخ هو الحاضنة الزمنية لهذه البذور والتصورات، وليس بعيداً أن تتبت في عصور تالية وفي أشكال ورموز

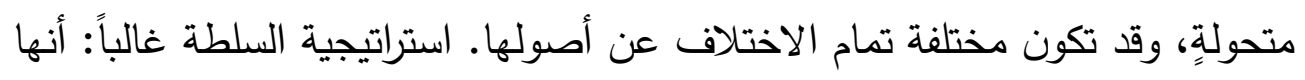

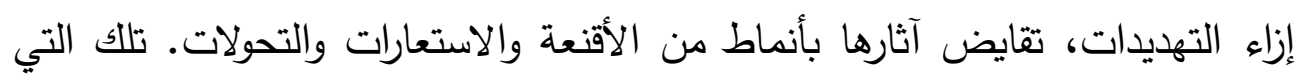
تغِّب وعي الأفراد اليقظ مقابل ظهورها في أبسط تفاصيل حياتهم وبالزخم نفساءه. ولعل ذللك يولا مفهوم الأداء الذي يميز اللعب. والأداء هو مداومة الإيقاع

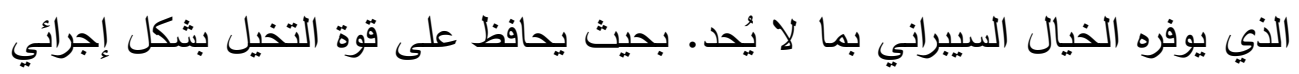

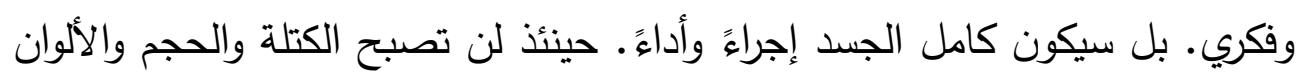

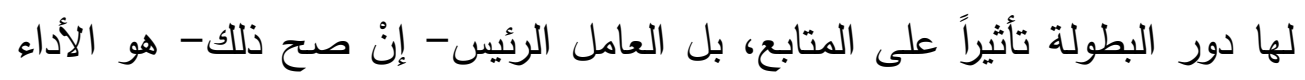
التثثيلي representative performance لها في الجسد الافتراضي من قدراتِ واحتمالاتٍ.

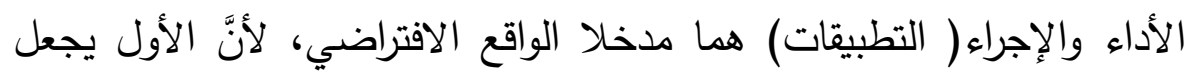

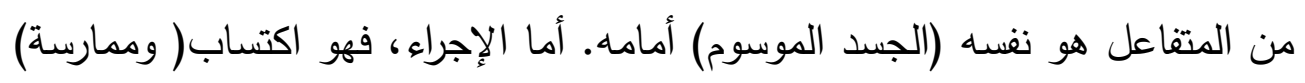

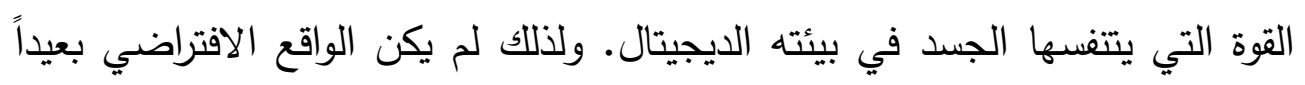

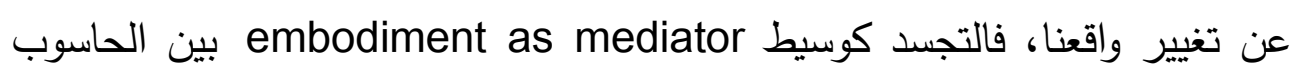
والعالم يمثل الثيء الجديد في التكنولوجيا الراهنة: ولا سيما دوره في جعل فئل عالمنا الحي تقنياً بشكل عالِّ، والتجسد هو الرابط الأول في ثنائية الجسد والعالم بدرجة التهات

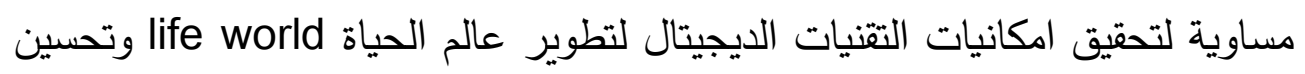

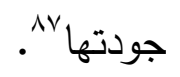

ولعلنا لو لا حظنا سمة الأداء في الواقع الافتراضي، سنجد أنَّها سمة بارزة

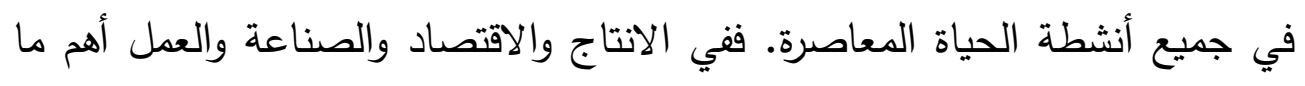
${ }^{87}$ - Mark b. N. Hansen, Bodies in Cod: Interfaces with Digital media, Routledge, Taylor \& Francis Group, LLC, New York, London, 2006. PP28 -29. 
يلتزم به التطور هو الأداء. للرجة أنَّ استمرارية الانتاج على وتيرة ثابتة يكون له

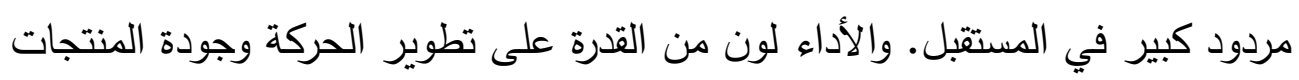

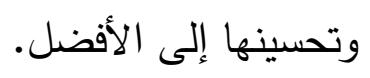

والأداء في السياسة أهم ما يميز السياسيين، فالبرامج والخطط التي يطرحها

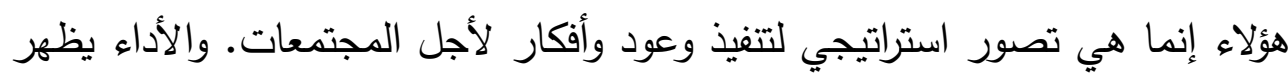

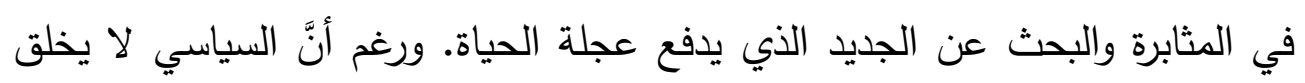

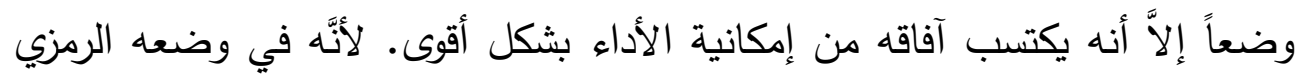

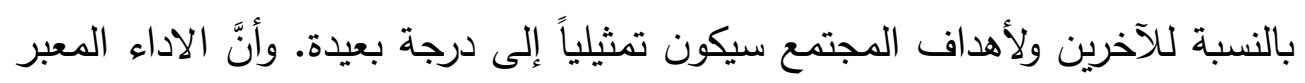
عن نشاطه بمثابة الفعل اليومي لتنفيذ البرامج والرؤية السياسية.

وربما السياسة هي الأقرب لمجال الافتراض أكثر من أي مجال آخر، لأن

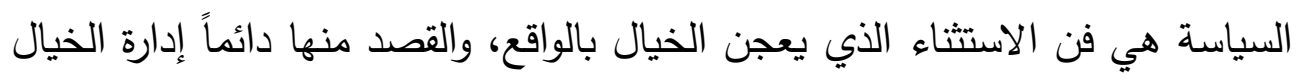

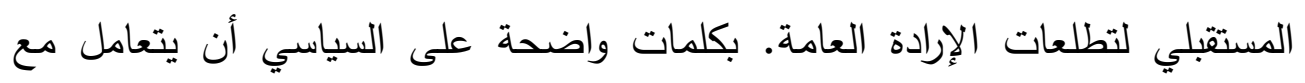
الرأسمال السياسي والاجتماعي(الأفكار والمعطيات) كنوع الأداء الذي يطور من آلئي آلياته

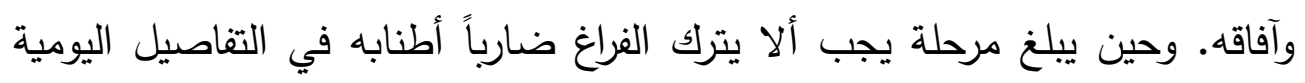
للأفراد والجماعات بل عليه أن يملأه دائماً.

والاداء ضمن الحياة الاجتماعية هو كنللك يرتبط بتمثلات استعارية في المجتمعات، فالثقافة تتيح لفاعليها أن يأخذوا أدواراً خيالية، وهي التي التئي تعطي هؤلاء

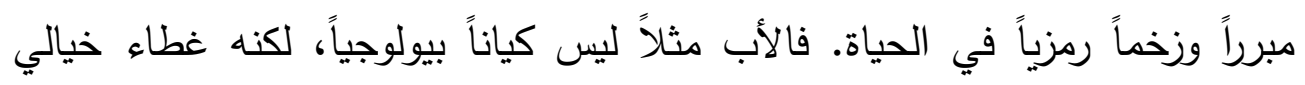

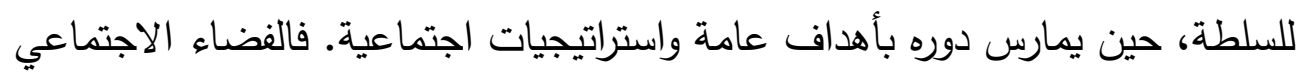
هو الوجه الآخر للسلطة، وحتى يكتسب الأب بعضاً مما يريد، فإنَّه يتمثل استعارة

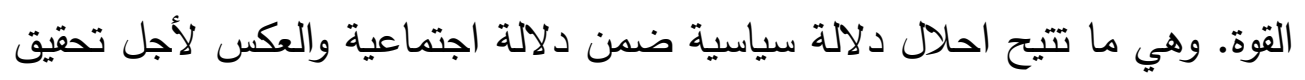


معنى القوة. وعلى الأب دوما البحص عما يجعله متماسكاً ونافذاً في الظواهر الاجتماعية. ولذلك فنمط الأبوة نمط ثقافي تتيح له السلطة انتشاراً وفاعلية. إنَّ أداء النمط هو عملية ثقافية تتسع لمواردها الإنسانية في رسم الأدوار

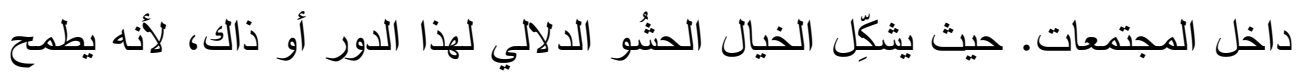

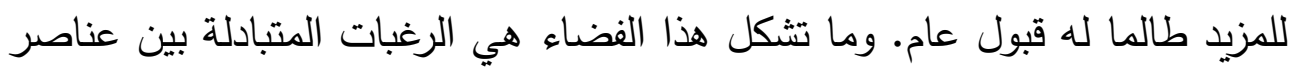

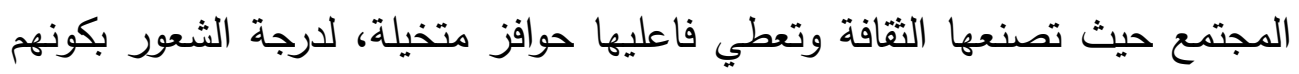

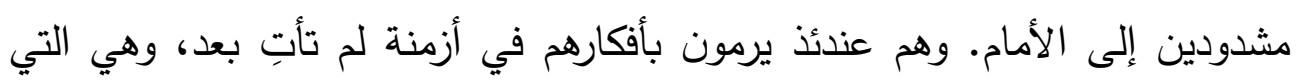
يتوهمون قدرتهم على بلوغها.

أما الأداء في الواقع الافتراضي، فيتحقق بأفكار شبه مكتملة، فهو يتعامل مع

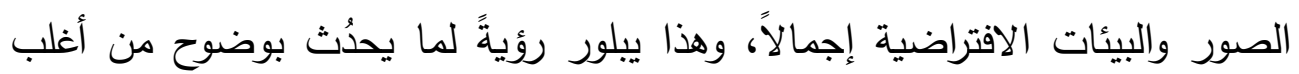

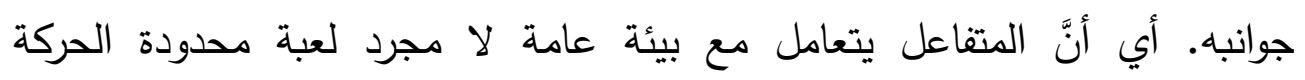

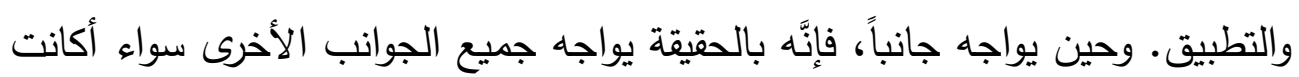

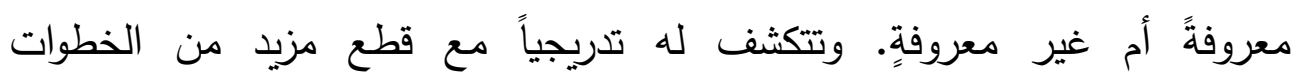

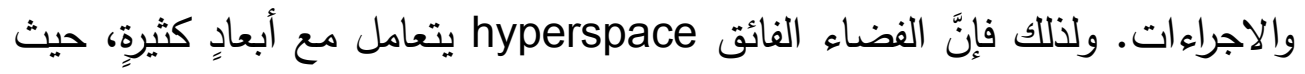

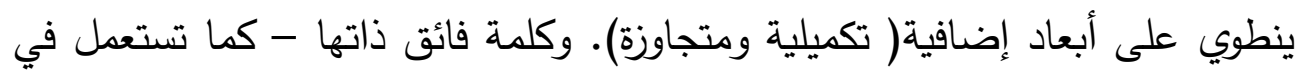

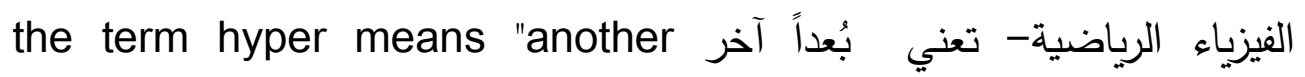
dimension" يتجزأ من الكلمة ^^.

إنَّ اللعب ينطوي على دلالة الثغف الذي يجدد مبرراته، لكونه لعباً -بلغة الفلسفة - غير مكتف بذاته. اللعب يحمل سمات الوسيط الذي يوجد فيه، ويسمح لئه

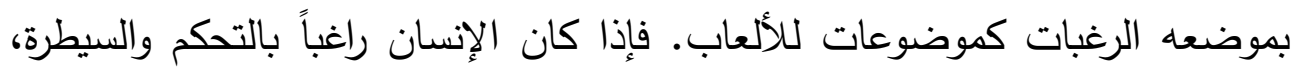

${ }^{88}$ - Michael Heim, Metaphysics of Virtual reality, Oxford University Press, Oxford New York 1993. P 30 -31. 
فاللعب هو الممارسة التي تعطيه اشباعاً لا يتوقف، بل بواسطة الإجراءات يواصل البحث عن المزيد وبذل المحاولة تلو المحاولة.

ومن ثم كان للعب طابحٌ كلي، أي ليس اللعب في الفضاء الفائق جزئياً بحركةٍ

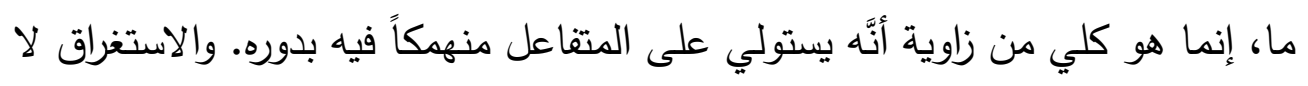

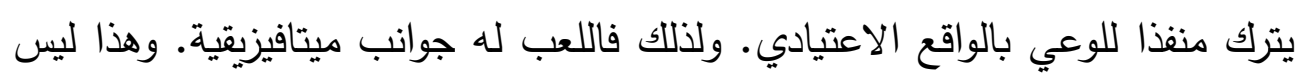

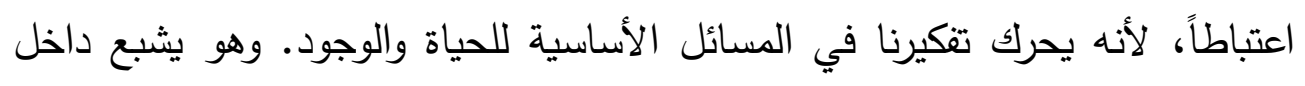
المتفاعل رؤيته للكون باعتباره يجرب إجابات بالواقع في مجمله. إنَّ البيئات

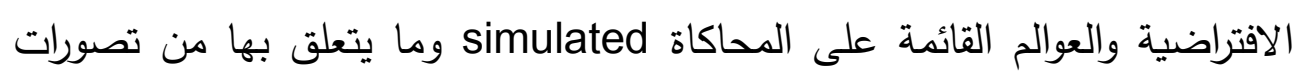

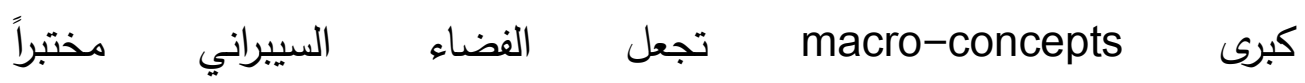
ميتافيزيقياً metaphysical laboratory، بمثابة أداةٍ ما لاختبار احساساتتا العميقة

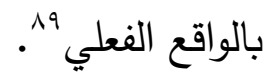

ثمة أسئلة فلسفية يثيرها الواقع الافتراضي: كيف تتكون لجسد الإنسان هوية

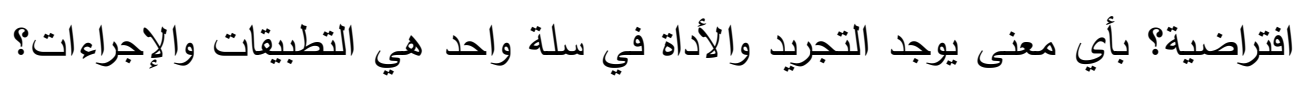

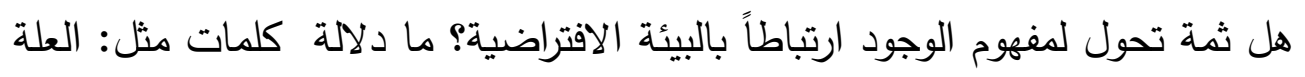

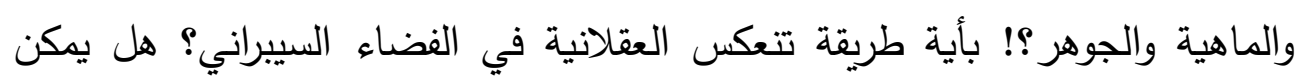

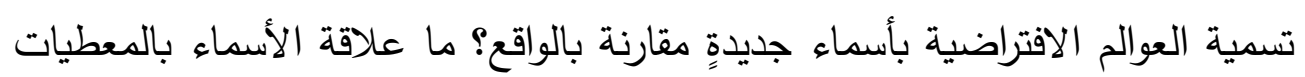

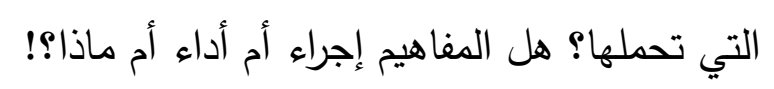

جميع الأسئلة لا اجابات نظرية لها، هي تُعاش وتجرب عبر مغامرة ممتعة،

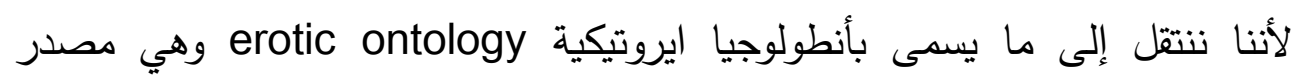
الاستغراق فيها كوضعية عاطفية وجسدية واعدة باللذة والإشباع. فنحن نحب لإنب الأسطح

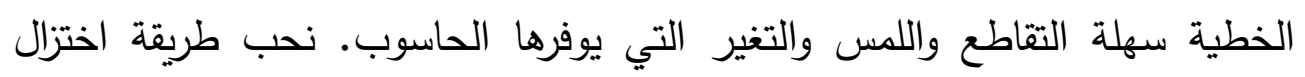

${ }^{89}$-Ibid, P82. 
الحاسوب لكم مهول من التعقيد والغموض في بيئاته الافتراضية، وقد صاغ الأشياء

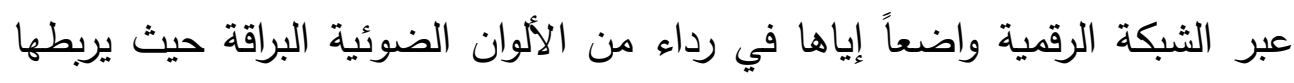
بأبنية هندسية دقيقة التفاعل والتنكلك".

إذ ذاك نشعر بكوننا نكتشف عالماً سرياً نود أنْ نرتاده ونعرف مجهولاته. إنَّ

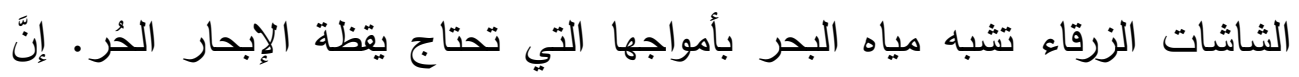

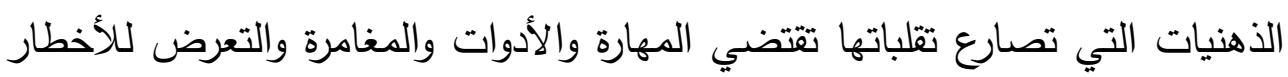

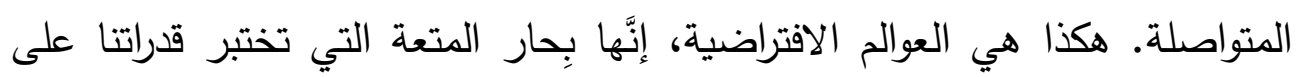
التحمل وتستنزف مخاوفنا ومخزوننا من الأوهام.

وفي هذا الإطار نختبر السلطة، لأننا نرى المعطيات التي تفرزها عبر الثبكة

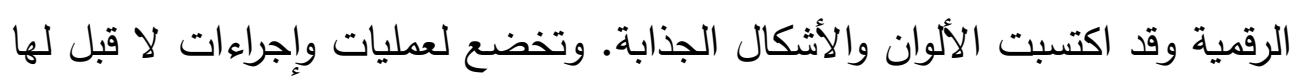

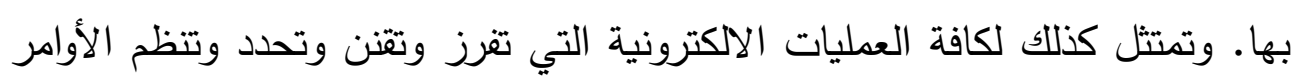
التي تطلقها من حين لآخر . وتبدو السلطة غارقة في تفاصيل كثيرة ولا يمكن تجميع قدرتها إلاًّ بحسب المتفاعلين المتداخلين معها في البيئة الافتراضية نفسيها.

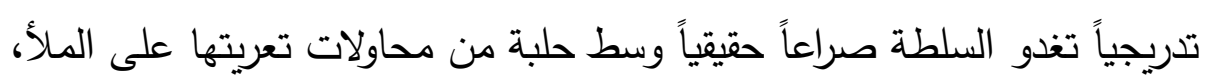

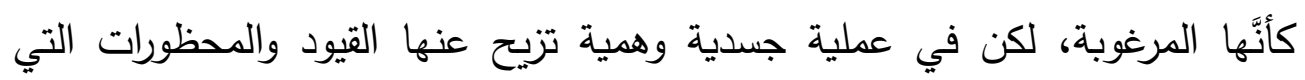

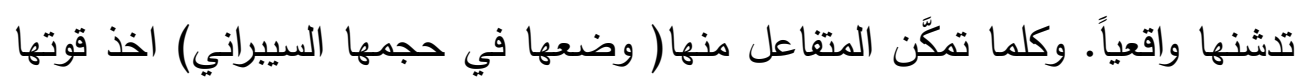

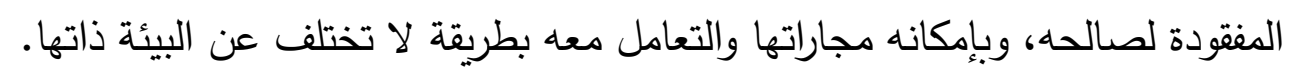
إنَّ التعامل مع السلطة سيبرانياً يفترض وجود قواعد نوعية لا حاكمة، أي الي العافي

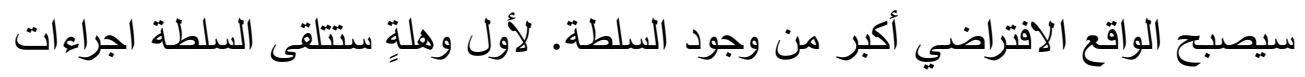

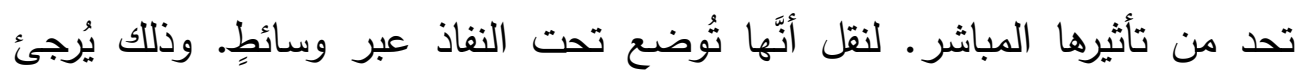
السلطة التي هي بالأساس ترجئ سواها، فلا سلطة هنالك دون توقيف لـتلقيها.

90 - Michael Heim, Metaphysics of Virtual reality, P 84. 
والسلطة في هذا الاتجاه توضع هي تحت المساءلة، لأنَّها لا تهيمن على فضاءٍ لا تمتلك أدواته ولا أساليب الخيال فيه.

لعلَّ عمليات القص واللصق والتقطيع والتأطير تضع محتوياتها في حالة أخرى بخلاف ما تقول، من هنا فالسلطة تتحول إلى نصوصٍ وأشكال ونسيج تصويري. عندئذ تصبح جزءاً من الأنطولوجيا الايروتيكية للفضاء السيبراني. وهذا معناه أنساه

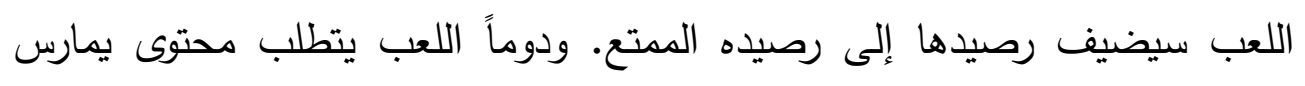

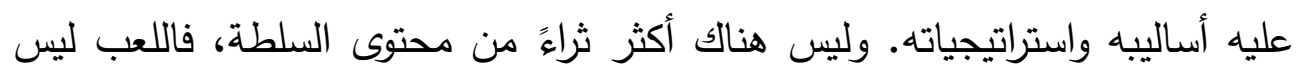
فوضوياً ولا خبط عشواء، لكنه يشتغل على خلفياتها الأعمق.

من ثنَّ فإن علاقات الثغف بالحواسيب، وبالجرافيك و graphics والنصوص

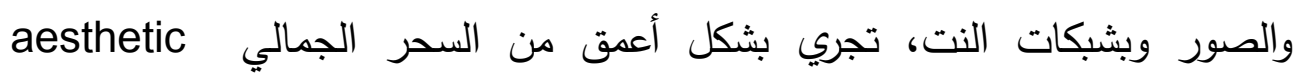

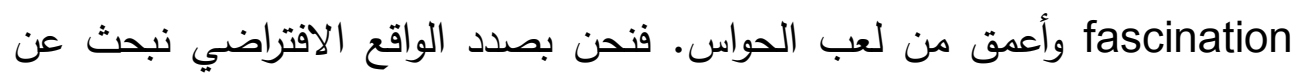
بيت للعقل والقلب جنباً إلى جنبٍ. إن سحرنا الرائع الذي نشعر به لهن عند استعمال

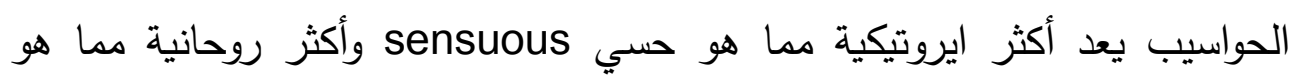

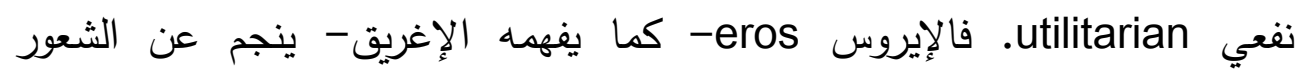
بالقصور insufficiency والنقص inadequacy. وإذ تحقق المشاعر الجمالية لعباً

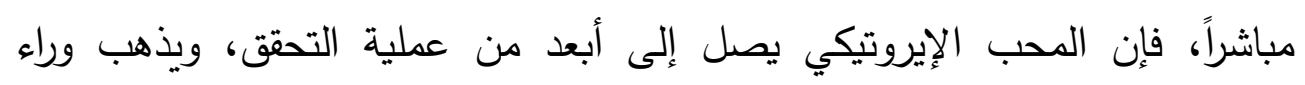

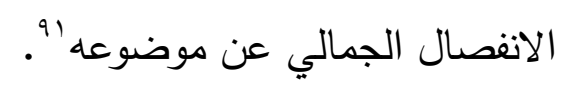

هذا الربط واضح في الهوس بوسائل التواصل الاجتماعي social media،

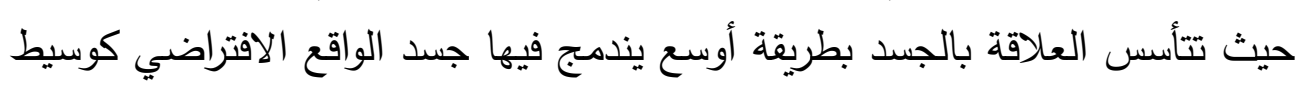

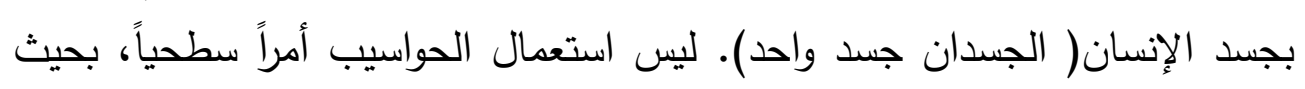

${ }^{91}$-Ibid, P 84. 
تتقطع علاقاتنا بمجرد الاغلاق. لكنها تمثل خيالنا الذي نعيش فيه، هي تقنيات تحمل أسرارنا ووجودنا.

التقنيات الإكترونية تتدمج في كياننا كجزٍ لا يتجزأ من وجودنا الحي، أجهزة الهواتف النقالة تدخل بكل قدراتها كطاقات تواصلية. وبذلك تحملنا ونحملها بالتبادل.

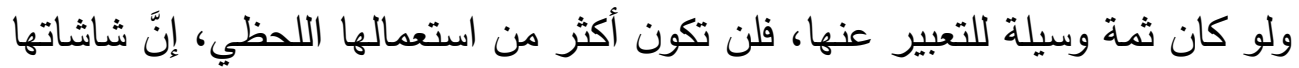

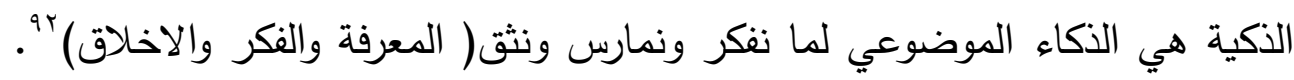

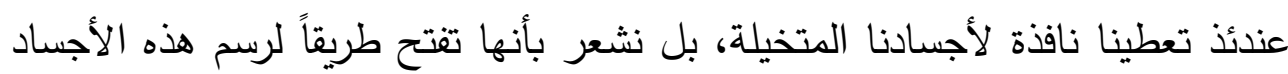

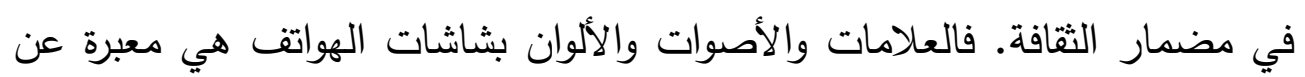

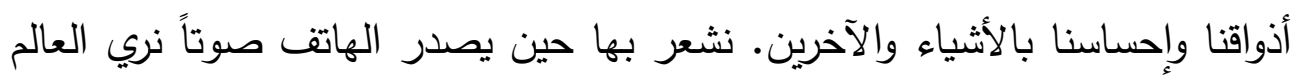

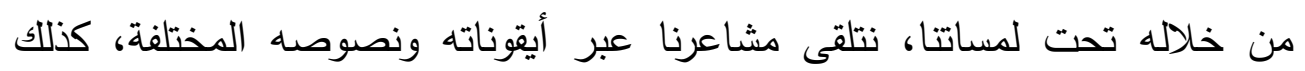

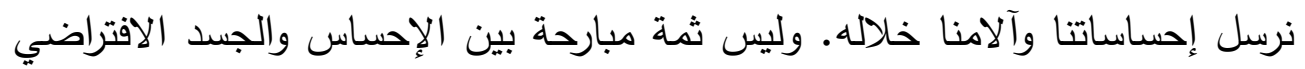

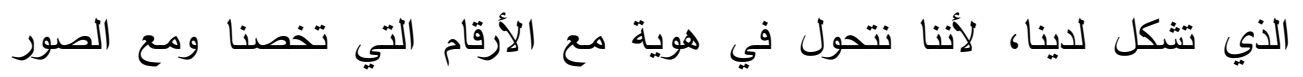

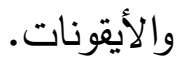

والأهم أننا نفكر عبر الجسد الافتراضي وتأتينا إحساساته بعلامات مرسومة

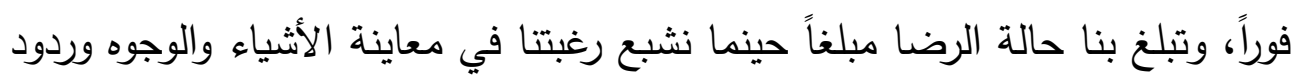

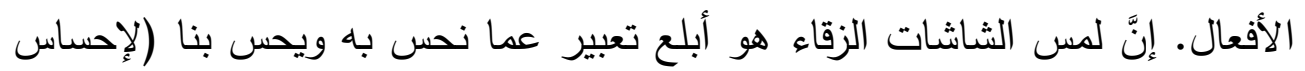
متبادل وإلاًّ لما سُمي كذلك).

92 -Cees J. Hamelink, The Ethics of Cyberspace, SAGE Publications :London, Thousand Oaks , New Delhi, 2000.P $32-40$.

- Fred B. Schneider (Editor), Trust in cyberspace,( Committee on Information Systems Trustworthiness Computer Science and Telecommunications Board Commission on Physical Sciences, Mathematics, and Applications National Research Council), National Academy Press ,Washington, D.C., 1999. 
واللمس كما هو معروف يحمل عدة معانٍ:

1- عملية القيام باللمس. والمعنى هنا دال على وجود الثخص( الفعل). اللمسات تعني الحضور في مواجهة الملموس وجهاً لوجه.

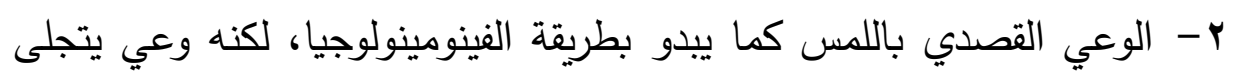
خلاله ماذا هناك من أفعال وتطبيقات إجرائية. وكأن القصد يترجم جوانياً على صعيد الافتراض، أي هو وعي في حالة أداء، قاصد ومقصود في في دائرة أئرة التفاعل والمشاركة.

r- الملموس وهو المعبر عن الاستجابة، لا ملموس دون ترجمة اللمس كثفرة

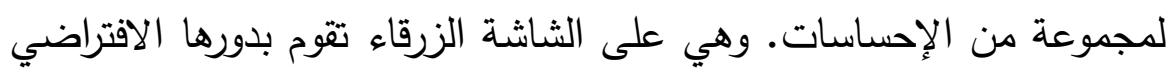
اندماجاً مع الأداء والإجراء.

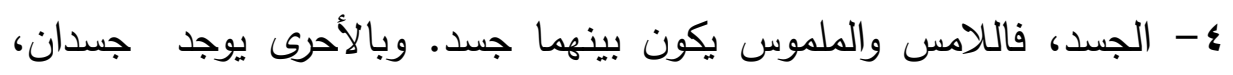

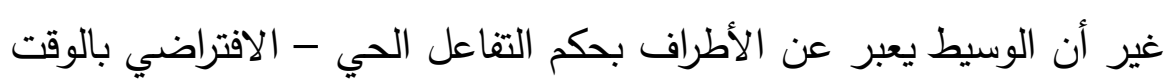
نفسه.

ه- هناك ظهور للواقع الاقتراضي أمام الرؤية، وإذا( تفاعلت) اللمسات مع

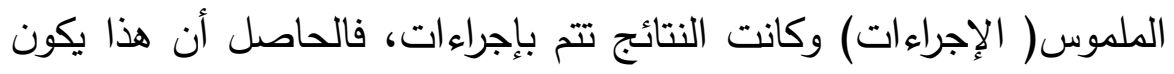

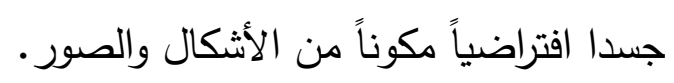
צ- هناك التغذية الراجعة feed back التي يتلقاها اللامس، لكنه لا يتلقاها من

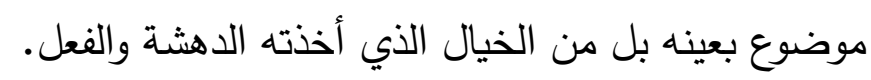

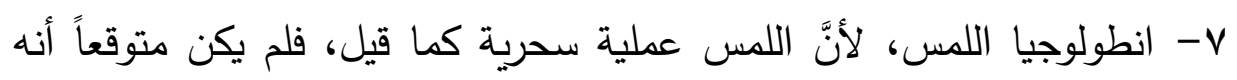

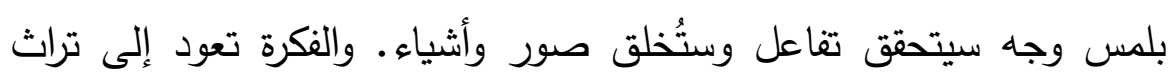
الإنسان ومحاولاته الوجودية لبناء عالمه.

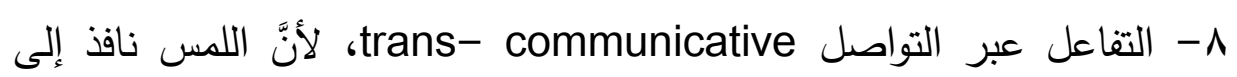
الغير، يلامس الآخر، وجوه الثاشات المختلفة. هناك يبدو ذلك مهاً حين 
ينعدم المكان والزمان وحين يسود الافتراض ويصبح اللمس عبر ( جسد واحد) هو الواقع الافتراضي. ومهما ظهرت اللمسات، فإنها تختلف وتتتوع بشكل لافت ، فمن الممكن إيقاع الأثر لاى كل المتفاعلين عبر المشاركة.

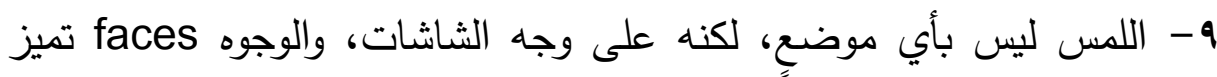

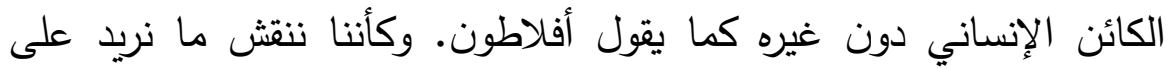

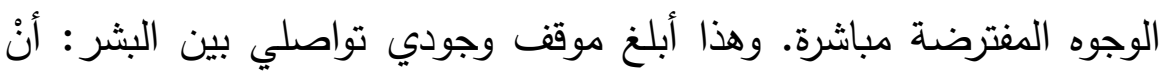

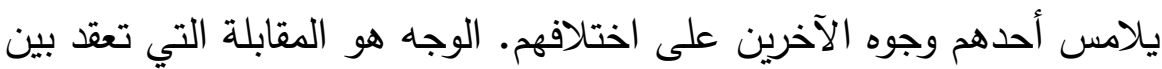

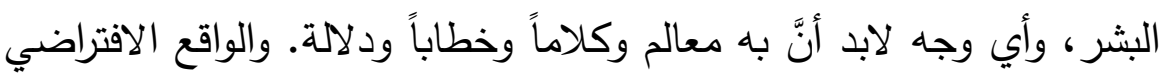
يحجب هذه الوجوه لصالح كثافتها التفاعلية وبالكتابة والرسوم والأيقونات.

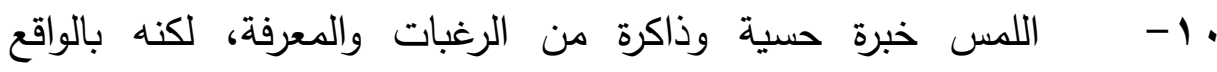

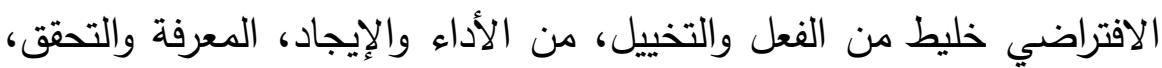
الفكر والغريزة، البهجة والترقب.

11- اللمس بهذا يعد حدثاً event بمله الكلمة، حدث يلخص قدراتنا

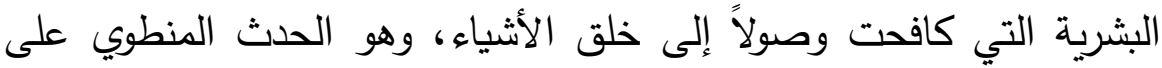
تغيير الموقف والواقع، لأن اللمس يدخلنا إلى واقع آخر أكثر إدهاشاً وغرابة.

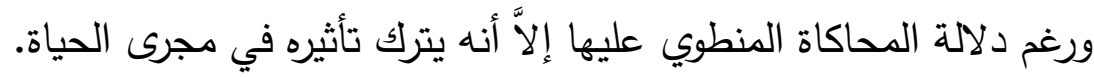

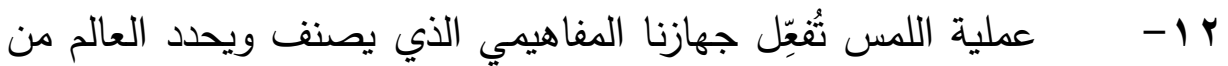

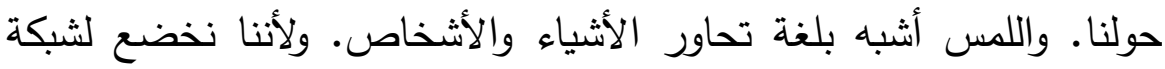
مفاهيم تتوسط بيننا وبين العالم، فاللمس يختبرها ويبرز الأوهام التي يجب الأن أنساء

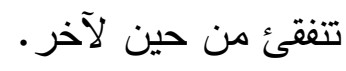

مرة أخرى في فيلم ماتريكس كانت حركة الكاميرا تقوم بذللك الدور، عن طريق

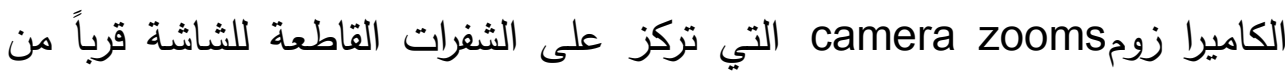
الأشكال والأحداث تحت أضواء كثيفة، شفرات سرعان ما تذوب dissolves وصور 
تختلط ببعضها البعض عبر أشعة المصابيح الكاشفة flashlight في أماكن رسمية

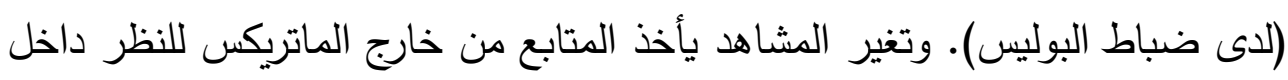

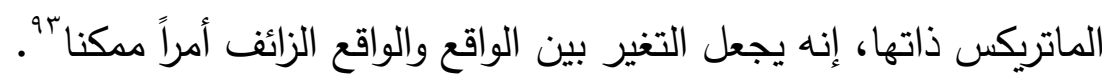

وبالتالي سنعرف أنَّ الماتريكس - وهنا تمثل السلطة- توجد في كل مكان، في

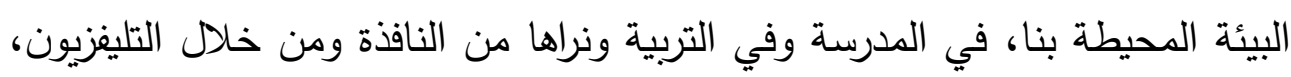

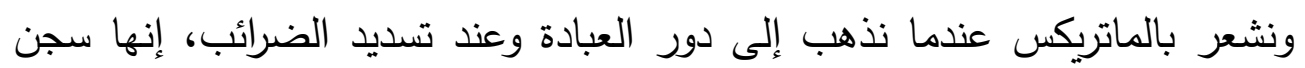

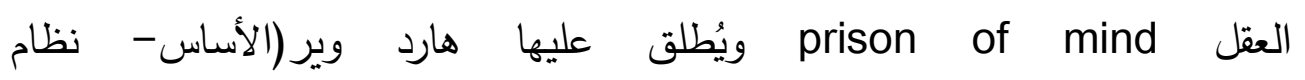
التشغيل)hardware وسوفت وير (البرامج-التطبيقات(software التي تحكم نظرتنا تجاه العالم والأثياء ؟9.

ولندقق أنَّ الجسد الافتراضي يُحدِث (انهياراً لذيذاً) في هذه المنظومة، ويصبح

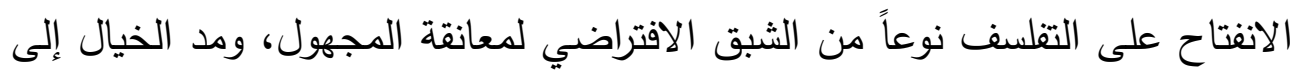

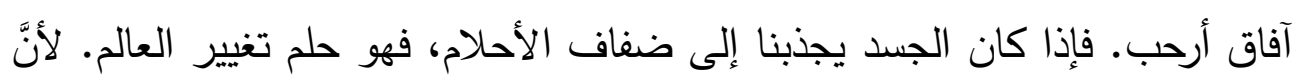

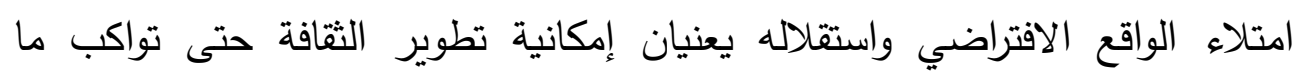
سيحدث.

\footnotetext{
${ }^{93}$-William R. Oliver, The Matrix : A Metaphorical Paralell To Language, P 96

${ }^{94}$-Roman Meinhold, Being in the Matrix: An Example of Cinematic Education in Philosophy, Article . January 2009.

ResearchGate (https://www.researchgate.net/publication/317398587), P 6.
} 


\section{خاتمة:}

\section{(الفلسفة والواقع الافتراضي)}

- - راهناً تحتاج الفلسفة إلى" الحدث الافتراضي"، لأنَّها بالتاريخ لم تكن لتُعنى به. فقط

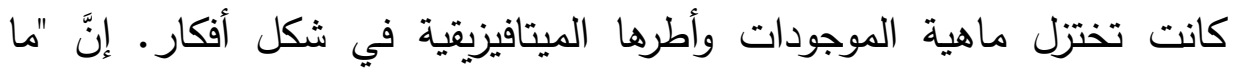

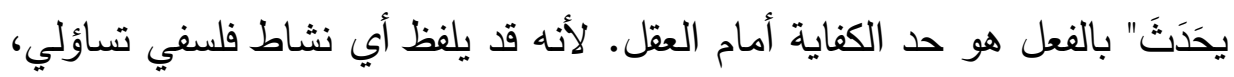

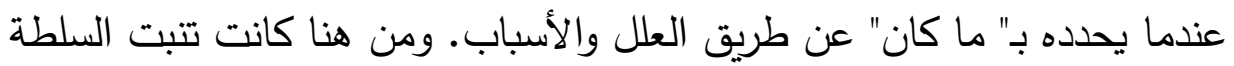

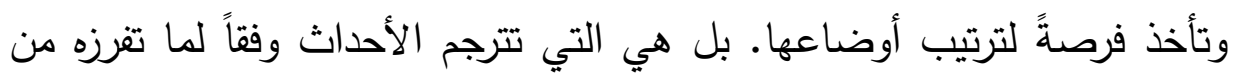

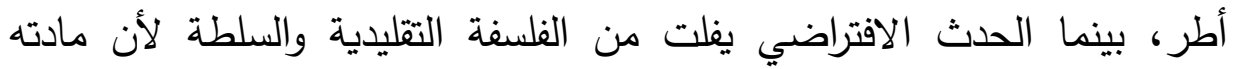

مختلفة. - مخرك

- الفلسفة لا تستطيع العيش تحت سقف سلطة تفتش فيما تفعل، لأنَّ الفلسفة تجدد

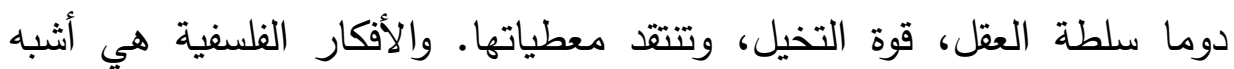
بسرديات مكتملة البناء والآثار والتداعي. - الواقع الافتراضي أصبح مجال (الحدث) على الأصالة. الحدث كصناعةٍ وابداع

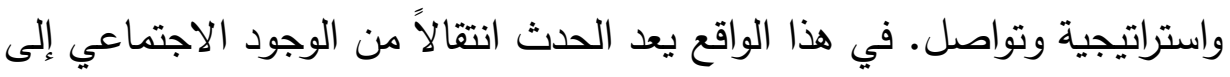

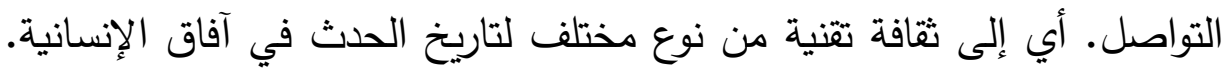
والحدث الافتراضي هو البعد السياسي لعلاقتنا بالآخر . فالخيال يتكون عبر عوالم فعليةٍ أمام التفلسف في أشكال وتقنيات وبيئات تثتبك مع سلطة ما. - الجسد الافتراضي يوفر للتفلسف شروط المتخيل، لأنَّه كائن له كافة المواصفات الوجودية على صعيد التقنيات. ويثير أسئلة من قبيل: كيف يتم تجديد ندط لئل

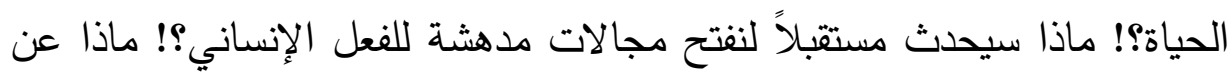
وجوه الإنسان عبر صوره الافتراضية الأكثر ابتكاراً!! كيف يرتبط الخيات الإنسانيال 
السيبراني بالميتافيزيقا؟! أية نظرية للمعرفة تصلح للخيال غير المحدود؟! ما هي الفي الفياء

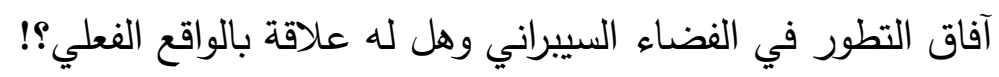

- الفلسفة لم تقترب كثيراً من الواقع الافتراضي، لكونها اهتمت بحكمة العيش حينا

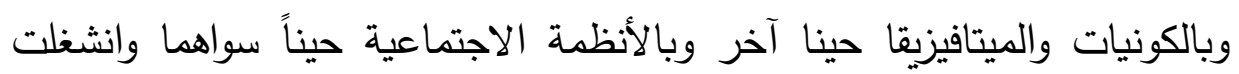

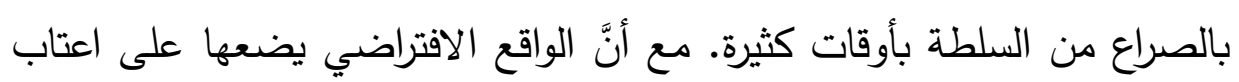
لغة كونية نستطيع مواكبتها والتفاعل معها.

- الجسد الافتراضي علامةُ غير قابلة للترويض. ولذلك هو يمارس حياته مشتغلاً على بنية السلطة، فهو لا يخضع لمنطق بيولوجي يحس ويشعر ويموت، لكنه يرسم حيوات ممكنة وغير قابلة للنهاية. كما أنه ينتج ذاكرة حسية كذلك للك بإبهار التكوين والبنية.

- يمكن للفلسفة أن تمارس أدوارها بحرية في الفضاء السيبراني فهو مجال لا حدود

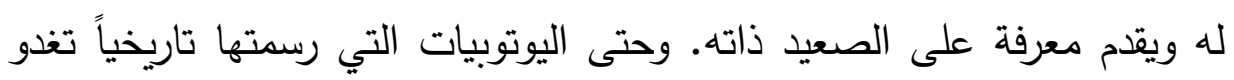

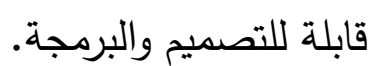

- إذا اهتم الفلاسفة بوسائط التواصل كالفيسبوك وتوتير وانستجرام وغيرها، لكان

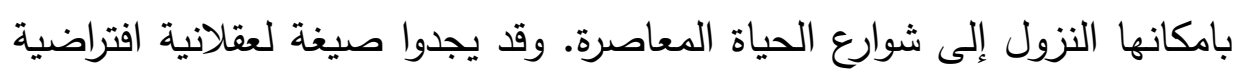
virtual rationality للتطور والنقد المتواصلين. - - قد يتحول الفيلسوف في عصر الديجيتال إلى رحّال، جوَّال يرتاد العقول الفسيحة ويربط المعاني بشبكات من العلامات والأيقونات، وقد تغدو الأفكار والأوهام

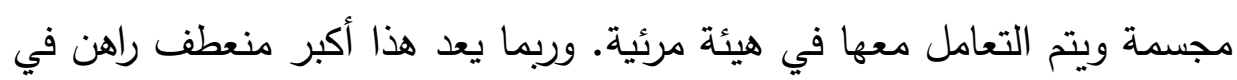
الخطاب الفلسفي ومفاهيمه وكيفية صياغته. 
- يتيح الجسد الافتراضي للفلسفة أنْ تصوغ أفكارها في برامج إلكترونية وسينمائية

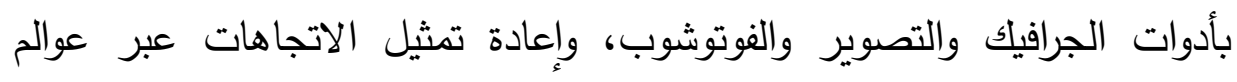

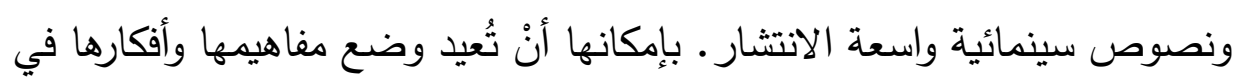
الحياة الإنسانية. - الجسيد الافتراضي يحول الأفكار من محاكاة الواقع إلى سيولة الخيال، وبالتالي

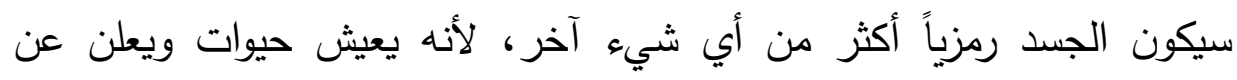
تداخل الأزمنة. كما أنه يثير تأويلات لا تتتهي لما يحاكيه ولما يطرحه من معانٍ. - يقدم الجسد الافتراضي لونا جديداً من المتعة الحسية الخيالية، نتيجة اختلاط لئل المعرفة والفنون والسيكولوجيا عبر الممارسة التقنية. وربما هذا المزيج يكون فريداً

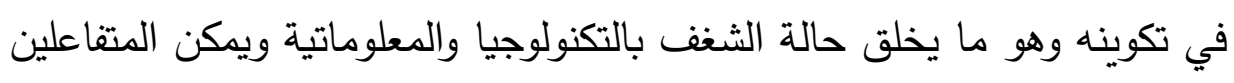
من مراوغة أي سلطة مترصدة. 


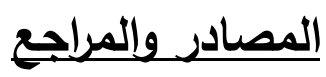

1- Ana Carden-Conyne, Reconstructing the Body :Classicism, Modernism, and the First World War, Oxford university Press, New York, 2009.

2- Andrei Catalin Coman, Giacomo Zara, Yaroslav Nechaev, Gianni Barlacchi, and Alessandro Moschitti, Exploiting Deep Neural Networks for Tweet-based Emoji Prediction, University of Trento,Trento,Italy\{andreicatalin.coman,giacomo.zara\}@studenti.unitn.it, moschitti@disi.unitn.it. PP 16- 128.

3- Andrew Feldheer, Playing gods: Ovid's Metamorphoses and the politics of fiction, Princeton University Press 2010.

4- Ann Thomson, Bodies of Thought: Science, Religion, and the Soul in the Early Enlightenment, Oxford University Press Inc., New York 2008.

5- Antonio José Planells de la Maza, Possible Worlds IN Video Games :From Classic Narrative to Meaningful Actions, Carnegie Mellon University: ETC Press Pittsburgh, PA, 2017.

6- Bernard Louis DeKoven, A Playful Path, ETC Press, U. S.A, 2014.

7- Brian J. McVeigh Wearing Ideology State, Schooling and Self-Presentation in Japan, Berg: Oxford - New York, 2000.

8- Cathy N. Davidson and David Theo Goldberg ,The Future of Thinking: Learning Institutions in a Digital Age, with the assistance of Zoë Marie Jones, The MIT Press Cambridge, Massachusetts London, England, 2010.

9- Cees J. Hamelink, The Ethics of Cyberspace, SAGE Publications :London, Thousand Oaks , New Delhi, 2000.

10- Charles T. Wolfe, Ofer Gal (editors), The Body as Object and Instrument of Knowledge Embodied Empiricism in Early Modern Science, Studies in history and philosophy of science 25, Springer Science-Business Media B.V Heidelberg- London - New York 2010.

11- Daniela Gobetti, Private and Public Individuals, households, and body politic in Locke and Hutcheson, Routledge: London and New York, 1992.

12- David Brown, God and Grace of Body: Sacrament in Ordinary, oxford University Press Inc., New York 2007. 
13- David Hakken, CYBORGS@CYBERSPACE?: An Ethnographer Looks to the Future, Routledge, New York-London, 1999.

14- David Hakken, The Knowledge Landscapes of Cyberspace, Routledge :New York \& London, 2003.

15- David L. Blaney and Naeem Inayatullah, Savage Economics : Wealth, poverty, and the temporal walls of capitalism, Routledge London and New York, 2010.

16- Dawn Perlmutter, Investigating religious terrorism and ritualistic crimes, CRC PRESS : London -New York -Washington, D.C. ,2004.

17- Donald Broadribb, The Mystical Chorus: Jung and the religious dimension, With Contributions by Marilyn Holly and Norma Lyons, Millennium Books E.J. Dwyer (Australia) Pty Ltd 1995.

18- Donn Welton, Body and Machines, in: Postphenomenology: A Critical Companion to Ihde,Edited by Evan Selinger, State University of New York Press 2006.

19- Douglas Rusbkoff, Cyberia : Life in the Trenches of Hyperspace, Clinamen Press, Manchester,2002.

20- Edward B.Tylor, Primitive Culture: Researches into The development of Mythology, Philosophy, Religion, Art and Custom, London: John Murray, Albemarle Street 1871.

21- Emile Dürkheim, The elementary forms of religious life, translated and with an introduction by Karen E. Fields, The Free Press: New York- London 1995.

22- Enney Norton, The Imoji Dictionary, ( Emoji-Presentation-1wijyi.pdf), (https://cpb-us2.wpmucdn.com/portfolio.newschool.edu/dist/4/3049/files/2015/05/Emoji-Presentation1wijyji.pdf) Pp 1- 23.

23- Eric Goldman, Emojis and the Law,( http://digital.law.washington.edu/dspacelaw/bitstream/handle/1773.1/1835/93WLR1227.pdf), PP1262 - 1266.

24- Fred B. Schneider (Editor), Trust in cyberspace,( Committee on Information Systems Trustworthiness Computer Science and Telecommunications Board Commission on Physical Sciences, Mathematics, and Applications National Research Council), National Academy Press ,Washington, D.C., 1999.

25- Friedrich Nietzsche, The Anti- Christ, Ecco Homo, Twilight of the Idols, and Other Writings, Edited by Aaron Ridley and Judith Norman, Translated by Judith Norman,(Cambridge Texts in the history of philosophy), Cambridge Uni- Press 2005.

26- Friedrich Wilhelm. J. Schelling, Historico-Critical Introduction to the Philosophy of Meythology (1856), Translated by Sydney C. Grew, London 1989. 
27- Geraldine Pinch, Handbook of Egyptian Mythology(Hand books of World Mythology), ABC-CLIO Santa Barbara, California - Denver, Colorado - Oxford, England, 2002.

28- Giorgio Agamben, Homo Sacer: Sovereign Power and Bare Life, translated by Daniel Heller-Roazen Stanford, CA: Stanford University Press, 1998.

29- Harry T. Hunt, Lives in Spirit Precursors and Dilemmas of a Secular Western Mysticism, State University of New York Press 2003.

30- Helen Morales, Classical Mythology: A Very Short Introduction, Oxford University Press 2007.

31- Hubert L. Dreyfus and Paul Rabinow, Michel Foucault: Beyond Structuralism and Hermeneutics, Second Edition with an Afterword and an interview with Michel Foucault, The University of Chicago Press 1983.

32- J. F. C. Fuller, The Secret Wisdom of Qabalah: A Study in Jewish Mystical Thought, AGNZ New York 2008.

33- J. J. Hopfield, Neural networks and physical systems with emergent collective computational abilities. Proceedings of the National Academy of Sciences of the United States of America, 79(8):2554-2558, April 1982.

34- James Fulcher, Capitalism: A Very Short Introduction, Oxford University Press, New York, 2004.

35- Jean Baudrillard, Simulacra and Simulation, Translated by Sheila Foria Glaser, Michigan University Press, 1980.

36- Jean Baudrillard, Simulations, Translated by Paul Foss, Paul Patton and Philip Beitchman, Semiotext[e], United States of America,1983.

37- Jennifer Whyte, Virtual Reality and the Built Environment, Architectural Press, London New York, 2002.

38- Jerome Iglowitz, Virtual Reality: Consciousness Really Explained!, (Second Edition), (February 22, 2010).

39- John Gray, Straw Dogs: Thought on Humans and other Animals, Ganata Books, London2002.

40- John Schwarzmantel, Ideology and Politics, SAGE: London - Los Anglos ,2008.

41- Joseph S. Nye, Soft Power and American Foreign Policy, in: Political Science Quarterly, Vol. 119, No. 2 ( Summer, 2004 ), pp. 255-270. 
42- Joseph S. Nye, Soft Power, in: Foreign Policy, No. 80, Twentieth Anniversary (Autumn, 1990), Washington post .Newsweek Interactive, LLC, pp. 153-171.

43- Joseph S. Nye, The Future of Power, Public Affairs, New York 2011.

44- Julia Kristeva, In the Beginning Was Love Psychoanalysis and Faith, translated byArthur Goldhammer, Columbia University Press New York, 1987.

45- Julia Kristeva, Revolution in Poetic Language, Translated by Margaret Waller with an Introduction by Leon S. Roudiez, Columbia University Press, New York1984.

46- Julien Offray de La Mettrie, Man a Machine ,Blackmask Online 2001. ( http://www.blackmask.com/).

47- Julien Offray de La Mettrie, Self-moving body parts: in :Man - Machine, Jonathan Bennett, London 2017.

48- Kai Sun, Explanation of Log-Normal Distributions and Power-Law Distributions in Biology and Social Science, Department of Physics, University of Illinois at UrbanaChampaign, 1110 W. Green St. , Urbana, IL 61801-3080, USA (Dated: May 6, 2004) (http://guava.physics.uiuc.edu/ nigel/courses/569/Essays 2 004/files/sun.pdf).

49- Kasper Simo Kristensen, Michel Foucault on Bio-power and Biopolitics, University of Helsinki Faculty of Social Sciences Social and Moral Philosophy Master's Thesis, April 2013.

50- Ken Hillis, Toward the light 'within' Optical technologies, spatial metaphors and changing subjectivities, In: Mike Crang, Phil Crang and Jon May(editors), Virtual Geographies Bodies, space and relations, Routledge: London and New York, 1999.

51- Lee Varis, Skin : The Complete Guide to Digitally Lighting, Photographing, and Retouching Faces and Bodies( Second Edition), Wiley Publishing, Inc., Indianapolis, Indiana, 2010.

52- Lucy Sargisson, Utopian Bodies and the Politics of Transgression, Routledge: London and New York 2000.

53- Luke Stark and Kate Crawford, The Conservatism of Emoji: Work, Affect, and Communication, Social Media + Society July-December 2015: 1-11,

( https://sites.tufts.edu/mythritualsymbol2017/files/2017/08/stark-crawford-conservatismemoji.pdf.) 
54- Lynn Enterline, The Rhetoric of the Body from Ovid to Shakespeare, Cambridge University Press 2004.

55- Marcel Mauss, Sociology and Psychology: Essays, London 1979.

56- Mark b. N. Hansen , Bodies in Cod: Interfaces with Digital media, Routledge, Taylor \& Francis Group, LLC, New York, London 2006.

57- Michael FreeMan, The photographer's Mind : Creative thinking for better digital photos, Focal Press ,Amsterdam, New York, London, 2011.

58- Michael Heim, Metaphysics of Virtual reality, Oxford University Press, Oxford New York 1993.

59- Michel Foucault,' Society Must Be Defended', Lectures at the College de France(19751976), Edited by Mauro Bertani and Alessandro Fontana, General Editors: Francois Ewald and Alessandro Fontana, English series Editor: Arnold I. Davidson Translated by David Macey, PICADOR, New York 1997.

60- Miri Rubin, The Body, Whole and Vulnerable, in Fifteenth- Century England, in: Bodies and disciplines: intersections of literature and history in fifteenth century England, Barbara A. Hana walt and David Wallace (editors), (Medieval cultures; volume 9), University of Minnesota Press ,Minneapolis-London 1996.

61- Nancy Dziedzic, World Poverty, Information Plus_ Reference Series ,Formerly Published by Information Plus, Wylie, Texas, Thomson Gale, San Francisco, London, 2007.

62- Noam Chomsky, "An American view of the ideological confrontation of our time", in: C. P. Otero, Language and Politics, Black Rose, 1988.

63- Paisley Livingston, Cinema, Philosophy, Bergman On Film as Philosophy, Oxford University Press Inc, Oxford New York, 2009.

64- Paul Harrison, Inside the Third World: The Anatomy of Poverty, Penguin Books, London, 1993.

65- Rachel S. Turner, Neo-Liberal Ideology History, Concepts and Policies, Edinburgh University Press, 2008.

66- René Descartes, Meditations On First Philosophy, in: The Philosophical Writings of Descartes( Volume 2), Translated by John Cottingham, Robert Stoothoff, Dugald Murdoch, Cambridge University- Press 1984.

67- Richard C. Lewontin, Biology as Ideology: The Doctrine of DNA, (CBC Radio Massey lectures series;1990). 
68- Richard H. Robbins, Global Problems and the Culture of Capitalism, Allyn and Bacon, London ( Second Edition) 2002.

69- Robert W. Lurz (editor), The Philosophy of Animals Minds, Cambridge University Press, New York 2009.

70- Roland Barthes, Mythologies, Selected and translated from the French by Annette Lavers, The NoonDay Press- NewYork ,Farrar Straus\& Giroux, 1991.

71- Roman Meinhold, Being in the Matrix: An Example of Cinematic Education in Philosophy, Article · January 2009.

72- Ruthanna Gordon, Alternate Reality Games For Behavioral and Social Science Research, London, 2015.

73- Sean M. Grady, Virtual reality: simulating and enhancing the world with computers,(Science \&Technology In Focus) Facts On File, Inc., New York ,New Edition 2003.

74- Silvia Federici, Prostitution and Globalization: Notes on a Feminist Debate, In: Matt Davies and Magnus Ryner(editors), Poverty and the Production of World Politics, Palgrve Macmillan London 2006.

75- Slavoj Žižek ,Introduction :The Spectre of Ideology, in: Slavoj Žižek (editor) Mapping Ideology, Verso: London -New York,1989.

76- Steven Creech and Kevin Ruesch, Egyptian Gods: The Lore of The Gods, Bastion Press, 2002.

77- Subashini Annamalai, Sobihatun Nur Abdul Salam, Undergraduates' Interpretation on WhatsApp Smiley Emoji, Jurnal Komunikasi Malaysian Journal of Communication Jilid 33(4) 2017: 89-103.

78- Sungook Hong, Man and Machine, In: Techné 7:3 Spring 2004 (https://scholar.lib.vt.edu/ejournals/SPT/v7n3/pdf/hong.pdf).

79- Tara Magdalinski, Sport, Technology and the Body : The nature of performance, Routledge London, New York, 2009.

80- Tim Highfield and Tama Leaver, Instagrammatics and digital methods: studying visual social media, from selfies and gifs to memes and emoji. Communication Research and Practice, 2(1):47-62, 2016.

81- Tim Jordan, Cyberpower: The culture and politics of cyberspace and the Internet, Routledge :London and New York,1999. 
82- Wikipedia:

(https://ar.wikipedia.org/wiki/\%D8\%A3\%D9\%81\%D8\%A7\%D8\%AA\%D8\%A7\%D8\% B1).

83- William R. Oliver, The Matrix : A Metaphorical Paralell To Language, A Thesis Submitted to the University of North Carolina Wilmington in Partial Fulfillment of the Requirements for the Degree of Master of Arts Department of English University of North Carolina Wilmington, 2008.

84- Yann LeCun and Yoshua Bengio. The handbook of brain theory and neural networks. chapter Convolutional Networks for Images, Speech, and Time Series, pages 255-258. MIT Press, Cambridge, MA, USA, 1998.

85- Zygmunt Bauman, Culture As Praxis, London, California, New Delhi SAGE Publications (New Edition) 1999. 